\title{
RNA Drugs and RNA Targets for Small Molecules: Principles, Progress, and Challenges
}

\author{
Ai-Ming Yu, Young Hee Choi, and Mei-Juan Tu \\ Department of Biochemistry and Molecular Medicine, UC Davis School of Medicine, Sacramento, California (A.-M.Y., Y.H.C., M.-J.T.) \\ and College of Pharmacy and Integrated Research Institute for Drug Development, Dongguk University-Seoul, Goyang-si, Gyonggi-do, \\ Republic of Korea (Y.H.C.)
}

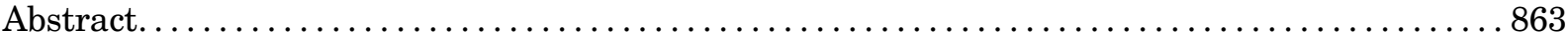

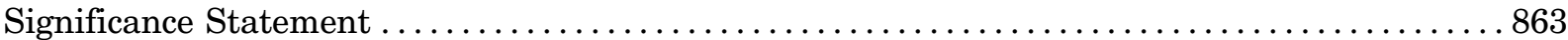

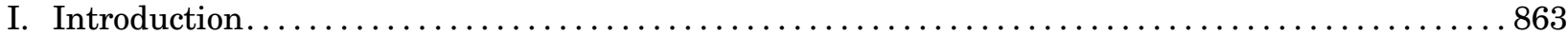

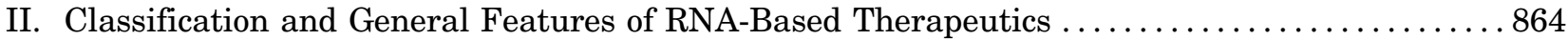

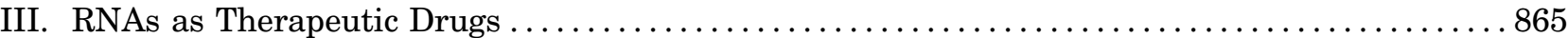

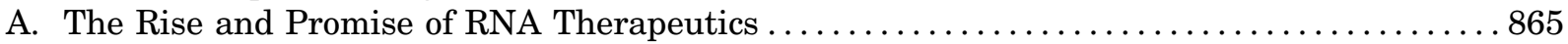

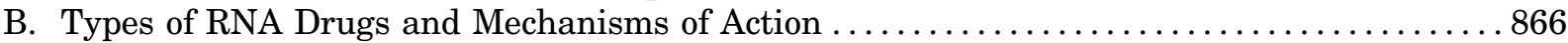

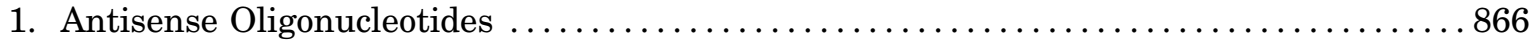

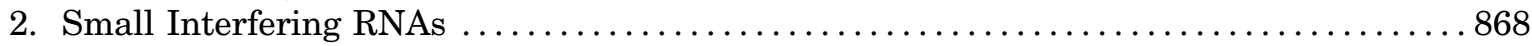

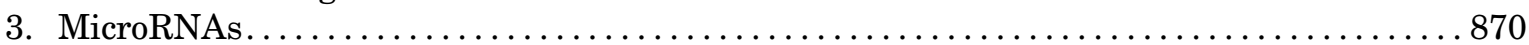

4. RNA Aptamers ................................................... 871

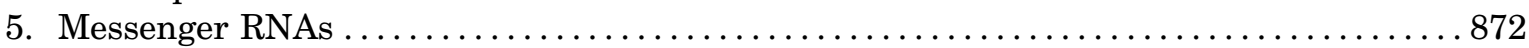

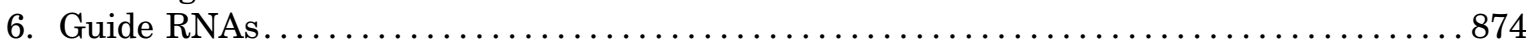

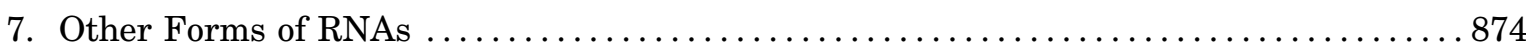

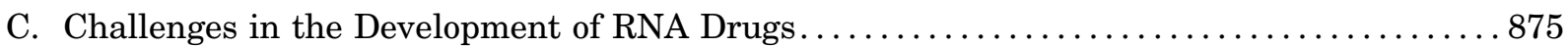

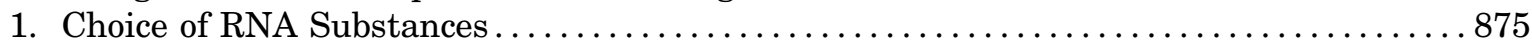

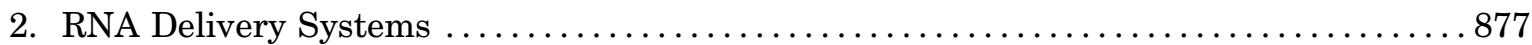

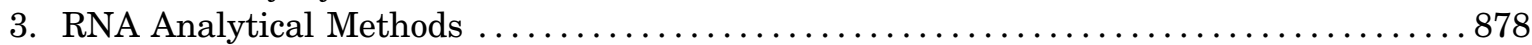

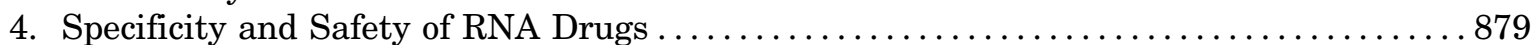

IV. RNAs as Therapeutic Targets for Small Molecules $\ldots \ldots \ldots \ldots \ldots \ldots \ldots \ldots \ldots \ldots \ldots \ldots \ldots \ldots 80$

A. Small Molecules Targeting Highly Structured RNAs $\ldots \ldots \ldots \ldots \ldots \ldots \ldots \ldots \ldots \ldots \ldots . \ldots 80$

B. Classes of RNA Targets . . . . . . . . . . . . . . . . . . . . . . . . . . . . . . . . . . . . . . . 883

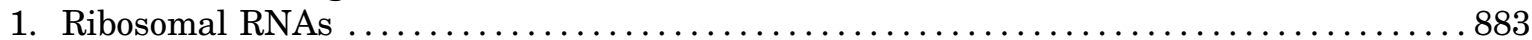

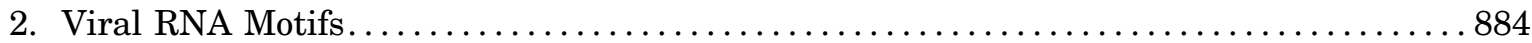

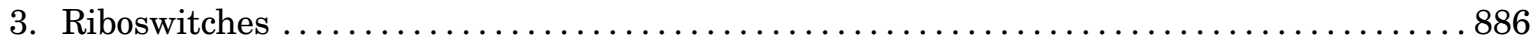

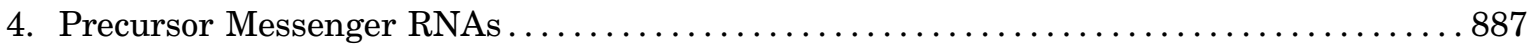

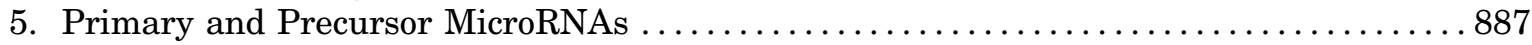

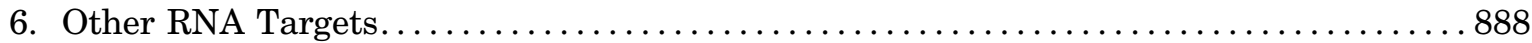

C. Challenges in the Discovery and Development of RNA-Targeted Small-Molecule Drugs ... 889

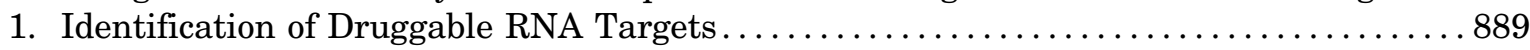

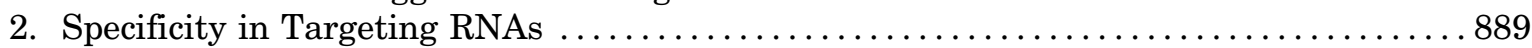

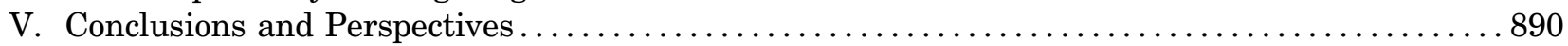

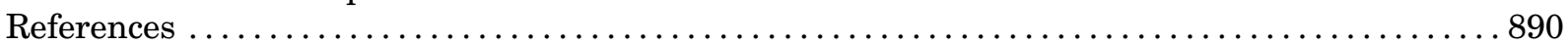

Address correspondence to: Dr. Ai-Ming Yu, Department of Biochemistry and Molecular Medicine, UC Davis School of Medicine, 2700 Stockton Blvd. Suite 2132, Oak Park Research Building, Sacramento, CA 95817. E-mail: aimyu@ucdavis.edu; or Dr. Young Hee Choi, College of Pharmacy and Integrated Research Institute for Drug Development, Dongguk University-Seoul, 32 Dongguk-lo, Ilsandong-gu, Goyang-si, Gyeonggi-do 10326, Republic of Korea. E-mail: choiyh@dongguk.edu

A.-M.Y. was funded by National Institutes of Health National Cancer Institute [Grant R01-CA225958] and National Institute of General Medical Sciences [Grant R01GM113888]. Y.H.C. was supported by the National Research Foundation of Korea grants funded by the Korea government (MIST) [NRF-2016R1C1B2010849 and NRF-2018R1A5A2023127].

https://doi.org/10.1124/pr.120.019554. 
Abstract-RNA-based therapies, including RNA molecules as drugs and RNA-targeted small molecules, offer unique opportunities to expand the range of therapeutic targets. Various forms of RNAs may be used to selectively act on proteins, transcripts, and genes that cannot be targeted by conventional small molecules or proteins. Although development of RNA drugs faces unparalleled challenges, many strategies have been developed to improve RNA metabolic stability and intracellular delivery. A number of RNA drugs have been approved for medical use, including aptamers (e.g., pegaptanib) that mechanistically act on protein target and small interfering RNAs (e.g., patisiran and givosiran) and antisense oligonucleotides (e.g., inotersen and golodirsen) that directly interfere with RNA targets. Furthermore, guide RNAs are essential components of novel gene editing modalities, and mRNA therapeutics are under development for protein replacement therapy or vaccination, including those against unprecedented severe acute respiratory syndrome coronavirus pandemic. Moreover, functional RNAs or RNA motifs are highly structured to form binding pockets or clefts that are accessible by small molecules. Many natural, semisynthetic, or synthetic antibiotics (e.g., aminoglycosides, tetracyclines, macrolides, oxazolidinones, and phenicols) can directly bind to ribosomal RNAs to achieve the inhibition of bacterial infections. Therefore, there is growing interest in developing RNA-targeted small-molecule drugs amenable to oral administration, and some (e.g., risdiplam and branaplam) have entered clinical trials. Here, we review the pharmacology of novel RNA drugs and RNA-targeted small-molecule medications, with a focus on recent progresses and strategies. Challenges in the development of novel druggable RNA entities and identification of viable RNA targets and selective small-molecule binders are discussed.

Significance Statement-With the understanding of RNA functions and critical roles in diseases, as well as the development of RNA-related technologies, there is growing interest in developing novel RNA-based therapeutics. This comprehensive review presents pharmacology of both RNA drugs and RNA-targeted small-molecule medications, focusing on novel mechanisms of action, the most recent progress, and existing challenges.

\section{Introduction}

Therapeutic drugs act on corresponding molecular targets, biological pathways, or cellular processes to elicit pharmacological effects for the treatment of human diseases. Small-molecule compounds and proteins/antibodies remain as the major forms of medications for medical use and the preferred modalities in drug development, acting mainly on protein targets such as enzymes, receptors, ion channels, transporters, and kinases (Santos et al., 2017; Usmani et al., 2017; Rock and Foti, 2019; Yin and Rogge, 2019). With unique physicochemical and pharmacological characteristics complementary to traditional protein-targeted small-molecule and protein drugs (Table 1), RNA molecules, such as aptamers, antisense oligonucleotides (ASO), small interfering RNAs (siRNA), and guide RNAs (gRNA), have emerged as a new class of modalities in clinical practice and are under active development (Crooke et al., 2018; Yin and Rogge, 2019; Yu et al., 2019); RNA molecules may act not only on conventional proteome but also on previously undrugged transcriptome, including mRNAs to be translated into proteins and functional noncoding RNAs (ncRNAs) which largely outnumber mRNAs (Mattick, 2004; Djebali et al., 2012), as well as the genome. Moreover, some mRNAs and ncRNAs, such as microRNAs (miRNA or miR), are also under preclinical and clinical development for replacement therapy or vaccination

\footnotetext{
ABBREVIATIONS: A, adenine; AHP, acute hepatic porphyria; ALA, $\delta$-aminolevulinic acid; ALAS1, $\delta$-ALA synthase 1 ; AMD, age-related macular degeneration; ApoB, apolipoprotein B; A-site, aminoacyl-tRNA site; ASO, antisense oligonucleotide; asRNA, antisense RNA; BERA, bioengineered or biological RNA agents; C, cytosine; Cas, CRISPR-associated protein; DC, dendritic cell; DMD, Duchenne muscular dystrophy; DPQ, 6,7-dimethoxy-2-(1-piperazinyl)-4-quinazolinamine; dsRNA, double-stranded RNA; EphA2, ephrin type-A receptor 2; E-site, exit site; EWS, Ewing sarcoma breakpoint region 1; FDA, Food and Drug Administration; FL, fluorescence; FLI1, Friend leukemia integration 1 transcription factor; FLT-1, fms-like tyrosine kinase; FMN, flavin mononucleotide; G, guanine; GalNAc, $N$-acetylgalactosamine; gRNA, guide RNA; hATTR amyloidosis, hereditary transthyretin-mediated amyloidosis; HCV, hepatitis C virus; HD, Huntington disease; HIV, human immunodeficiency virus; HoFH, homozygous familial hypercholesterolemia; HPLC, high-performance liquid chromatography; HTT, huntingtin; IL, interleukin; IRES, internal ribosome entry site; IVT, in vitro-transcribed; LC, liquid chromatography; LC-HRMS, LC tandem high-resolution accurate MS; LDL, low-density lipoprotein; LNA, locked nucleic acid; LNP, lipid nanoparticle; LPP, lipopolyplex; LPX, lipoplex; Mage, melanoma-associated antigen; miR or miRNA, microRNA; MMA, methylmalonic acidemia; 2'-MOE, 2'-O-methoxyethyl; MS, mass spectrometry; MTDB, 2-[[4-(2-methylthiazol-4-ylmethyl)-(1,4)diazepane-1-carbonyl]amino]benzoic acid ethyl ester; MUT, methylmalonyl CoA mutase; ncRNA, noncoding RNA; NPET, nascent peptide exit tunnel; NSCLC, non-small-cell lung cancer; NY-ESO-1, New York Esophageal Squamous Cell Carcinoma-1; PBG, porphobilinogen; PD, pharmacodynamics; PD-1, programmed cell death protein 1; pDNA, plasmid DNA; PK, pharmacokinetics; PMO, phosphorodiamidate morpholino oligomers; PO, phosphodiester; pre-miRNA, precursor miRNA; pri-miRNA, primary miRNA; PS, phosphorothioate; P-site, peptidyl-tRNA site; PTC, peptidyl transferase center; qPCR, quantitative polymerase chain reaction; RISC, siRNA-induced silencing complex; RNAi, RNA interference; RNP, ribonucleoprotein; rRNA, ribosomal RNA; SARS-CoV, severe acute respiratory syndrome coronavirus; SDF-1, stromal cell-derived factor 1; shRNA, short or small hairpin RNA; siRNA, small interfering RNA; SMA, spinal muscular atrophy; SMN, survival motor neuron; sRNA, small RNA; TAR, transactivation response; Tat, transactivating regulatory protein; TCR, T cell receptor; TGP, targaprimir; TPP, thiamine pyrophosphate; TTR, transthyretin; U, uracil; UTR, untranslated region; VEGF, vascular endothelial growth factor.
} 
TABLE 1

Characteristics of inorganic and small-molecule organic compound drugs, as well as macromolecule protein and nucleic acid therapeutics

\begin{tabular}{|c|c|c|c|c|}
\hline Properties & Inorganic Compound Drugs & $\begin{array}{l}\text { Small-Molecule Organic } \\
\text { Compound Drugs }\end{array}$ & Protein Therapeutics & RNA Therapeutics \\
\hline Chemistry & $\begin{array}{c}\text { Typical mol. wt. }<200 \\
\text { Da; ionic }\end{array}$ & $\begin{array}{c}\text { Typical mol. wt. }<500 \\
\text { Da; hydrophobic }\end{array}$ & $\begin{array}{l}\text { Typical mol. wt. }>100 \mathrm{kDa} ; \\
\text { positive/negative/neutral }\end{array}$ & $\begin{array}{c}\text { Typical mol. wt. }>7 \mathrm{kDa} \text {; negative } \\
\text { charge }\end{array}$ \\
\hline Dosing & Primarily oral; often daily & Primarily oral; often daily & $\begin{array}{l}\text { Mainly intravenous and } \\
\text { subcutaneous; weekly to monthly }\end{array}$ & $\begin{array}{c}\text { Intravenous, subcutaneous, intrathecal, } \\
\text { intravitreal (various); weekly to once } \\
\text { every } 3-6 \text { mo }\end{array}$ \\
\hline $\begin{array}{l}\mathrm{ADME} / \mathrm{PK} \\
\text { properties }\end{array}$ & $\begin{array}{l}\text { Orally bioavailable; } \\
\text { distributed to all organs } \\
\text { and tissues, cell } \\
\text { permeable; } \\
\text { usually not metabolized; } \\
\text { excreted primarily in } \\
\text { urine }\end{array}$ & $\begin{array}{c}\text { Orally bioavailable; } \\
\text { distributed to all organs } \\
\text { and tissues, cell } \\
\text { permeable; } \\
\text { metabolized by phase I } \\
\text { and II enzymes; } \\
\text { excreted mainly in bile } \\
\text { and urine }\end{array}$ & $\begin{array}{l}\text { Not orally bioavailable; } \\
\text { distributed mainly in plasma or } \\
\text { extracellular fluids, cell } \\
\text { impermeable; } \\
\text { catabolized extensively to } \\
\text { peptides or amino acids; } \\
\text { limited excretion }\end{array}$ & $\begin{array}{l}\text { Not orally bioavailable; } \\
\text { Distributed extensively to kidney and } \\
\text { liver, cell impermeable; } \\
\text { catabolized extensively by nucleases to } \\
\text { (oligo)nucleotides; } \\
\text { limited excretion }\end{array}$ \\
\hline $\begin{array}{l}\text { Molecular } \\
\text { targets }\end{array}$ & Proteins & Mainly proteins & Proteins & $\begin{array}{c}\text { Mainly RNAs, besides proteins and } \\
\text { DNAs }\end{array}$ \\
\hline $\begin{array}{l}\text { Site of action } \\
\text { and PD }\end{array}$ & $\begin{array}{l}\text { Extra-/intracellular; } \\
\text { direct or indirect } \\
\text { relationship to blood PK }\end{array}$ & $\begin{array}{l}\text { Extra-/intracellular; } \\
\text { Direct or indirect } \\
\text { relationship to blood PK }\end{array}$ & $\begin{array}{c}\text { Extracellular/membrane; } \\
\text { direct or indirect models linked to } \\
\text { blood PK }\end{array}$ & $\begin{array}{l}\text { Primarily intracellular; } \\
\text { more relevant to tissue PK, whereas PD } \\
\text { can be linked to blood PK }\end{array}$ \\
\hline $\begin{array}{l}\text { Safety/ } \\
\text { toxicity }\end{array}$ & Risk of off-target effects & Risk of off-target effects & Risk of immunogenicity & Risk of immunogenicity \\
\hline
\end{tabular}

ADME, absorption, metabolism, distribution, and excretion.

(Bader et al., 2010; Sahin et al., 2014; Lieberman, 2018), and new approaches and technologies are emerging to tackle some inherited or overlooked issues, such as the choice of RNA molecules (Ho and Yu, 2016; Yu et al., 2019). On the other hand, traditional small-molecule compounds may be employed to directly target pathogenic RNAs for the treatment of diseases (Donlic and Hargrove, 2018; Warner et al., 2018; Costales et al., 2020), providing another unparalleled opportunity to expand the range of therapeutic targets.

In this review, we first provide a classification of RNA-based therapeutics, RNA drugs, and RNA-targeted small molecules and describe their general characteristics. After summarizing the promise of RNA drugs, we review specific types of RNA drugs and their novel mechanisms of action and discuss major barriers in the development of RNA therapeutics, as well as respective proven and potential strategies. Next, we summarize the strategies and potential in developing RNA-targeted small-molecule drugs, including recent advances in structural understanding of antibiotic-ribosomal RNA (rRNA) interactions and identification of novel RNAbinding small molecules. Challenges in the identification of therapeutic RNA targets and determination of the selectivity of RNA-small-molecule interactions for the control of specific diseases are also discussed.

\section{Classification and General Features of RNA-Based Therapeutics}

RNA-based therapeutics are classified as two types of entities: RNA molecules or analogs directly used as therapeutic drugs (Kole et al., 2012; Sahin et al., 2014; Crooke et al., 2018; Yu et al., 2019) and RNA-targeted small-molecule medications (Donlic and Hargrove, 2018; Warner et al., 2018; Costales et al., 2020). Firstly, a number of RNA drugs have been approved by the US Food and Drug Administration (FDA) for the treatment of various human diseases, including RNA aptamers (e.g., pegaptanib) (Gragoudas et al., 2004; Gryziewicz, 2005), ASOs or antisense RNAs (asRNAs) (e.g., mipomersen, eteplirsen, nusinersen, inotersen, and golodirsen) (Morrow, 2013; Stein, 2016; Syed, 2016; Ottesen, 2017; Keam, 2018), and siRNAs (e.g., patisiran and givosiran) (Wood, 2018; Scott, 2020) (Table 2; this review). RNA molecules have appeared to be highly specific in acting on a wide variety of proven and possible therapeutic targets, including proteins, transcripts, and genes (Table 1), that may not be accessible by small-molecule compounds and proteins. Nevertheless, RNAs are prone to catabolism by serum RNases and are required to pass the cellular membrane barriers to access intracellular targets. Similar to protein therapeutics (e.g., insulin, trastuzumab, and pembrolizumab, etc.), RNA drugs (e.g., mipomersen and patisiran, etc.) are not orally bioavailable; hence, both RNA and protein drugs are usually administered to patients via other routes, such as intravenous or subcutaneous injection (Table 1). This is totally different from many smallmolecule inorganic (e.g., lithium carbonate) and organic (e.g., acetaminophen, dextromethorphan, and ibuprofen, etc.) compound drugs, which exhibit favorable or acceptable oral bioavailability and are primarily administered orally to patients.

Secondly, conventional small-molecule compounds with broad structural diversities and drug-like physicochemical and PK properties are preferred entities to bind and manipulate highly structured RNA targets (Hermann, 2016; Donlic and Hargrove, 2018; Warner et al., 2018; Costales et al., 2020). After the identification of an RNA target, selection of proper drug-like small molecules, and determination of RNA-small-molecule interactions (e.g., binding affinity and selectivity), the 
TABLE 2

RNA therapeutics approved by the US Food and Drug Administration for the treatment of human diseases

Note that two PMO drugs are included because the nucleobase thymine (T) is also known as 5-methyluracil, or $\mathrm{m}^{5} \mathrm{U}$.

\begin{tabular}{|c|c|c|c|c|c|c|c|}
\hline RNA Drug & Chemistry & Dosage Regimen & Mechanisms of Action & Disease & $\begin{array}{c}\text { Year } \\
\text { Approved }\end{array}$ & Current Status & References \\
\hline $\begin{array}{l}\text { Pegaptanib } \\
\text { (aptamer) }\end{array}$ & $\begin{array}{l}\text { 28-nt aptamer; } \\
\text { pegylated, all PO, } \\
\text { 2'-F, and 2'-OMe; } \\
\text { G and A } \\
\text { methylated; mol. } \\
\text { wt. } \sim 50 \mathrm{kDa}\end{array}$ & $\begin{array}{l}0.3 \mathrm{mg} \text { every } 6 \mathrm{wk} \\
\text { intravitreal injection }\end{array}$ & $\begin{array}{l}\text { Selective VEGF (165 } \\
\text { isoform) antagonist; } \\
\text { antiangiogenesis in the } \\
\text { eye }\end{array}$ & $\begin{array}{c}\text { Neovascular } \\
\text { AMD }\end{array}$ & 2004 & Prescription & $\begin{array}{l}\text { Gragoudas et al., } \\
\text { 2004; Gryziewicz, } \\
2005\end{array}$ \\
\hline $\begin{array}{l}\text { Mipomersen } \\
\text { (ASO) }\end{array}$ & $\begin{array}{l}\text { 20-mer gapmer; all } \\
\text { PS, 2'-MOE, and } \\
\text { 2'-deoxy; C and U } \\
\text { methylated; mol. } \\
\text { wt. } \sim 7.6 \mathrm{kDa}\end{array}$ & $\begin{array}{l}200 \mathrm{mg} \text { once weekly, } \\
\text { s.c. }\end{array}$ & $\begin{array}{c}\text { Selectively binds to ApoB- } \\
100 \text { mRNA to inhibit the } \\
\text { translation of synthesis of } \\
\text { ApoB in liver }\end{array}$ & $\mathrm{HoFH}$ & 2013 & $\begin{array}{l}\text { Discontinued } \\
\text { in } 2018\end{array}$ & $\begin{array}{c}\text { Crooke and } \\
\text { Geary, 2013; } \\
\text { Morrow, 2013 }\end{array}$ \\
\hline $\begin{array}{l}\text { Eteplirsen } \\
\text { (ASO) }\end{array}$ & $\begin{array}{l}30 \text {-mer PMO; } \mathrm{m}^{5} \mathrm{U} ; \\
\text { mol. wt. } \sim 10.3 \mathrm{kDa}\end{array}$ & $\begin{array}{c}30 \mathrm{mg} / \mathrm{kg} \text { once } \\
\text { weekly, i.v. infusion }\end{array}$ & $\begin{array}{l}\text { Selectively binds to exon } \\
51 \text { of dystrophin pre- } \\
\text { mRNA to alter splicing, } \\
\text { leading to production of } \\
\text { functional muscle protein } \\
\text { dystrophin }\end{array}$ & DMD & 2016 & Prescription & $\begin{array}{l}\text { Cirak et al., 2011; } \\
\text { Mendell et al., } \\
\text { 2016; Stein, 2016; } \\
\text { Syed, } 2016\end{array}$ \\
\hline $\begin{array}{l}\text { Nusinersen } \\
\text { (ASO) }\end{array}$ & $\begin{array}{l}\text { 18-mer; all PS, } \\
\text { fully } 2^{\prime}-\mathrm{MOE} ; \mathrm{m}^{5} \mathrm{U} ; \\
\mathrm{m}^{5} \mathrm{C} ; \mathrm{mol} \text { wt. } \\
\quad \sim 7.5 \mathrm{kDa}\end{array}$ & $\begin{array}{l}\text { Loading: } 12 \mathrm{mg} \\
\text { every } 2 \text { wk for three } \\
\text { doses, then } 12 \mathrm{mg} \\
\text { for } 30 \text { days, i.t. } \\
\text { Maintenance: } 12 \mathrm{mg} \\
\text { once every } 4 \text { mo, i.t. }\end{array}$ & $\begin{array}{l}\text { Selectively binds to } \\
\text { SMN2 mRNA to alter } \\
\text { splicing, leading to the } \\
\text { production of full-length } \\
\text { SMN protein }\end{array}$ & SMA & 2016 & Prescription & $\begin{array}{l}\text { Aartsma-Rus, } \\
\text { 2017; Ottesen, } \\
2017\end{array}$ \\
\hline $\begin{array}{l}\text { Patisiran } \\
\text { (siRNA) }\end{array}$ & $\begin{array}{c}\text { 21-bp double- } \\
\text { stranded siRNA; } \\
\text { all PO, and } \\
2^{\prime} \text {-OMe; lipid } \\
\text { nanoparticle mol. } \\
\text { wt. } \sim 14.3 \mathrm{kDa}\end{array}$ & $\begin{array}{c}0.3 \mathrm{mg} / \mathrm{kg} \text { (b.wt. }< \\
100 \mathrm{~kg} \text { ) or } 30 \mathrm{mg} \\
\text { (b.wt. } \geq 100 \mathrm{~kg}) \\
\text { every } 3 \mathrm{wk}, \text { i.v. } \\
\text { infusion }\end{array}$ & $\begin{array}{l}\text { Selectively binds to TTR } \\
\text { mRNA to decrease } \\
\text { hepatic production of TTR } \\
\text { protein }\end{array}$ & $\begin{array}{c}\text { hATTR } \\
\text { amyloidosis }\end{array}$ & 2018 & Prescription & $\begin{array}{l}\text { Adams et al., } \\
\text { 2018; Wood, } \\
\text { 2018; Zhang } \\
\text { et al., 2020b }\end{array}$ \\
\hline $\begin{array}{l}\text { Inotersen } \\
\text { (ASO) }\end{array}$ & $\begin{array}{l}\text { 20-mer gapmer; all } \\
\text { PS, 2'-MOE, and } \\
\text { 2'-deoxy; C and U } \\
\text { methylated; mol. } \\
\text { wt. } \sim 7.2 \mathrm{kDa}\end{array}$ & $\begin{array}{l}284 \mathrm{mg} \text { once weekly, } \\
\text { s.c. }\end{array}$ & $\begin{array}{l}\text { Selectively binds to TTR } \\
\text { mRNA to cause mRNA } \\
\text { degradation and reduce } \\
\text { protein production }\end{array}$ & $\begin{array}{c}\text { hATTR } \\
\text { amyloidosis }\end{array}$ & 2018 & Prescription & $\begin{array}{c}\text { Benson et al., } \\
\text { 2018; Keam, } 2018\end{array}$ \\
\hline $\begin{array}{l}\text { Givosiran } \\
\text { (siRNA) }\end{array}$ & $\begin{array}{l}\text { Double-stranded } \\
\text { siRNA; PO and PS, } \\
\text { 2-F', } 2^{\prime}-\mathrm{O}-\mathrm{Me} \text {, and } \\
\text { triantennary } \\
\text { GalNAc; mol. wt. } \\
\sim 16.3 \mathrm{kDa}\end{array}$ & $\begin{array}{l}2.5 \mathrm{mg} / \mathrm{kg} \text { once } \\
\text { monthly, s.c. }\end{array}$ & $\begin{array}{c}\text { Selectively binds to } \\
\text { hepatic ALAS1 mRNA, } \\
\text { leading to ALAS1 mRNA } \\
\text { degradation through RNA } \\
\text { interference }\end{array}$ & AHP & 2019 & Prescription & $\begin{array}{l}\text { Sardh et al., } \\
\text { 2019; de Paula } \\
\text { Brandao et al., } \\
\text { 2020; Scott, } 2020\end{array}$ \\
\hline Golodirsen & $\begin{array}{l}\text { 25-mer PMO; }{ }^{5} \mathrm{U} \\
\text { mol. wt. } \sim 8.6 \mathrm{kDa}\end{array}$ & $\begin{array}{c}30 \mathrm{mg} / \mathrm{kg} \text { once } \\
\text { weekly, i.v. infusion }\end{array}$ & $\begin{array}{l}\text { Selectively binds to exon } \\
53 \text { of dystrophin pre- } \\
\text { mRNA to alter splicing, } \\
\text { leading to production of } \\
\text { functional muscle protein } \\
\text { dystrophin in patients } \\
\text { with genetic mutations } \\
\text { that are amenable to exon } \\
53 \text { skipping }\end{array}$ & DMD & 2019 & Prescription & Heo, 2020 \\
\hline
\end{tabular}

2'-F, 2'-fluoro; 2'-OMe, 2'-methoxy.

RNA-targeted small molecules may be processed for further preclinical and clinical investigations to define efficacy and safety profiles. Supporting this concept, many antibiotic drugs, such as natural and semisynthetic aminoglycosides (e.g., streptomycin, paromomycin, neomycin, etc.) (Fourmy et al., 1996; Ogle et al., 2001; Demeshkina et al., 2012; Demirci et al., 2013), tetracyclines (e.g., tetracycline, tigecycline, etc.) (Brodersen et al., 2000; Anokhina et al., 2004; Schedlbauer et al., 2015), and macrolides (erythromycin, azithromycin, telithromycin, etc.) (Vannuffel and Cocito, 1996; Hansen et al., 2002; Berisio et al., 2003; Tu et al., 2005; Bulkley et al., 2010), as well as synthetic oxazolidinones (e.g., linezolid, etc.) (Ippolito et al., 2008; Wilson et al., 2008), being approved for clinical use have been revealed to mechanistically bind to rRNAs within the $30 \mathrm{~S}$ or $50 \mathrm{~S}$ subunits to interfere with protein synthesis for the control of infections (Wilson, 2009, 2014; Lin et al., 2018). Therefore, large efforts are underway to identify viable RNA targets and assess new RNA-targeted small molecules for the treatment of various types of human diseases (Warner et al., 2018).

\section{RNAs as Therapeutic Drugs}

\section{A. The Rise and Promise of RNA Therapeutics}

With the understanding of new biological processes and development of novel technologies, such as those for gene silencing and genome editing (Stephenson and Zamecnik, 1978; Zamecnik and Stephenson, 1978; 
Lee et al., 1993; Wightman et al., 1993; Fire et al., 1998; Jinek et al., 2012; Cong et al., 2013; Mali et al., 2013), diverse RNA molecules have been used to interfere with potential therapeutic targets (Fig. 1). Firstly, RNA aptamers can directly bind to extracellular, cell surface, or intracellular proteins (Gragoudas et al., 2004; Gryziewicz, 2005) that are traditionally targeted by small-molecule and protein drugs. Secondly, ASOs or asRNAs, siRNAs, and miRNA mimics may be delivered into cells to target intracellular mRNAs or functional ncRNAs through complementary base pairings, leading to gene silencing or control of gene expression for the treatment of diseases. Thirdly, a sense RNA or mRNA molecule can be introduced into cells and then translated into target proteins for protein replacement therapy or vaccination (Sahin et al., 2014; Lieberman, 2018). In addition, the genetic sequences dictating disease initiation and progression may be directly changed by using proper gRNAs and other necessary components to achieve eradication of the disease. As such, RNAs are unique molecules that are able to interact with three major forms of biological macromolecules-DNAs, RNAs, and proteins (Fig. 1) - and the development of RNA therapeutics is expected to expand the range of druggable targets, including conventional proteins and previously undrugged or "undruggable" transcripts and genes.

The development of novel RNA therapeutics has proven highly challenging given the fact that RNA drugs are anticipated to act primarily on intracellular targets (Fig. 1) and that RNA molecules exhibit "undrug-like" physicochemical and PK properties, especially when compared with small-molecule compounds (Table 1).

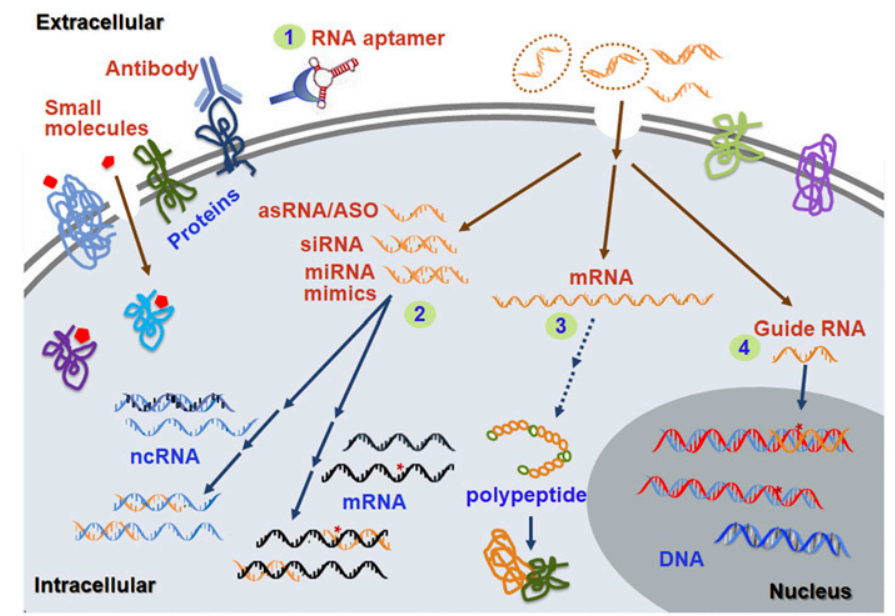

Fig. 1. RNA therapeutics are expected to expand the range of druggable targets from proteins to RNAs and DNAs. Cell surface, extracellular, and intracellular proteins remain favorable targets for the development of small-molecule and protein (e.g., antibody) therapeutics, as well as RNA aptamer drugs (1). Actually, the majority of human genome sequences transcribed as functional ncRNAs largely outnumbered mRNAs to be translated into proteins. Both mRNAs and ncRNAs can be directly targeted by RNA drugs such as ASO/asRNAs, miRNAs, and siRNAs (2). Once introduced into cells, mRNA therapeutics (3) may be developed for protein replacement therapy or vaccination. In addition, gRNAs (4) could be used along with other elements to directly edit the target gene sequences for the treatment of particular diseases.
As a polymeric molecule consisting of a sequence of variable numbers of four major forms of ribonucleotides that differ in their nucleobases, adenine (A), uracil (U), guanine (G), and cytosine (C), naked and unmodified RNAs are extremely susceptible to hydrolysis by nonspecific RNases (e.g., RNase A) that are highly abundant in the blood (Houseley and Tollervey, 2009). Furthermore, RNAs are large molecules (e.g., with molecular weights $>7 \mathrm{kDa}$ ) and are negatively charged (Table 1); thus, it is hard for them to cross the cell membrane. In addition, upon entering into cells, exogenous RNAs need to escape from endosomal trapping and/or degradation by large classes of intracellular ribonucleases or RNases (e.g., endonucleases, and $5^{\prime}$ and $3^{\prime}$ exonucleases), become incorporated into specific complex, and get access to the targets (Fig. 1) to exercise pharmacological effects.

With the development of new strategies to improve the druggability of RNA molecules, as well as the understanding of mechanisms of action, a number of RNA analog drugs have been approved by the FDA for the treatment of human diseases (Table 2), and many others are under active trials [for recent reviews, see Kowalski et al. (2019), Yu et al. (2019)]. The approval of the first RNA aptamer drug, pegaptanib (Gragoudas et al., 2004; Gryziewicz, 2005), supports the concept of using RNA molecules to inhibit protein targets (Fig. 1). Through specific chemical modifications to improve metabolic stability, targeting, binding affinity, and silencing efficacy (Eckstein, 1985; Campbell et al., 1990; Wheeler et al., 2012; Summerton, 2017; Crooke et al., 2018), ASOs [including "gapmers" and phosphorodiamidate morpholino oligomers (PMOs)] have become the most successful class of RNA drugs (e.g., mipomersen, eteplirsen, nusinersen, inotersen, and golodirsen) (Table 2). Furthermore, the most recent approval of two siRNA drugs, patisiran (Adams et al., 2018; Wood, 2018) and givosiran (Scott, 2020), not only testifies to the benefits of developing new approaches to improve the PK and pharmacodynamics (PD) properties of RNA drugs (Nair et al., 2017) but also supports the potential of RNA therapeutics.

\section{B. Types of RNA Drugs and Mechanisms of Action}

1. Antisense Oligonucleotides. The use of chemically synthesized, single-stranded oligonucleotide to selectively inhibit target gene expression via complementary base pairings with targeted mRNA was first reported in 1978 (Stephenson and Zamecnik, 1978; Zamecnik and Stephenson, 1978). Since then, ASOs have been widely used for the study of gene functions and development of novel therapeutics [for reviews, see Kole et al. (2012), Bennett (2019), Levin (2019)]. This is in parallel with the discovery of the presence of natural asRNAs in virtually all species (Spiegelman et al., 1972; Light and Molin, 1983; Simons and Kleckner, 1983; Izant and Weintraub, 1984; Ecker and Davis, 1986) and thus broad recognition of their critical functions in post-transcriptional gene regulation [for reviews, 
see Vanhée-Brossollet and Vaquero (1998), Pelechano and Steinmetz (2013), Nishizawa et al. (2015)]. The knockdown of target gene expression with ASOs includes RNase-dependent cleavage of mRNAs and precursor mRNAs (pre-mRNAs) (RNase $\mathrm{H}$ and RNase P), as well as RNase-independent suppression of protein synthesis. Furthermore, ASOs can be employed to modulate RNA splicing to produce functional proteins or preferred genetic products (Condon and Bennett, 1996; McClorey et al., 2006). Although they differ from siRNAs and miRNAs that rely mainly on cytoplasmic siRNAinduced silencing complexes (RISCs)/miRNA-induced silencing complexes to control target gene expression, ASOs designed to target the same sites of common transcripts could be equally active as siRNAs, with some exceptions (Vickers et al., 2003). In addition, ASOs seem to be more effective to knock down nuclear targets, whereas siRNAs are superior at suppressing cytoplasmic targets (Lennox and Behlke, 2016), likely due to the fact that RNases H \& P are highly abundant in the nucleus and RISCs are present within the cytoplasm.

To make ASOs druggable, a wide variety of chemical modifications have been developed to improve their metabolic stability and cell penetration efficiency, including the change of phosphodiester (PO) linker to phosphorothioate (PS), protection of the 2 '-hydroxyl group on ribose with methyl (2'-methoxy) or methoxyethyl ( $2^{\prime}$-MOE), or direct substitution with fluorine ( $2^{\prime}$-fluoro), and connection of the $2^{\prime}-O$ and $4^{\prime}-C$ with a methylene bridge, namely locked nucleic acid [for reviews, see Ho and $\mathrm{Yu}$ (2016), Khvorova and Watts (2017), Crooke et al. (2018), Yu et al. (2019)]. More extensive modifications are also established for ASOs, among which the nucleobases are retained for base pairings while the ribose 5-phosphate linkages may be fully substituted with morpholino phosphorodiamidate backbones, leading to PMOs (Heasman et al., 2000). In addition, specific ligands, such as hepatocyte asialoglycoprotein receptor-binding $N$-acetylgalactosamine (GalNAc) (Nair et al., 2014, 2017), may be covalently attached to ASOs (and siRNAs, miRNAs, aptamers, etc.) to achieve cell- or organ-selective gene silencing. Some chemical modifications are proven to be very useful for the development of ASO drugs, as demonstrated by their utility in FDA-approved RNA drugs (Table 2).

Since the first ASO drug, fomivirsen, an antisense oligodeoxynucleotide (5'-GCG TTT GCT CTT CTT CTT GCG-3') with phosphorothioate linkages, was approved by FDA in 1998 for the treatment of cytomegalovirus retinitis (Roehr, 1998), a number of ASO therapeutics have been successfully marketed in the United States (Table 2) (Mendell et al., 2013; Morrow, 2013; Robinson, 2013; Syed, 2016; Aartsma-Rus and Krieg, 2017; Ottesen, 2017; Stein and Castanotto, 2017; Benson et al., 2018; Keam, 2018; Wood, 2018). Among them, mipomersen (5'$\mathrm{G}^{*}-\mathrm{MeC}^{*}-\mathrm{MeC}^{*}-\mathrm{MeU}^{*}-\mathrm{MeC}^{*}$-dA-dG-dT-dMeC-dG-dT-dMeCdT-dT-dMeC-G*-MeC*-A*-MeC*-MeC*-3'; * $2^{\prime}-\mathrm{MOE}$; $\mathrm{Me}=5$-methyl, and $\mathrm{d}=$ deoxy; all PS linkages) and inotersen $\left(5^{\prime}-\mathrm{MeU}^{*}-\mathrm{MeC}^{*}-\mathrm{MeU}^{*}-\mathrm{MeU}^{*}-\mathrm{G}^{*}\right.$-dG-dT-dT-dAdMeC-dA-dT-dG-dA-dA-A*-MeU*-MeC*-MeC*-MeC*-3'; $*$ = 2'-MOE; $\mathrm{Me}=5$-methyl, and $\mathrm{d}=$ deoxy; all PS linkages) are also known as gapmers, consisting of modified antisense oligoribonucleotides at both $5^{\prime}$ and 3 ' ends with a "gap" of oligodeoxynucleotide in the middle. Upon selective binding to a targeted transcript, the resulting DNA-RNA heteroduplex is recognized by RNase $\mathrm{H}$, leading to the cleavage of targeted RNA strand and the knockdown of targeted gene expression. Specifically, mipomersen has been shown to selectively bind to $A p o B-100$ mRNA to reduce ApoB-100 protein levels, which is the major constituent of low-density lipoprotein (LDL); thus, it exhibits effectiveness for the treatment of patients with homozygous familial hypercholesterolemia (HoFH) (Stein et al., 2012; Crooke and Geary, 2013; Thomas et al., 2013). Rather, mipomersen was discontinued in 2018 because of competition from other therapeutics and an incapability of achieving marketing success (Yin and Rogge, 2019). On the other hand, inotersen selectively binds to transthyretin (TTR) mRNA to achieve the suppression of hepatic TTR protein expression levels and thus exerts therapeutic benefits among adults with hereditary transthyretinmediated amyloidosis (hATTR amyloidosis) (Benson et al., 2018; Coelho et al., 2020).

Nusinersen (5'-UCA CUU UCA UAA UGC UGG-3'; fully modified with 2 '-MOE and PS linkages; all Us and Cs are 5'-methylated) was approved by FDA in 2016 (Aartsma-Rus, 2017; Ottesen, 2017) for the treatment of a rare autosomal recessive neuromuscular disorder, spinal muscular atrophy (SMA), which is caused by genetic variations in the chromosome 5q11.2-q13.3 locus, affecting survival motor neuron (SMN) gene expression and leading to an insufficient level of SMN protein (Brzustowicz et al., 1990; Lefebvre et al., 1995). Nusinersen is an extensively modified 18-mer ASO whose PO linkages are completely changed to PS, and all ribose rings are protected with 2 '-MOE (Table 2). Through the modulation of alternate splicing of SMN2 pre-mRNA to increase exon 7 inclusion to achieve the expression of full-length functional SMN protein (Rigo et al., 2014), nusinersen was found to be effective in improving patient survival or motor function (Finkel et al., 2017; Mercuri et al., 2018).

Eteplirsen and golodirsen are two PMO drugs (Table 2), approved in 2016 (Stein, 2016; Syed, 2016) and 2019 (Heo, 2020), respectively, for the treatment of Duchenne muscular dystrophy (DMD), a lethal neuromuscular disorder commonly caused by genetic mutations disrupting the reading frame of the $\mathrm{X}$-linked dystrophin gene and which might be found in one of 3500 newborn boys (Cirak et al., 2011). Eteplirsen and golodirsen contain 30 and 25 linked PMO subunits whose sequences of bases are $5^{\prime}$-CUC CAA CAU CAA GGA AGA UGG CAU UUC UAG-3' and 5' GUU GCC UCC GGU UCU GAA GGU GUU C-3', respectively, among which all $U_{s}$ are methylated or regarded as T. Both eteplirsen and golodirsen are designed 
to restore the reading frame of dystrophin gene for the production of an internally truncated, yet functional, dystrophin protein. In particular, eteplirsen selectively binds to the exon 51 of dystrophin pre-mRNA (Popplewell et al., 2010), leading to exclusion of this exon during mRNA processing among patients with DMD showing genetic mutations amenable to exon 51 skipping (van Deutekom et al., 2007). With the production of functional dystrophin protein, eteplirsen-treated patients were shown to have a slower rate of decline in ambulation (Cirak et al., 2011; Mendell et al., 2013, 2016; Khan et al., 2019). Likewise, golodirsen selectively binds to the exon 53 of dystrophin pre-mRNA to achieve the exclusion of this exon during mRNA processing (Popplewell et al., 2010) and thus the expression of functional muscle protein dystrophin among patients with confirmed genetic mutations that are amenable to exon 53 skipping (Frank et al., 2020; Heo, 2020).

Many clinical trials are ongoing to investigate some new ASOs for the treatment of specific diseases, spanning from orphan genetic disorders to infectious diseases and cancers (https://www.clinicaltrials.gov/) (Yu et al., 2019). For instance, a deep intronic c. $2991+1655 \mathrm{~A}>\mathrm{G}$ mutation in CEP290 underlying Leber congenital amaurosis type 10 , an inherited retinal dystrophy, may be corrected by ASO therapy. Indeed, QR-110 was identified to effectively restore wild-type CEP290 mRNA and protein expression levels in CEP290 c.2991+1655A $>\mathrm{G}$ homozygous and heterozygous Leber congenital amaurosis type 10 primary fibroblasts as well as induced pluripotent stem cellsderived retinal organoids, and it was tolerated in monkeys after intravitreal injection (Dulla et al., 2018). Therefore, a double-masked, randomized, multiple-dose phase II/III study (NCT03913143) is underway to evaluate the efficacy, safety, tolerability, and systemic exposure of intravitreally administered QR-110 in patients with Leber congenital amaurosis who are amenable to the CEP290 p.Cys998X mutation. As another example, IONISAR-2.5Rx, a next-generation ASO against androgen receptor, has entered into a phase Ib/II single-arm study (NCT03300505) to identify an effective and safe dose level for the treatment of metastatic castrationresistant prostate cancer as combined with a fixed dose of enzalutamide.

2. Small Interfering RNAs. Since the discovery and development of RNA interference (RNAi) technologies with double-stranded RNAs (dsRNAs) (Fire et al., 1998; Zamore et al., 2000; Elbashir et al., 2001), 18- to 22-bp siRNAs have been routinely used for selective and effective knockdown of target gene expression in basic research, and some have entered clinical drug development [for reviews, see Castanotto and Rossi (2009), Setten et al. (2019), Yu et al. (2019)]. Different from the single-stranded ASO, siRNA comprises two strands, in which the guide strand is characterized by two 3 '-overhang ribonucleotides crucial for the duration of gene silencing (Strapps et al., 2010). The endoribonuclease Dicer or helicase with RNase motif (Bernstein et al., 2001; Hutvágner et al., 2001) trims dsRNAs and separates the guide and passenger strands within the RISC (Hammond et al., 2000). The passenger strand is preferentially cleaved by the endonuclease argonaute- 2 (Matranga et al., 2005; Rand et al., 2005), which is the catalytic core of RISC (Hammond et al., 2001; Martinez et al., 2002; Liu et al., 2004; Meister et al., 2004; Okamura et al., 2004; Rand et al., 2004). The guide strand containing a thermodynamically less stable $5^{\prime}$ end retained within the RISC (Khvorova et al., 2003; Schwarz et al., 2003) acts on its targeted mRNA through perfect complementary base pairings, leading to a sequence-specific cleavage of the targeted mRNA by argonaute- 2 and consequently the knockdown of target gene. Because RISC is solely located within cytoplasm, whereas RNase $\mathrm{H}$ is predominately in nucleus, as mentioned previously, siRNAs are usually more effective than ASOs in knocking down cytoplasmic targets (Lennox and Behlke, 2016).

To develop siRNA therapeutics, it is essential to achieve potent, specific, and long-lasting gene silencing while minimizing off-target effects (Kim et al., 2005; UiTei et al., 2008; Wang et al., 2009). With an improved understanding of RNAi mechanisms, some specific guidelines may be followed, and particular software can be used for the design of effective siRNAs [for reviews, see Jackson and Linsley (2010), Naito and Ui-Tei (2012), Fakhr et al. (2016)]. The selection of a proper target site, usually closer to the start codon within the coding sequence, is critical for the effectiveness of siRNA. This is also crucial to ensure selectivity and lessen off-target effects of siRNA. The composition of siRNA, such as the use of specific ribonucleotides at particular locations and overall G/C content, affects not only the stability but also the efficacy of siRNA. As siRNA may induce immune response in sequence-independent and sequence-dependent manners (Alexopoulou et al., 2001), it is important to avoid immune-stimulatory motifs such as U-rich sequences when designing siRNAs (Kleinman et al., 2008; Goodchild et al., 2009). In addition, similar to the development of ASO drugs, chemical modification is a common strategy to improve the metabolic stability and PK properties of siRNAs (Bramsen and Kjems, 2012; Yu et al., 2019). In any case, the effectiveness, selectivity, and safety of individual siRNAs require extensive and critical experimental validation.

The first siRNA drug, patisiran (Table 2), was approved by the FDA in 2018 for the treatment of the polyneuropathy of hATTR amyloidosis in adults (Wood, 2018; Yu et al., 2019) over 20 years after the discovery of siRNA-controlled gene silencing. hATTR amyloidosis is an autosomal-dominant, life-threatening disease caused by genetic mutations of TTR. As TTR protein is primarily produced in the liver, pathogenic mutations lead to misfolded TTR proteins that deposit as amyloid in peripheral nerves, heart, kidney, and gastrointestinal tract 
(Adams et al., 2018; Zhang et al., 2020b). Patisiran is a 21-bp siRNA with extensive chemical modifications (Table 2) whose sense sequence is $5^{\prime}$-G-MeU-A-A-MeC-MeC-A-AG-A-G-MeU-A-MeU-MeU-MeC-MeC-A-MeU-dT-dT-3' and antisense sequence is $5^{\prime}-\mathrm{A}-\mathrm{U}-\mathrm{G}-\mathrm{G}-\mathrm{A}-\mathrm{A}-\mathrm{MeU}-\mathrm{A}-\mathrm{C}-$ U-C-U-U-G-G-U-MeU-A-C-dT-dT-3' (Me = 2'-O-methyl, and $\mathrm{d}=$ deoxy), formulated as a lipid nanoparticle (LNP) for delivery to hepatocytes (Zhang et al., 2019, 2020b). Different from conventional siRNAs that are usually projected to target coding sequence regions, patisiran is designed to follow miRNA mechanisms by selectively binding to a conserved sequence in the 3 '-untranslated regions (UTR) of mutant and wild-type TTR mRNA, leading to a reduction of circulating TTR protein levels and accumulation in tissues. Clinical studies demonstrated the benefits of patisiran $(0.3 \mathrm{mg} / \mathrm{kg}$ every 3 weeks, i.v. infusion) for the treatment of patients with hATTR amyloidosis, as indicated by a decrease of the modified Neuropathy Impairment Score +7 from baseline to month 18 among the patisiran treatment group compared with a steady increase in the placebo group (Adams et al., 2018). Meanwhile, overall incidence and types of adverse events did not differ in patisiran and placebo groups, suggesting that patisiran was tolerated in patients (Adams et al., 2018; Zhang et al., 2020b). It is also notable that, although both patisiran and inotersen act on the same molecular target for the treatment of the same disease, patisiran is administered less frequently and at much lower doses than inotersen ( $284 \mathrm{mg}$ once weekly, s.c.), although their routes of administration are different (Table 2).

In November 2019, givosiran was the second siRNA drug approved by the FDA for the treatment of adults with acute hepatic porphyria (AHP) (Table 2) (de Paula Brandao et al., 2020; Scott, 2020). AHP is a rare, inherited, and life-threatening disease caused by disruption of hepatic heme biosynthesis. The accumulation of neurotoxic heme intermediates $\delta$-aminolevulinic acid (ALA) and porphobilinogen (PBG) in patients leads to acute debilitating neurovisceral attacks and even disabling chronic symptoms (Sardh et al., 2019). Givosiran is a 19-bp, chemically modified siRNA (Table 2) whose sense and antisense sequences are 5'-MeC-MeA-MeGMeA-MeA-MeA-fG-MeA-fG-MeU-fG-MeU-fC-MeU-fCMeA-MeU-MeC-MeU-MeU-MeA-3' and 5'-MeU-fA-fAfG-MeA-fU-MeG-fA-MeG-fA-MeC-fA-MeC-fU-MeC-fUMeU-fU-MeC-fU-MeG-MeG-MeU-3', respectively $(\mathrm{Me}=$ 2 -O-methyl and $\mathrm{f}=2^{\prime}$-fluoro). The sense sequence is covalently attached to a triantennary GalNAc ligand at the $3^{\prime}$ end for an improved internalization of GalNacconjugated siRNAs into hepatocytes. Givosiran selectively binds to the mRNA of $\delta$-ALA synthase 1 (ALAS1), a rate-limiting enzyme in hepatic heme biosynthesis that is responsible for the formation of ALA from succinyl-CoA and glycine, to induce gene silencing, which subsequently reduces ALA and PBG levels and lessens factors associated with attacks and other symptoms of AHP (de Paula Brandao et al., 2020; Sardh et al., 2019). Although the results of a phase III clinical trial have not been published yet, a phase I study showed that monthly subcutaneous administration of $2.5 \mathrm{mg} / \mathrm{kg}$ givosiran to patients with AHP sharply decreased the ALAS1 mRNA levels and returned ALA and PBG levels to near normal, and it subsequently led to a $79 \%$ lower mean annualized attack rate than the placebo group (Sardh et al., 2019). The approval of givosiran also highlights the utility of a GalNAc-based delivery system for the development of RNA therapeutics for the treatment of hepatic diseases.

The very recent approval of two siRNA drugs by the FDA provides incentives to develop novel siRNA therapeutics, and many are now under active clinical trials (https://www.clinicaltrials.gov/) (Yu et al., 2019). Lumasiran, or ALN-GO1, is a GalNAc-conjugated investigative siRNA drug for the treatment of primary hyperoxaluria type 1, an inherited rare disease arising from disruption of glyoxylate metabolism (Liebow et al., 2017). Preclinical studies have demonstrated that, through selective targeting of the mRNA of hydroxyacid oxidase (glycolate oxidase) 1, lumasiran administered subcutaneously was able to reduce oxalate production in multiple animal models (Liebow et al., 2017). Presently, an open-label phase III clinical trial (NCT03905694) is underway for the investigation of the efficacy, safety, PK, and PD of lumasiran among infants and young children with primary hyperoxaluria type 1. Inclisiran, or ALN-PCSSC, is another synthetic siRNA with extensive chemical modifications and is covalently connected to a triantennary GalNAc ligand that is designed to target the mRNA of hepatic proprotein convertase subtilisin kexin type 9. Previous clinical studies consistently demonstrated the effectiveness of inclisiran in reducing the plasma proprotein convertase subtilisin kexin type 9 and LDL cholesterol levels in healthy individuals and patients at high risk for cardiovascular disease who had elevated LDL cholesterol levels (Fitzgerald et al., 2014, 2017; Ray et al., 2017). Moreover, a single-dose treatment with inclisiran was shown to cause a durable reduction in LDL cholesterol levels among the subjects over 1 year (Ray et al., 2019), and inclisiran showed similar efficacy and safety profiles among individuals with normal and impaired renal functions (Wright et al., 2020). A double-blind, placebo-controlled, and open-label phase II/III study (NCT03851705) is ongoing to evaluate the safety and efficacy of inclisiran in patients with $\mathrm{HoFH}$. In addition, fitusiran (or ALN-AT3SC) is an investigative siRNA drug that is designed to suppress the production of antithrombin (encoded by the gene serpin family $\mathrm{C}$ member 1 (SERPINC1) through selective interference with SERPINC1 mRNA in the liver for the treatment of hemophilia A and B, inherited bleeding disorders arising from impaired thrombin production (Machin and Ragni, 2018). Administered subcutaneously once monthly, fitusiran was shown to reduce plasma antithrombin levels 
in a dose-dependent manner and increase thrombin production in patients with hemophilia A or B who did not have inhibitory alloantibodies (Pasi et al., 2017). Presently, two phase III clinical trials (NCT03549871 and NCT03754790) are underway to evaluate the efficacy and safety of fitusiran among patients with hemophilia A and B.

siRNA drugs under clinical development are also expanded to other therapeutic areas, including oncology, that impact millions of patients. For instance, siG12D-LODER is an siRNA that specifically targets the Kirsten rat sarcoma viral oncogene homolog (KRAS) mutant G12D mRNA, a driver oncogene present in various types of cancers, especially pancreatic cancer (Zorde Khvalevsky et al., 2013; Golan et al., 2015; Ramot et al., 2016). A previous phase I clinical study showed that combination treatment with siG12D-LODE and gemcitabine was well tolerated, and potential efficacy among patients with locally advanced pancreatic cancer was shown (Golan et al., 2015). As such, siG12D-LODER is currently under a phase II clinical study to evaluate its efficacy, safety, tolerability, and PK for the treatment of patients with unresectable, locally advanced pancreatic cancer, as combined with standard chemotherapy (i.e., gemcitabine plus nanoparticle albumin-bound paclitaxel) in comparison with chemotherapy alone. As another example, synthetic siRNA targeting a protein-tyrosine kinase named ephrin type-A receptor 2 (EphA2) was shown to be effective in controlling tumor growth in xenograft mouse models (Landen et al., 2005). Furthermore, EphA2-siRNA encapsulated with 1,2dioleoyl-sn-glycero-3-phosphatidylcholine nanocomplex at tested doses was tolerated in murine and primate models (Wagner et al., 2017). A phase I clinical trial (NCT01591356) is now recruiting patients with advanced solid tumors to evaluate the safety and toxicity profiles of an 1,2-dioleoyl-sn-glycero-3-phosphatidylcholineencapsulated, EphA2-targeted siRNA drug administered intravenously.

3. MicroRNAs. MicroRNAs are a superfamily of genome-derived small ncRNAs governing posttranscriptional gene regulation that was first discovered in Caenorhabditis elegans in 1993 (Lee et al., 1993; Wightman et al., 1993). More than 1900 miRNAs have been identified in humans (Kozomara and Griffiths-Jones, 2014; Kozomara et al., 2019). Canonical biogenesis of miRNAs starts from the transcription of miRNA-coding sequences by RNA polymerase II to long primary miRNA (pri-miRNA) transcripts within the nucleus (Lee et al., 2004). The pri-miRNA is then cleaved to shorter precursor miRNA (pre-miRNA) by the RNase III Drosha complexed with RNA-binding protein DiGeorge syndrome chromosome region 8 (Lee et al., 2003; Denli et al., 2004; Gregory et al., 2004; Han et al., 2004). After being transported into the cytoplasm by RAS-related nuclear proteinGTP-dependent exportin-5 (Bohnsack et al., 2004; Lund et al., 2004), pre-miRNAs are cleaved, double-stranded
miRNA duplexes by cytoplasmic RNase III Dicer complexed with transactivation-responsive RNA-binding protein (Hutvágner et al., 2001; Lee et al., 2002; Zhang et al., 2004a; Haase et al., 2005). The miRNA duplex associated with miRNA-induced silencing complex is then unwound to offer two strands, among which the guide strand mature miRNA binds to the target mRNA through partial complementary base pairings, with corresponding miRNA response element usually present within the $3^{\prime}$ UTR, leading to translational inhibition or transcript degradation or cleavage (Hutvágner and Zamore, 2002; Bagga et al., 2005; Pillai et al., 2005; Petersen et al., 2006). On the other hand, functional miRNAs may be generated through noncanonical pathways, such as those premiRNAs directly excised from introns not dependent upon Drosha (Okamura et al., 2007; Ruby et al., 2007), Dicer-independent miRNAs (Cheloufi et al., 2010; Cifuentes et al., 2010; Ho et al., 2018) 3), and miRNAs or small RNAs (sRNAs) derived from small nucleolar RNAs (Ender et al., 2008; Pan et al., 2013) or transfer RNAs (tRNAs) (Maute et al., 2013; Kuscu et al., 2018).

One miRNA can simultaneously regulate the expression of multiple transcripts, since the recognition of a target mRNA by miRNA does not require perfect base pairing. Through the control of multiple genes involved in the same biological processes, many miRNAs have been shown to play important roles in pathogenesis of human diseases, including lethal cancers [for reviews, see Ambros (2004), Bader et al. (2010), Esteller (2011), Rupaimoole and Slack (2017)]. In addition, compared with normal tissues, there is generally a decrease or loss of oncolytic miRNAs (e.g., let-7a/b/c-5p, miR-34a-5p and miR-124-3p) and overexpression of oncogenic miRNAs (e.g., miR-21-5p) in tumor tissues and carcinoma cells [for reviews, see Esteller (2011), Rupaimoole and Slack (2017)], although there are some exceptions. Therefore, some tumor-suppressive miRNAs lost in cancer cells may be restored, e.g., by using synthetic miRNA mimics and virus- or plasmid-based expression, and oncogenic miRNAs overexpressed in cancer cells may be inhibited, e.g., with chemically synthesized single-stranded ASO (termed antagomirs or miRNA inhibitors) for the control of tumor progression (Ho and Yu, 2016; Petrek and $\mathrm{Yu}, 2019$; Yu et al., 2019). The "miRNA replacement therapy" strategy is of particular interest, compared with "antagonism" of oncogenic miRNAs, because miRNAs are endogenous components and reintroduced miRNAs may be well tolerable in cells. The premise of an miRNA replacement therapy strategy has been demonstrated by many preclinical studies (Bader et al., 2010; Rupaimoole and Slack, 2017; Petrek and Yu, 2019) that are amendable to clinical investigations (Beg et al., 2017; Hong et al., 2020).

Human miR-34a-5p is one of the most promising miRNAs for replacement therapy, with well established tumor-suppressive functions while downregulated in a wide range of solid tumors [for reviews, see Bader (2012), 
Yu et al. (2019)]. Through effective interference with various oncogenes underlying tumor progression and metastasis, the efficacy of miR-34a-5p was consistently documented in many types of xenograft tumor mouse models (Wiggins et al., 2010; Liu et al., 2011; Pramanik et al., 2011; Craig et al., 2012; Kasinski and Slack, 2012; Wang et al., 2015b; Zhao et al., 2015, 2016; Jian et al., 2017; Ho et al., 2018). Therefore, a liposomeencapsulated synthetic miR-34a mimic, MRX34, became the first miRNA entering phase I clinical trial for the treatment of advanced solid tumors, including unresectable liver cancer (Beg et al., 2017; Hong et al., 2020). As the maximum tolerated dose was revealed to be $110 \mathrm{mg} / \mathrm{m}^{2}$ in patients without hepatocarcinoma, a high incidence of adverse events (e.g., 100\% all grades and $38 \%$ grade 3 among all patients), such as fever, fatigue, back pain, nausea, diarrhea, anorexia, and vomiting, was found among patients with liver cancer receiving treatment with MRX34 (10-50 mg/m ${ }^{2}$, i.v., biweekly) who required palliative management with dexamethasone premedication. Nevertheless, MRX34 did exhibit antitumor activity among patients with refractory advanced solid tumors (Beg et al., 2017; Hong et al., 2020), offering valuable insight into the development of miRNA therapeutics.

One randomized, double-blind, phase I/II clinical trial (NCT04120493) is underway to explore the safety, tolerability, and efficacy signals of multiple ascending doses of striatally administered, adenoassociated viral vector-carried miR-155, which targets the total huntingtin (HTT) transcripts-namely, rAAV5-miHTT or AMT-130 - in early manifest Huntington disease (HD). This strategy is based on previous findings on the efficacy and safety of miHTT therapy in preclinical models, including the use of an Hu128/21 HD mouse model (Miniarikova et al., 2016), acute HD rat model (Miniarikova et al., 2017), transgenic HD minipig model (Evers et al., 2018), neuronal and astrocyte cells derived from patients with HD (Keskin et al., 2019), and humanized Hu128/21 mouse model of HD (Caron et al., 2020).

Although there is no single miRNA drug that has yet to be approved by the FDA for medical use, the first siRNA drug, patisiran, seems to mimic miRNA mechanisms of action aforementioned, i.e., through selective binding to the $3^{\prime}$ UTR of TTR mRNA. In addition, many studies have been conducted, and others are still underway, for the identification of miRNAs as potential diagnostic or prognostic biomarkers for patients with particular diseases or treatments (Hayes et al., 2014; Kreth et al., 2018; Pogribny, 2018), besides the use of miRNAs as interventional agents.

4. RNA Aptamers. Aptamers are single-stranded, highly structured DNA or RNA oligonucleotides that can bind to a wide variety of molecular targets, including proteins, peptides, DNAs, RNAs, small molecules, and ions, with high affinity and specificity. Upon binding to target protein, RNA aptamer behaves like a nucleic acid antibody or chemical inhibitor to modulate protein function (Fig. 1) for the control of disease (Bunka and Stockley, 2006; Bouchard et al., 2010; Kaur et al., 2018). Actually, natural RNA-protein complex was first identified in bacteria, among which the RNA molecule is an essential component for the activity of RNase $\mathrm{P}$ complex in the processing of precursor tRNA into active tRNA, which could also be inhibited by various RNAs or aptamers (Stark et al., 1978; Kole and Altman, 1979). There is also autocatalytic RNA or ribozyme, which undergoes self-splicing upon binding with monovalent and divalent cations (Kruger et al., 1982). Highly structured RNA elements, or "aptamers," are also present within human immunodeficiency virus (HIV)-1 to interact with target proteins for gene expression and viral replication (Feng and Holland, 1988; Marciniak et al., 1990). Moreover, intrinsic RNAs or riboswitches can sense small-molecule metabolites and then control target gene expression (Mironov et al., 2002; Nahvi et al., 2002; Winkler et al., 2002a). Ligand binding ribozymes and riboswitches have been identified in humans, as well (Salehi-Ashtiani et al., 2006; Ray et al., 2009).

With the understanding of the interactions of functional RNAs with proteins as well as other ligands, a high-throughput technology, systematic evolution of ligands by exponential enrichment, was also developed for the identification and development of selective and potent RNA aptamers or ribozymes (Ellington and Szostak, 1990; Robertson and Joyce, 1990; Tuerk and Gold, 1990). Chemical modifications of selected RNA aptamers may increase metabolic stability and improve PK properties, similar to ASOs and siRNAs (Khvorova and Watts, 2017; Yu et al., 2019, Ho and Yu 2016). Furthermore, mirror-image $L$-ribonucleic acids resistant to degradation by RNases have been used for the synthesis and development of artificial aptamers called Spiegelmer (Vater and Klussmann, 2015).

In 2004, pegaptanib was the first RNA aptamer drug approved by the FDA for the management of neovascular age-related macular degeneration (AMD) (Table 2) (Gryziewicz, 2005), supporting the utility of aptamers to interfere with protein targets for the control of human diseases (Fig. 1).

AMD is a leading cause of low vision in the elderly in developed countries, and neovascular AMD, accounting for approximately $10 \%$ of all forms, is responsible for $90 \%$ of the severe loss of vision (Gragoudas et al., 2004). With the understanding of the role of vascular endothelial growth factor (VEGF) in pathogenesis of neovascular AMD, ocular VEGF has become an attractive target for the treatment of neovascular AMD (Hubschman et al., 2009; Miller, 2019). Pegaptanib, a 28-nt RNA aptamer (Table 2) with a sequence 5'-fC-MeG-MeG-AA-fU-fC-MeA-MeG-fU-MeG-MeA-MeA-fU-MeG-fC-fU-fUMeA-fU-MeA-fC-MeA-fU-fC-fC-MeG-3'-3'-dT-5' and 
covalently linked to two branched $20-\mathrm{kDa}$ polyethylene glycol moieties was designed to selectively bind and block the activity of extracellular VEGF_-in particular, the 165-amino-acid isoform ( $\mathrm{VEGF}_{165}$ ) (Gragoudas et al., 2004). The benefits of pegaptanib in improving visual acuity were demonstrated in patients with neovascular $\mathrm{AMD}$, and intravitreal injection could induce some potentially modifiable risk of adverse events (Gragoudas et al., 2004; Gonzales, 2005). Nevertheless, the market share of pegaptanib declined since 2011 because of competition from anti-VEGF antibody drugs such as ranibizumab and bevacizumab (Yin and Rogge, 2019).

Olaptesed pegol (NOX-A12), a pegylated 45-nt RNA Spiegelmer designed to selectively target the small chemokine stromal cell-derived factor 1 or C-X-C motif chemokine 12 with high affinity, was effective at preventing the binding of stromal cell-derived factor 1 to its receptors CXC receptor 4 and CXC receptor 7 and thus inhibiting the subsequent signal transduction to achieve control of angiogenesis and metastasis, as well as improvement of other anticancer therapies (Roccaro et al., 2014; Deng et al., 2017). Two phase IIa studies showed that patients with relapsed/refractory multiple myeloma (Ludwig et al., 2017) and chronic lymphocytic leukemia (Steurer et al., 2019) were highly responsive to olaptesed pegol therapy in combination with bortezomibdexamethasone and bendamustine-rituximab, respectively. One active clinical trial (NCT04121455) is underway to evaluate the safety and efficacy of olaptesed pegol in combination with irradiation among patients with inoperable or partially resected first-line glioblastoma. Another pegylated Spiegelmer, lexaptepid pegol (NOX-94), binds to human hepcidin with high affinity and thus inhibits its biological function (Schwoebel et al., 2013) for the treatment of anemia of chronic disease. A firstin-human study (NCT01372137) showed that lexaptepid pegol was able to inhibit hepcidin and dose dependently elevate serum iron and transferrin saturation, and it was generally safe and tolerated in healthy subjects, with mild and transient transaminase increases at higher doses (Boyce et al., 2016). After additional investigations in patients (e.g., NCT02079896), no clinical trial is currently open to evaluate the safety and efficacy of lexaptepid pegol. Although clinical development of new aptamer drugs seems less active in recent years, there is growing interest in developing aptamers for drug delivery and as diagnostic agents (Bouvier-Müller and Ducongé, 2018; Kaur et al., 2018).

5. Messenger RNAs. The development and use of mRNAs as a novel class of drug modalities has great potential in vaccination, protein replacement therapy, and antibody therapy for the treatment of a wide variety of human diseases, including infections, cancers, and genetic disorders (Sahin et al., 2014; Weissman and Kariko, 2015; Pardi et al., 2018; Kowalski et al., 2019). This concept was first demonstrated by the findings on efficient expression of target proteins in mouse tissues in vivo after the administration of in vitro-transcribed (IVT) mRNAs, which was reported in 1990 (Wolff et al., 1990). After extensive preclinical studies, many IVT mRNA therapeutics have already entered clinical trials (Heiser et al., 2002; Weide et al., 2009; Rittig et al., 2011; Allard et al., 2012; Van Gulck et al., 2012; Maus et al., 2013; Wilgenhof et al., 2013; Bahl et al., 2017; Leal et al., 2018; de Jong et al., 2019; Papachristofilou et al., 2019). Different from plasmid DNA or virus-based gene therapy, mRNA drugs are translated into target proteins by the cellular machinery without interference with the genome (Fig. 1). To ensure translation ability and efficiency, an mRNA needs to contain not only the whole open reading frame of target protein but also intact $5^{\prime}$ and $3^{\prime}$ UTRs as well as $5^{\prime}$ cap and $3^{\prime}$ poly(A) tail. Therefore, the mRNA drug molecule is much bigger than other types of RNA therapeutics (Fig. 1). Likewise, direct administration of mRNA therapeutics to patients requires efficient delivery systems to protect mRNAs from degradation by RNases and cross-cellular barrier in vivo. Alternatively, patients may be treated with autologous transplantation of $\mathrm{T}$ cells or dendritic cells (DCs) that are reprogrammed with mRNA drugs ex vivo.

Because of the high sensitivity of immune cells in recognizing antigens that can be coded by exogenous mRNAs, as well as their intrinsic immune-stimulatory effects (Hoerr et al., 2000; Weissman et al., 2000; FotinMleczek et al., 2011), mRNA therapeutics hold great promise as vaccines for the treatment of infectious and cancerous diseases. For instance, a phase I study revealed the effectiveness and safety of autologous transplantation of DCs transfected with mRNA encoding prostate-specific antigen in the induction of prostate-specific antigenspecific immunity and impact on surrogate clinical endpoints among patients with metastatic prostate cancer (Heiser et al., 2002). Another phase I/II study showed the impact of intradermal injection of protamineformulated mRNAs coding multiple tumor-associated antigens, e.g., melan-A, tyrosinase, glycoprotein 100, melanoma-associated antigen (Mage)-A1, Mage-A3, and survivin, in patients with metastatic melanoma (Weide et al., 2009). A very recent phase Ib clinical trial also established the benefits of immunotherapy consisting of protamine-protected, sequence-optimized mRNA (BI1361849 or CV9202) encoding six non-small-cell lung cancer (NSCLC)-associated antigens [New York Esophageal Squamous Cell Carcinoma-1 (NY-ESO-1), MAGE-C1, MAGE-C2, survivin, 5T4, and Mucin-1] among patients with stage IV NSCLC (Papachristofilou et al., 2019). As such, a phase I/II study (NCT03164772) is underway to evaluate the safety and efficacy of combination therapy with CV9202 mRNA vaccine and checkpoint inhibitors (e.g., anti-programmed death-ligand 1 durvalumab and anti-cytotoxic T-lymphocyte antigen 4 tremelimumab) for the treatment of NSCLC. Other ongoing clinical trials include a dose-escalation and efficacy study of intratumoral administration of LNP-encapsulated 
mRNA-2416 encoding human OX40L (NCT03323398) and mRNA-2752 encoding human OX40L, IL-23, and IL-36 $\gamma$ (NCT03739931), alone or combined with durvalumab, for patients with advanced malignancies.

Managing infectious diseases through mRNA vaccine is also actively assessed in a clinical setting. One investigation demonstrated that autologous transplantation of monocyte-derived DCs pretreated with mRNAs encoding Group-specific antigen and a chimeric transactivating regulatory protein (Tat)-anti-repression trans-activator (Rev)-negative regulatory factor (Nef) protein was tolerated and effective at enhancing antiviral responses in six patients infected with HIV-1 and under stable and highly active antiretroviral therapy (Van Gulck et al., 2012). Another phase I/IIa study showed that vaccinations with autologous DCs electroporated with mRNA encoding Tat-Rev-Nef were well tolerated and able to induce vaccine-specific immune responses among $17 \mathrm{HIV}$ 1-infected patients who were stable on combined antiretroviral therapy, after which combined antiretroviral therapy was interrupted (Allard et al., 2012). The benefits of this vaccination therapy with mRNA-transfected DCs were further demonstrated by very recent clinical studies (Gandhi et al., 2016; Leal et al., 2018; de Jong et al., 2019); however, the exact mRNA vaccines are different. Furthermore, clinical studies revealed a robust prophylactic immunity of LNP-carried, specifically modified mRNA vaccines encoding hemagglutinin proteins of avian influenza virus A H10N8 induced in humans, although some mild to severe adverse events were noted (Bahl et al., 2017). In addition, a randomized, observer-blind, placebo-controlled, and dose-ranging phase I study (NCT04064905) is recruiting healthy flavivirus seropositive and seronegative adults for the evaluation of the safety and immunogenicity of a Zika vaccine (mRNA-1893).

To combat against the ongoing global severe acute respiratory syndrome coronavirus (SARS-CoV)-2 pandemic, or coronavirus disease 2019 crisis, which as of the acceptance of this paper for publication, has caused more than 17 million confirmed cases and over 673,000 deaths worldwide and more than 4.6 million cases and over 154,000 deaths in the United States (https:// www.worldometers.info/coronavirus/), enormous efforts are underway to develop treatment and preventive strategies, including mRNA vaccines (Corey et al., 2020; Yi et al., 2020a). The SARS-CoV-2 virus belongs to a family of positive-sense, single-stranded RNA coronaviruses whose replication depends on the translation of viral RNA into proteins and reproduction of viral RNAs, as well as assembly of the capsid within host cells, after the interactions between viral spike proteins and host cellular membrane proteins (Hoffmann et al., 2020; Letko et al., 2020). Given the important role in SARS-CoV-2 viral infection, the spike proteins have emerged as potential targets for the development of smallmolecule and protein drugs as well as vaccines. Indeed, one LNP-encapsulated mRNA vaccine encoding a 103 transmembrane-anchored SARS-CoV-2 spike protein with the native furin cleavage site (mRNA-1273) has quickly entered into clinical trials (NCT04405076 and NCT04283461), attributable to the structure-guided design of target protein/mRNA, fast $\mathrm{LNP} / \mathrm{mRNA}$ vaccine platform technology, and some promising preclinical observations (K. S. Corbett et al., preprint, https://doi.org/ 10.1101/2020.06.11.145920). Although the unprecedented need for vaccination against SARS-CoV-2 is clear, establishing the safety and efficacy of a vaccine takes time before it can be used to immunize a large population to protect global public health.

IVT mRNAs encoding target proteins and antibodies may be developed for protein replacement therapy and antibody therapy, respectively. This is an alternative strategy to classic gene therapy using DNA materials, protein/antibody molecules, and the most recent gene editing technology for the treatment of monogenic disorders caused by impaired or disrupted protein synthesis in body (Martini and Guey, 2019), as well as some common diseases such as infection and cancer (Schlake et al., 2019). As an example, methylmalonic acidemia (MMA) is an inherited metabolic disorder usually found in early infancy that ranges from mild to life-threatening, and about $60 \%$ of MMA cases are attributed to the deficiency of hepatic methylmalonyl CoA mutase (MUT) synthesis, caused by mutations in the MUT gene. A pseudouridine-modified, codonoptimized mRNA encoding human MUT formulated with LNP has been developed as mRNA replacement therapy for the treatment of MMA, and its efficacy and safety profiles have been established very recently in murine models (An et al., 2017, 2019). Currently, an open-label, dose-escalation phase I/II clinical study (NCT03810690) is underway to evaluate the safety, PK, and PD of mRNA-3704 encoding functional MUT enzyme among patients with isolated MMA due to MUT deficiency between 1 and 18 years of age with elevated plasma methylmalonic acid.

With the discovery of gene editing technologies and development of novel therapeutic strategies, there is also growing interest in using mRNAs to introduce target proteins to achieve gene editing. They include the use of mRNAs encoding zinc finger nucleases (Geurts et al., 2009; Wood et al., 2011; Huang et al., 2014; Wang et al., 2015a; Conway et al., 2019), transcription activator-like effector nucleases (Tan et al., 2013; Wefers et al., 2013; Poirot et al., 2015; Nanjidsuren et al., 2016), transposases (Wilber et al., 2006; Ivics et al., 2014a,b; Ellis et al., 2017), CRISPR-associated proteins, or endonucleases (e.g., Cas9 and Cas12a) (Wang et al., 2013; Wu et al., 2013; Yin et al., 2016; Ren et al., 2017; Cromer et al., 2018; Xu et al., 2018; Gurumurthy et al., 2019) to enable genome editing or alteration of specific gene sequences. Rather, the specificity and safety of editing a genome with such new modalities warrant more extensive and critical 
studies, and their utility for the treatment of human diseases is mainly under preclinical investigations thus far.

6. Guide RNAs. The prokaryotic CRISPR/Cas immune system (Jansen et al., 2002; Makarova et al., 2006; Barrangou et al., 2007) has been developed as a novel and accessible technology to precisely edit genome sequence toward irreversible knockout or knockin of a target gene in mammalian cells and organisms (Jinek et al., 2012; Cong et al., 2013; Mali et al., 2013; Mashiko et al., 2013; Kim et al., 2017; Anzalone et al., 2019), as compared with RNAi, which does not completely eradicate gene expression, and mRNA therapy, which transiently introduces functional proteins. The CRISPR/Cas-based gene editing technology relies on two essential components, a designed gRNA and the RNA-guided Cas nuclease. Through its hairpin scaffold binding to Cas to form Cas-gRNA ribonucleoprotein (RNP) complex, the gRNA recognizes a protospacer-adjacent motif element and a 20-nucleotide sequence in the genome through complementary base pairings and thus directs the Cas nuclease to generate a double-stranded DNA break or a single-stranded break (nick) to achieve genome engineering. As such, the CRISPR/Cas technology has been actively evaluated toward the development of new therapies for the treatment of human diseases, including monogenetic disorders, infection, and cancer (Xue et al., 2014; Dever et al., 2016; Long et al., 2016; Nelson et al., 2016; Tabebordbar et al., 2016; Eyquem et al., 2017; Zhang et al., 2017; Georgiadis et al., 2018; Xu et al., 2019b).

Different from other types of RNA therapeutics, the success of CRISPR/Cas-based genome editing and therapy relies not only on exogenous gRNA but also foreign Cas nuclease, that latter of being a large protein around $160 \mathrm{kDa}$ in size. Moreover, both the gRNA and Cas9 protein need to get into the nucleus and form RNP to exercise genome editing (Fig. 1). Besides conventional intracellular expression using plasmid DNA (pDNA) or virus vector-based materials, the gRNAs may be produced by IVT or chemical synthesis and directly introduced into cells or organisms with particular delivery systems, alone or combined with Cas nuclease as RNP. Each approach has its own advantages and disadvantages regarding the cost, stability, efficiency, specificity, and safety [for reviews, see Sahel et al. (2019), Chen et al. (2020)]. With the knowledge of chemical modifications in protecting against RNase digestion and avoiding immunogenicity, chemically modified gRNAs have been shown to enhance genome editing efficiency and target specificity in mammalian cells (Hendel et al., 2015; Rahdar et al., 2015; McMahon et al., 2018). Thus, chemoengineered gRNAs are expected to improve the development of CRISPR/Cas-based therapies.

Multiple clinical trials have been launched to investigate the safety and effectiveness of CRISPR/Cas-based therapies (https://www.clinicaltrials.gov/), but no results are reported yet. The first clinical trial involving CRISPR/Cas gene editing (NCT02793856), open in 2016, was a dose-escalation study on autologous implantation of programmed cell death protein 1 (PD-1; coded by PDCD1 gene) knockout T cells for the treatment of patients with advanced NSCLC that has progressed after all standard treatments. Immune checkpoint regulator PD-1 is a membrane receptor responsible for the inhibition of $\mathrm{T}$ cell activation, thereby decreasing autoimmune reactions and allowing immune escape of cancers. Antibodies against PD-1 or its ligand have been successfully used for the treatment of various types of cancers, and CRISPR/Cas-based PD-1 immunotherapy represents a novel strategy to combat cancer. Another phase I trial (NCT03399448) was initiated in 2018 to define the safety profile of NY-ESO-1 redirected autologous $\mathrm{T}$ cells with CRISPR-edited endogenous $\mathrm{T}$ cell receptor (TCR) and PD-1 autologous T cells, in particular, transduced with a lentiviral vector to express cancer/ testis antigen 1 or NY-ESO-1 and electroporated with CRISPR gRNA to disrupt expression of endogenous T cell receptor TCR $\alpha$ and TCR $\beta$, as well as PD- 1 (NYCE T Cells), among subjects with a confirmed diagnosis of relapsed refractory multiple myeloma, melanoma, synovial sarcoma, or myxoid/round cell liposarcoma. Presently, there are a number of phase I/II studies on the safety and efficacy of autologous CD34+ human hematopoietic stem and progenitor cells modified with CRISPR/Cas at the erythroid lineage-specific enhancer of the B-cell lymphoma/leukemia 11A gene (CTX001) in patients with transfusion-dependent $\beta$-thalassemia (NCT03655678) and patients with severe sickle cell disease (NCT03745287). In addition, the safety and efficacy of CD19-directed T cell immunotherapy comprising allogeneic $\mathrm{T}$ cells modified with CRISPR/Cas (CTX110) for the treatment of patients with relapsed or refractory B cell malignancies are currently under clinical evaluation (NCT04035434).

7. Other Forms of RNAs. There are also efforts devoted to develop other forms of RNAs for the treatment of human diseases, such as short or small hairpin RNAs (shRNAs) (Brummelkamp et al., 2002; Paddison et al., 2002), ribozymes or catalytic RNAs (Burnett and Rossi, 2012), and circular RNAs (Holdt et al., 2018; Santer et al., 2019). Like siRNAs and miRNAs, shRNAs can be used to achieve selective gene silencing effects via the RNAi mechanism. They are usually introduced into cells through viral vectors or pDNA, and shRNAs can be chemically synthesized with desired modifications. Similar to a pre-miRNA in size and with hairpin structure, shRNA follows the miRNA biogenesis pathway once shRNA precursor is transcribed from the coding sequence integrated into the host genome in the nucleus. The guide strand derived from shRNA in the cytoplasm is loaded into the RISC to silence target gene expression in the same manner as synthetic siRNAs. Likewise, there are some ongoing clinical studies on the 
benefits of new modalities involving shRNAs (https:// www.clinicaltrials.gov/). For instance, an open-label phase I study (NCT03282656) is recruiting patients with sickle cell disease to evaluate the feasibility of autologous bone marrow-derived CD34+ HSC cells transduced with the lentiviral vector containing an shRNA targeting B-cell lymphoma/leukemia 11A. As another example, a plasmid named pbi-shRNA Ewing sarcoma breakpoint region 1 (EWS)/Friend leukemia integration 1 transcription factor (FLI1) was developed to target the EWS/FLI1 fusion gene, which is a driver in the pathogenesis and maintenance of Ewing's sarcoma (Rao et al., 2016). Formulated with lipoplex (LPX), the pbi-shRNA EWS/FLI1 LPX was found effective in type 1 Ewing's sarcoma xenograft mouse models (Rao et al., 2016), leading to the opening of a phase 1 clinical study (NCT02736565) on pbi-shRNA EWS/FLI1 LPX in patients with advanced Ewing's sarcoma.

Ribozymes are a specific group of RNA molecules that are able to catalyze biochemical reactions (Kruger et al., 1982). The hammerhead or hairpin structures facilitate a ribozyme to cleave target RNAs in specific sequences, and the substrate recognition domain of the ribozyme can be artificially engineered to stimulate site-specific cleavage in cis (the same nucleic acid strand) or trans (a noncovalently linked nucleic acid) (Scherer and Rossi, 2003). Moreover, ribozymes are amenable to in vitro selection or evolution, e.g., by systematic evolution of ligands by exponential enrichment approaches (Ellington and Szostak, 1990; Robertson and Joyce, 1990; Tuerk and Gold, 1990), toward improved properties or new functions for therapeutic and diagnostic purposes. As with enzymes, catalytic RNAs often require cofactor magnesium ions to exert biotransformations (Ban et al., 2000). The development of ribozymes as therapeutic molecules has been largely dependent on the improvement of PK properties via chemical modifications (Burnett and Rossi, 2012). Indeed, a chemoengineered, antiangiogenic ribozyme against the oncogene fms-like tyrosine kinase (FLT-1) by targeting the vascular endothelial growth factor receptor-1 mRNA was effective at cleaving FLT-1/vascular endothelial growth factor receptor-1 mRNA and dose dependently inhibiting lung metastasis in an animal model (Pavco et al., 2000). Although anti-FLT-1 ribozyme (RPI.4610 or Angiozyme) was well tolerated among patients in both phase I and II studies (Kobayashi et al., 2005; Morrow et al., 2012), there was a lack of clinical efficacy for the treatment of patients with metastatic breast cancer, precluding RPI.4610 from further development (Morrow et al., 2012). In addition, a phase II clinical study (NCT01177059) was conducted to evaluate the potential benefits of an anti-HIV-1 ribozyme (OZ1) for the treatment of patients with HIV-1 infection; however, the results have not been published yet.

\section{Challenges in the Development of RNA Drugs}

Although they offer an unprecedented opportunity to expand the range of druggable targets for the control of potentially all kinds of human diseases, there were only fewer than 10 RNA drugs approved by the FDA over the past 2 decades (Table 2). Most RNA drugs are designed to act on intracellular pharmacological targets (Fig. 1), whereas RNA molecules are intrinsically unstable and are unable to freely cross cellular membranes, unlike traditional small-molecule and protein medications (Table 1). In addition, RNA drugs may not be highly selective toward their targets, as expected. Indeed, exogenous RNAs are commonly recognized by cellular defense systems, which could lead to acute immune response, cytokine release syndrome, or even severe cytokine storms. Therefore, the development of efficacious and safe RNA therapeutics has proven to be highly challenging.

1. Choice of RNA Substances. The chemical nature of RNA molecules makes them highly susceptible to ubiquitous RNases (Houseley and Tollervey, 2009), and chemically modified RNA analogs dominate RNA drug discovery and development. Indeed, a wide variety of chemical modifications may be introduced into an RNA molecule, the major strategy to improve RNA metabolic stability and PK properties (Bramsen and Kjems, 2012; Khvorova and Watts, 2017; Yu et al., 2019). For example, the change of PO linkage to PS makes the resulting RNA analog resistant to RNase degradation, and its PK properties can be further improved when its 2 '-hydroxyl group on ribose is protected or directly substituted with fluorine. This approach has found ultimate success in the development of sRNA drugs such as ASOs, siRNAs, miRNAs, and aptamers, as all RNA drugs approved by the FDA thus far are chemoengineered RNA analogs (Table 2), supporting the utility of chemical modifications. Additionally, although it becomes much more expensive to chemically synthesize and modify longer RNAs, those chemoengineered molecules, such as gRNAs, can exhibit greater metabolic stability and biological function in human cells (Hendel et al., 2015; Rahdar et al., 2015).

The mRNA drugs are usually much bigger in size than other sRNAs used for gene silencing or genome editing (Fig. 1). In addition to the entire open reading frame of encoded protein, the therapeutic mRNA needs to contain the complete $5^{\prime}$ and $3^{\prime}$ UTRs as well as $5^{\prime}$ cap and $3^{\prime}$ poly(A) tail to ensure an efficient translation within cells. Therefore, mRNA drug molecules are generally produced by a conventional IVT method using the T7 or SP6 RNA polymerase (Milligan et al., 1987; Beckert and Masquida, 2011). Compared with chemical synthesis, IVT represents an efficient and economic approach to generating a large therapeutic mRNA molecule that consists of essential components for intracellular translation. Although IVT is unable to specifically assemble post-transcriptionally modified or natural nucleosides into an mRNA molecule at particular sites, and the effects of such modifications on the efficiency of intracellular translation remain obscure, systemic incorporation 
of pseudouridine (Karikó et al., 2008) or N1-methylpseudouridine (Svitkin et al., 2017) into mRNA substances could be achieved by IVT reactions, leading to an improvement of translational capacity and biological stability, as compared with unmodified counterparts.

The primary sequence, particularly a series of nucleobases, is critical for the RNA molecule to act on its RNA or DNA therapeutic target. This notion is also supported by the successful marketing of PMO drugs (Table 2), in which nucleobases are linked by morpholino phosphorodiamidate bonds. However, RNA secondary (e.g., helices or stems, loops, and bulges), tertiary (e.g., junctions, pseudoknot, and motifs), and quaternary (e.g., complexes) structures formed by Watson-Crick complementary base pairings and/or other types of physicochemical interactions (Butcher and Pyle, 2011; Jones and Ferré-D'Amaré, 2015; Schlick, 2018) are essential for its stability, plasticity, interactions with cofactors, function, and safety. There are also various types and unique post-transcriptional modifications (Limbach et al., 1994; Cantara et al., 2011; Yu et al., 2019) that are critical for the folding and functions of natural RNAs produced in living cells. In addition, post-transcriptional modifications have been shown to suppress immune responses in cells (Nallagatla et al., 2008; Gehrig et al., 2012), whereas many chemical modifications induce immunogenicity. Therefore, there are growing interests in developing bioengineering technologies to produce true biological RNA molecules in living cells for research and development (Ho and Yu, 2016; Yu et al., 2019, 2020), similar to protein research and drug development that create and use recombinant or bioengineered proteins.
Two novel approaches have been developed very recently to offer high-yield and large-scale fermentation production of bioengineered or biological RNA agents (BERAs), e.g., tens of milligrams target RNAs from 11 of bacterial culture. One strategy involves the use of stable RNA carriers (Ponchon and Dardel, 2007; Ponchon et al., 2009; Li et al., 2014, 2015, 2018b; Chen et al., 2015; Ho et al., 2018), and the other method seeks direct overexpression in RNase III-deficient bacteria (Hashiro et al., 2019a,b). Among them, stable hybrid tRNA/pre-miRNA molecules have been identified and proven as the most robust and versatile carriers to accommodate various types of warhead RNAs, including miRNAs, siRNAs, aptamers, and other sRNAs (Chen et al., 2015; Wang et al., 2015b; Ho et al., 2018; $\mathrm{Li}$ et al., 2018b). This approach follows a similar workflow as protein bioengineering (Fig. 2). After a BERA/miRNA, siRNA, or sRNA substance of interest is designed, the corresponding coding sequence is cloned into a vector. Overexpression of target BERA in pDNA-transformed bacteria can be assessed by RNA gel electrophoresis analysis of total bacterial RNAs. Recombinant BERA may be isolated with different methods (e.g., anion exchange fast protein liquid chromatography), and the quality of purified BERA can be controlled by high-performance liquid chromatography (HPLC) analysis and endotoxin pyrogen testing (Chen et al., 2015; Ho et al., 2018; Petrek et al., 2019).

BERAs produced in living cells have been revealed to carry no or minimal post-transcriptional modifications (Ponchon and Dardel, 2007; Li et al., 2015; Wang et al., 2015b). Although naked BERAs are still susceptible to degradation by serum RNases, BERAs are readily

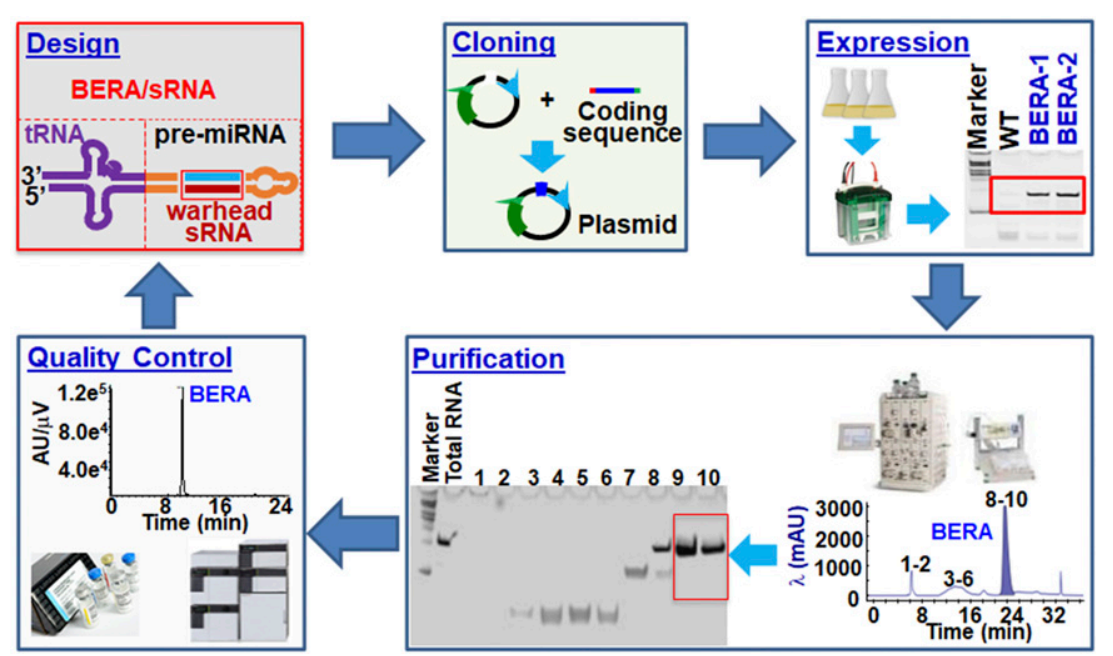

Fig. 2. The tRNA/pre-miRNA-based RNA bioengineering technology for the production of biological RNAi agents (BERA) for research and development. After the design of a target BERA/sRNA (e.g., miRNA, siRNA, and asRNA, etc.), the corresponding coding sequence is cloned into a vector. Expression of target BERA in bacterial culture is readily verified through RNA gel electrophoresis, and BERA can be purified to a high degree of homogeneity using different methods [e.g., anion exchange fast protein liquid chromatography (FPLC)]. Purity of isolated BERA is determined by HPLC analysis and endotoxin pyrogen testing. These bioengineered RNA molecules should better recapitulate the properties of natural RNAs to exert biological or pharmacological actions, as both are produced and folded in living cells. Indeed, BERA/sRNAs can be selectively processed to warhead sRNAs for the modulation of target gene expression in human cells and control of diseases in animal models. WT, wild type. 
delivered into human carcinoma cells and xenograft tumor tissues by lipid or polymer-based materials; selectively processed to target warhead miRNAs or siRNAs to modulate target gene expression; and consequently inhibit cancer cell proliferation, tumor progression, and metastasis (Chen et al., 2015; Zhao et al., 2016; Jian et al., 2017; Jilek et al., 2017, 2019; Ho et al., 2018; Zhang et al., 2018; Li et al., 2019; Tu et al., 2019; Xu et al., 2019a; Yi et al., 2020b). In addition, these BERA-carried miRNAs and siRNAs have been shown to be equally or more effective than synthetic counterparts in the regulation of target gene expression and suppression of cancer cell growth (Chen et al., 2015; Wang et al., 2015b). These bioengineered RNA molecules should better recapitulate the properties of natural RNAs to exert structural, biological, or pharmacological actions, as both are produced and folded in living cells.

2. RNA Delivery Systems. A major challenge in the development of RNA drugs is to overcome the degradation by serum RNases and make RNAs to cross the membranes of targeted cells so that a sufficient number of RNA molecules can access intracellular targets to exert pharmacological effects (Fig. 3). As mentioned previously, some chemical modifications can greatly improve the metabolic stability and PK properties (Bramsen and Kjems, 2012; Ho and Yu, 2016; Khvorova and Watts, 2017; Yu et al., 2019) and thus make the resulting RNA substances more druggable. All the ASO therapeutics approved by the FDA carry extensive chemical modifications (Table 2). Without additional excipients, these ASOs can be distributed to targeted cells to achieve efficacy, like small-molecule drugs. On the other hand, RNA drugs may be "actively delivered" to targeted cells or tissues through encapsulation/ formulation with specific materials (Fig. 3) or carried by viral vectors, pDNAs, or intact cells (Tibbitt et al., 2016; Dowdy, 2017; Kaczmarek et al., 2017; Kowalski et al., 2019). The latter tends to switch the modalities to DNA/gene materials or engineered cells, whereas the former keeps the RNA substances as the active ingredients.

Lipids and lipid-like materials that resemble the lipid component of cell membrane and offer great biocompatibility are commonly used for the delivery of RNA agents besides peptides, hydrogels, dendrimers, and synthetic (e.g., polyamidoamine and polyethyleneimine) and natural polymers (e.g., chitosan) (Tibbitt et al., 2016; Kaczmarek et al., 2017). Similar to positively charged polymers or other substances, cationic lipids can electrostatically bind to RNAs to protect them against RNase cleavage and facilitate endocytosis. Interestingly, ionizable lipids that only become positively charged in acidic conditions have been shown to enhance endosomal release and reduce cytotoxicity (Kanasty et al., 2013). The successful use of LNP in RNA drug development is evident in the first FDAapproved siRNA drug, patisiran (Table 2). LNP is also used for the delivery of novel mRNA therapeutics, such as human MUT mRNA replacement therapy for the treatment of MMA, which has been evaluated in murine models (An et al., 2017, 2019) and entered clinical trials. In addition, LNP has been employed

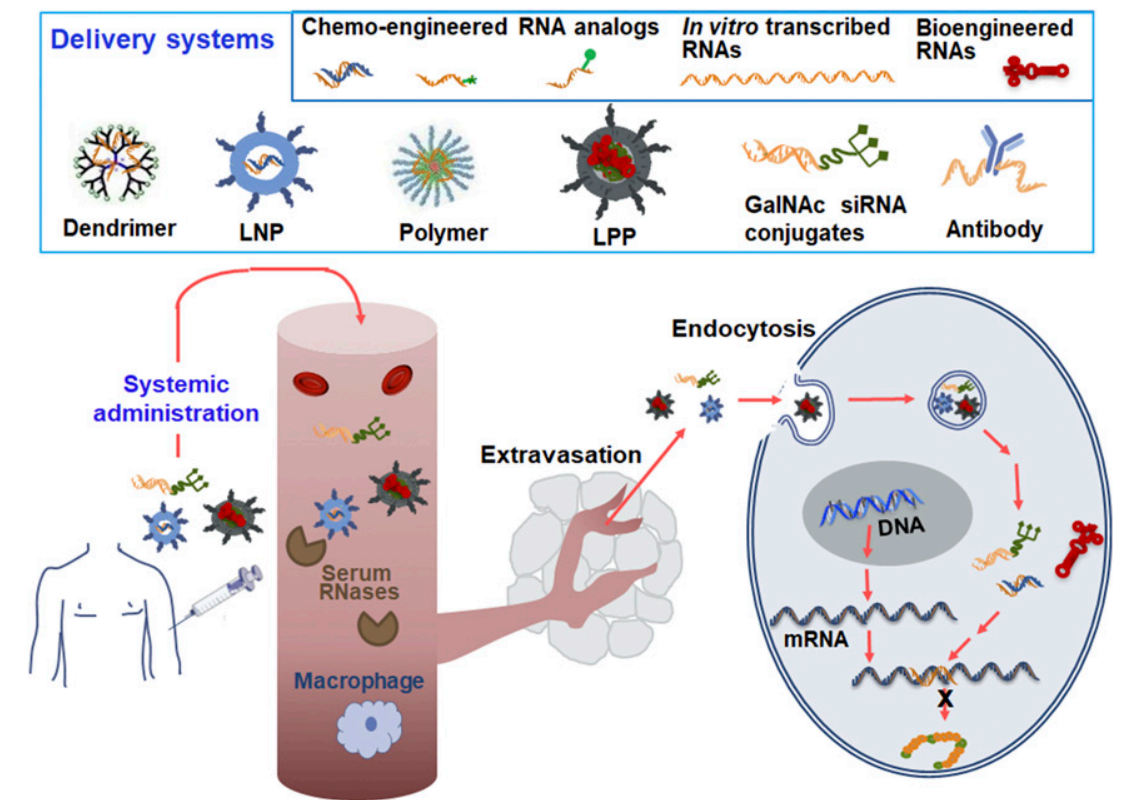

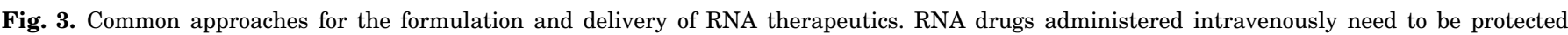

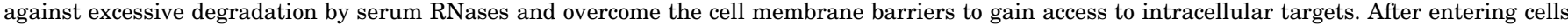

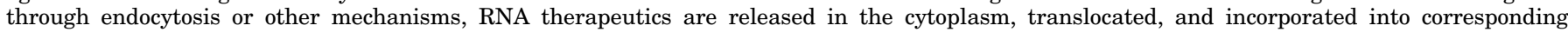

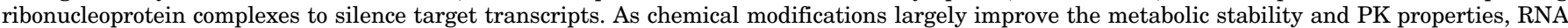

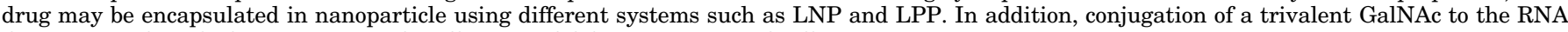
drug or use of antibody can improve the efficiency of delivery to targeted cells. 
for the delivery of the gRNA-Cas9 RNP complex for genome editing (Wang et al., 2016).

To optimize LNP formulations, some hydrophobic moieties, such as cholesterol-lipid poly(ethylene glycol)-lipid, may be included to improve RNA delivery efficiency, and the ionizable property of LNP seems to be a determinant factor (Akinc et al., 2008; Love et al., 2010; Dahlman et al., 2014). Furthermore, as polyethyleniminebased polyplexes provide excellent delivery efficiency but pose a high risk of toxicity (Lv et al., 2006), lipidation of the polyethylenimine-RNA polyplex offers lipopolyplex (LPP), which may retain the benefits of both materials while reducing the toxicity of polyplex (Rezaee et al., 2016). Indeed, some recent studies have demonstrated that LPP showed more favorable biological properties for the delivery of nucleic acid agents (Schäfer et al., 2010; Ewe et al., 2014, 2017), including these novel BERAs produced and folded in living cells (Zhang et al., 2018; Jilek et al., 2019).

RNAs may be covalently conjugated to specific ligands, ranging from relatively smaller molecules (e.g., aptamers) to large molecules (e.g., lipids, peptides, and antibodies). Ligand-directed delivery is expected to improve targeting toward particular types of cells. The conjugation of RNA drug to GalNAc is the most successful example to target hepatocytes through interactions with the cell surface receptor (Nair et al., 2014, 2017). Givosiran is a GalNAcconjugated siRNA drug (Table 2) in which the GalNAc facilitates hepatocyte uptake of givosiran to act on intracellular TTR mRNA. In other cases, aptamers can be used to facilitate targeted delivery of RNAs to specific cells, including siRNAs, miRNAs, and shRNAs (Dassie and Giangrande, 2013; Aaldering et al., 2015). Interestingly, ligand- (Davis et al., 2010) and aptamermediated RNA delivery (Pastor et al., 2010; Neff et al., 2011) not only increased drug efficacy but also reduced off-target effects.

As targeted delivery may facilitate the internalization of RNA drugs into targeted tissues and cells (e.g., tumor tissues and carcinoma cells), RNAs entering the systemic circulation can still be distributed into other tissues, especially liver and kidney, like small-molecule drugs. Indeed, liver and kidney are the most important organs for the elimination of xenobiotics and exogenous medications including RNA drugs (via hepatic metabolism and renal excretion, respectively), commonly showing higher levels of drug accumulation than other tissues. Interestingly, many novel RNA drugs approved by the FDA (Table 2) and currently under development are designed to act on hepatic targets. In any case, the overall efficacy and safety profiles determine whether a drug can be marketed or not, and both are attributed to the levels of drug exposure. In addition, caution must be exercised when interpreting RNA delivery/distribution/ PK data obtained from studies using small-molecule dye supplemented in the RNA formulation or covalently attaching a fluorescent core to RNA as a tracer or surrogate for the convenience of analyses. On the one hand, upon release from the formulation, a smallmolecule dye with its own physicochemical and PK properties that are totally different from RNA substances will be distributed or redistributed in the body in its own way, e.g., accumulated in highly proliferative tissues/cells such as tumors and carcinoma cells, whereas the RNA drugs of interest might not. On the other hand, conjugation of fluorescent core to an RNA molecule shall result in a new, different, conjugated RNA substance that undoubtedly has its own physicochemical and PK properties. Moreover, the conjugate may be metabolized in the body, and the cleaved fluorescent core will exhibit its own distribution/PK profiles. Therefore, it is vital to define the validity of such tracing approaches in related studies or directly examine the actual warhead RNAs.

3. RNA Analytical Methods. Reliable bioanalytical methods are pivotal for the quantification of drugs during discovery and development. Method validation including RNA stability, calibration range, matrix effects, sensitivity, selectivity, accuracy, and precision should be conducted in line with the regulatory guidelines on bioanalytical method validation, despite there being a lack of specific recommendations for RNAs (Kaza et al., 2019). Rather, challenges in the development of an accurate method for quantitative analysis of target RNA drug in complex biological samples seem to be overlooked. Two major strategies are commonly used for RNA analyses: hybridization-based (or biology) methods and chromatographic (or chemistry) methods (Wang and Ji, 2016). Hybridization-based assays, which may [e.g., quantitative polymerase chain reaction, (qPCR)] or may not (e.g., ELISA) involve the amplification of RNA analytes (Table 3), indirectly analyze RNAs through the use of complementary, fluorophore-labeled, or ligand-labeled oligonucleotide probes or antibodies to interact with target RNA analytes and then quantify the hybridization complexes through different readouts. On the other hand, chromatography methods aim at direct analysis of target RNAs through liquid chromatographic separation followed by detection of intrinsic UV or mass spectrometry (MS) signals (Table 3). Hybridization methods are usually highly sensitive and applicable to the analyses of all types of RNAs, whereas chromatography methods are relatively more specific and accurate in absolute quantification of sRNAs such as ASOs and siRNAs. Hybridization and chromatography may be used together in the same method, e.g., hybridization-based HPLC-fluorescence (FL) assay (Table 3).

Classic Northern blot and in situ hybridization methods are highly sensitive in detecting target RNAs through radioactivity or fluorescence detections without polymerase chain reaction-based amplification; however, these methods are semiquantitative. Conventional microarray methods and modern RNA sequencing technologies require amplification and conversion of RNAs to cDNAs, 
TABLE 3

Analytical methods for oligonucleotides or RNAs

\begin{tabular}{|c|c|c|c|}
\hline Method & Analytes & Advantages & Disadvantages \\
\hline qPCR (amplification) & $\begin{array}{l}\text { Unmodified oligonucleotides } \\
\text { (chemical modifications may } \\
\text { affect the assay) }\end{array}$ & $\begin{array}{c}\text { High sensitivity, broad dynamic range (4-8 } \\
\text { orders of magnitudes), medium to high } \\
\text { throughput }\end{array}$ & $\begin{array}{c}\text { Extensive sample preparation } \\
\text { Depends on primers and } \\
\text { fluorophore } \\
\text { Low resolution, accuracy, and } \\
\text { precision } \\
\text { Limited specificity and potential } \\
\text { matrix effects } \\
\text { May not distinguish metabolites } \\
\text { from the analyte }\end{array}$ \\
\hline $\begin{array}{l}\text { Hybridization-based } \\
\text { assays or ELISA (no } \\
\text { amplification) }\end{array}$ & $\begin{array}{l}\text { Modified or unmodified } \\
\text { oligonucleotides }\end{array}$ & $\begin{array}{l}\text { High specificity (sequence dependent) } \\
\text { Wide dynamic range } \\
\text { Good sensitivity } \\
\text { Reasonable accuracy and reproducibility }\end{array}$ & $\begin{array}{l}\text { Depends on the reliability of probe, } \\
\text { detection marker, or antibody } \\
\text { Possible matrix effects } \\
\text { May not distinguish metabolites } \\
\text { from the analyte }\end{array}$ \\
\hline LC-UV (or FL) & $\begin{array}{l}\text { Modified or unmodified } \\
\text { oligonucleotides }\end{array}$ & $\begin{array}{l}\text { High specificity after separation } \\
\text { Good accuracy } \\
\text { Broad dynamic range } \\
\text { Low to medium throughput }\end{array}$ & $\begin{array}{c}\text { Extensive sample preparation } \\
\text { Low sensitivity } \\
\text { Requires good separation } \\
\text { (Sensitive FL detection depends on } \\
\text { the fluorophore-labeled probe to be } \\
\text { hybridized with the analyte) }\end{array}$ \\
\hline LC-MS/MS & $\begin{array}{l}\text { Small oligonucleotides } \\
\quad(\text { e.g., }<25 \mathrm{nt})\end{array}$ & $\begin{array}{l}\text { High specificity (for modified RNAs), wide } \\
\text { dynamic range, good sensitivity (for modified } \\
\text { RNAs), medium to high throughput, good } \\
\text { accuracy and reproducibility }\end{array}$ & $\begin{array}{l}\text { Costly instrument } \\
\text { Limited specificity and sensitivity, } \\
\text { particularly for unmodified RNAs }\end{array}$ \\
\hline
\end{tabular}

LC-MS/MS, LC tandem mass spectrometry.

which are both high-throughput approaches but offer merely relative quantification. It is also noteworthy that the efficiencies of individual RNAs can be widely variable and affected by the matrices, whereas they are generally not evaluated. For quantitative bioanalysis of RNAs, realtime qPCR (Kelnar et al., 2014) and ELISA (Humphreys et al., 2019; Thayer et al., 2019) methods (Table 3) have been commonly used. The former approach is applicable to both longer RNAs (e.g., mRNAs) and various types of sRNAs [e.g., miRNAs and siRNAs by stem-loop reverse transcription, real-time polymerase chain reaction (Chen et al., 2005)]. Nevertheless, these biological methods largely rely on the robustness of hybridization probe, amplification primers, or antibody used in the assays. Another major caveat is that these hybridization-based methods may not be able to distinguish the RNA drug from its metabolites, e.g., 1 nt deleted at the $3^{\prime}$ end, which the latter has been able to recognize (Ewles et al., 2014; Husser et al., 2017; Liu et al., 2019; Post et al., 2019).

After chromatographic separation, target RNA drugs can be accurately quantified by UV detection (McGinnis et al., 2012, 2013). As UV absorbance is common for nucleic acids, as well as proteins and many smallmolecule compounds, the robustness of LC-UV analysis of RNA drug is dependent on efficient RNA isolation and chromatographic separation of target RNA from other components (Table 3). The use of LC tandem mass spectrometry and high-resolution accurate MS can greatly improve the specificity in quantitative analysis of ASOs and siRNAs (Watanabe et al., 2016; Liu et al., 2019) that are chemically modified and different from natural RNAs. LC-MS methods often provide good accuracy, precision/reproducibility, and wide dynamic range while offering a limited sensitivity (Table 3), dependent on the structures of RNAs and biological matrices. Compared with hybridization-based methods, LC-MS methods, especially high-resolution accurate MS, may improve the fidelity of RNA bioanalysis because they can separate and/or distinguish the metabolites from the RNA drug. With a highly demanded specificity in drug quantification, a lower sensitivity might be compromised.

4. Specificity and Safety of RNA Drugs. The specific interaction between a drug and target is critical to not only induce selective, on-target, therapeutic effects but also avoid nonspecific, off-target, adverse events. This is of particular concern because exogenous RNAs may trigger sequence-dependent and -independent immune responses. Indeed, immune-related and dose-limiting toxicities are major reasons for the failure of many RNA drugs during clinical investigations (Kleinman et al., 2008; Davis et al., 2010; DeVincenzo et al., 2010; Beg et al., 2017). The underlying targets are known as cell membrane or endosomal Toll-like receptors and cytosolic sensors (e.g., RNA-dependent protein kinase) (Karikó et al., 2005; García et al., 2006; Hornung et al., 2006; Anderson et al., 2010). The recognition of specific sequences or structures of RNA molecules by their corresponding immune receptors triggers immune events such as cytokine secretion, immune cell proliferation and survival, and adaptive immunity activation as the host's natural defense. As such, administration of pharmacological RNA agents may cause immunogenic response or cytokine release syndrome depending on the doses and structures (e.g., size, sequence, etc.) of RNA molecules (Dalpke and Helm, 2012; Tanji et al., 2015). Interestingly, although natural post-transcriptional modifications may suppress immune responses (Karikó and Weissman, 2007; 
Robbins et al., 2007; Nallagatla et al., 2008; Gehrig et al., 2012), various and extensive chemical modifications can induce immunogenicity (Robbins et al., 2007; Bramsen and Kjems, 2012). Therefore, chemoengineering of RNA drugs using naturally occurring modifications (e.g., 2'-methoxyribonucleoside, pseudouridine, methyladenosine, methylcytidine, etc.) may help to reduce immunogenicity (Robbins et al., 2007; Kauffman et al., 2016). The development and use of natural RNAs made in living cells is also expected to minimize the risk of induction of immune responses (Ho and $\mathrm{Yu}, 2016$; $\mathrm{Yu}$ et al., 2019).

While acting on targets through designed complementary base pairing, RNA agents may induce other off-target effects, particularly the interactions with unintended homologous targets. This issue is present not only in using ASOs and siRNAs for target gene silencing (Chi et al., 2003; Jackson et al., 2003; Semizarov et al., 2003) but also in utilizing gRNAs for gene editing (Frock et al., 2015; Liang et al., 2015; Filippova et al., 2019). Compared with miRNAs that may act on multiple targets, siRNAs (and ASOs) are usually postulated as specific agents in knocking down the expression of targeted genes that are rarely assessed. By contrast, genome-wide experiments showed that many transcripts with partial complementarities to siRNAs were altered in cells (Chi et al., 2003; Jackson et al., 2003; Semizarov et al., 2003). Based upon cellular miRNAgoverned post-transcriptional regulation mechanism, it is hard to imagine that siRNAs do not affect other transcripts through seed-dependent complementary interactions with their $3^{\prime}$ UTRs. Indeed, the $3^{\prime}$ UTR matches or miRNA-like "off-target" effects have been confirmed experimentally (Birmingham et al., 2006; Jackson et al., 2006). Rather, proper design of RNAi agents can achieve relatively specific targeting and desired efficacy with minimal or manageable adverse effects, and natural miRNAs acting on multiple targets in the common pathways could be helpful for the control of particular diseases.

It is noteworthy that, like all other classes of drugs (Table 1), the selectivity and safety of RNA therapeutics are dose-dependent. Dose-limited off-target effects were commonly observed when higher or exaggerated doses of RNAi agents were used (Semizarov et al., 2003; Janas et al., 2018). Therefore, in addition to the design of optimal sequence and use of proper chemical/natural modifications to avoid or minimize immunogenicity and off-target effects, identification of the right dose to achieve therapeutic efficacy and safety is critical for the development of RNA drugs.

Since RNAs are usually delivered with particular carriers, the safety of carrier materials as well as the final formulated drug product should be critically assessed. Toxicities may come from the degradation of these materials during storage, infusion reactions of the modality, and accumulation in nontarget tissues (Vogel, 2010; Zuckerman and Davis, 2015; Szebeni et al., 2018).
The use of clinically verified safe carriers, such as LNPs, and the development of targeted delivery approaches may help to minimize the risk of toxicity caused by delivery vehicles or induced in nontarget tissues. Actually, some medications can be used proactively to protect against possible adverse effects or afterward to lessen the toxicity. This is extremely important during clinical practice because all medications may cause toxicity while also offering benefits. In terms of RNA therapies, patients may be treated with corticosteroids or antiallergy medications to manage infusion reactions to FDA-approved patisiran and investigational RNA drugs (Adams et al., 2017; Beg et al., 2017).

\section{RNAs as Therapeutic Targets for Small Molecules}

\section{A. Small Molecules Targeting Highly Structured RNAs}

Although disease-related mRNAs and ncRNAs may be targeted by sRNAs such as ASOs or asRNAs, siRNAs and miRNAs described above (Fig. 1; Table 2), which are conventional small-molecule compounds, are still the preferred entities in drug discovery and development. With the understanding of mechanistic actions of many natural antibiotic drugs, including aminoglycosides, tetracyclines, macrolides, and oxazolidinones (Fig. 4), on rRNAs in the inhibition of microbial protein synthesis (Table 4) (Wilson, 2009, 2014; Lin et al., 2018), there is growing interest in discovering and developing RNAtargeted small-molecule drugs [for recent reviews, see Hermann (2016), Donlic and Hargrove (2018), Warner et al. (2018)]. The notion of developing small-molecule drugs targeting RNAs is also supported by the fact that riboswitches can be selectively bound by small-molecule ligands in the control of gene expression (McCown et al., 2017). Indeed, a number of novel classes of rRNA-targeted synthetic or semisynthetic antibiotics, including oxazolidinone (e.g., linezolid and tedizolid, etc.), ketolides (e.g., telithromycin), phenicols (e.g., chloramphenicol), and lincosamides (e.g., clindamycin), have been approved for medical use (Deak et al., 2016; Lin et al., 2018). Moreover, the first ribosome-targeted ataluren was approved in Europe for the treatment of patients with DMD with a nonsense mutation in the dystrophin gene (Haas et al., 2015), and it is undergoing phase III clinical trials in the United States (Table 4). There are also many other small molecules under clinical and preclinical development that act on existing and new RNA targets for the treatment of various human diseases, including genetic disorders, infections, and cancer (Table 4).

Similar to protein targets, macromolecule RNAs are folded into highly structured entities for their interactions with small molecules (Cruz and Westhof, 2009) or proteins (Hentze et al., 2018). Through complementary base pairings and other forms of physicochemical 


\section{Aminoglycosides}

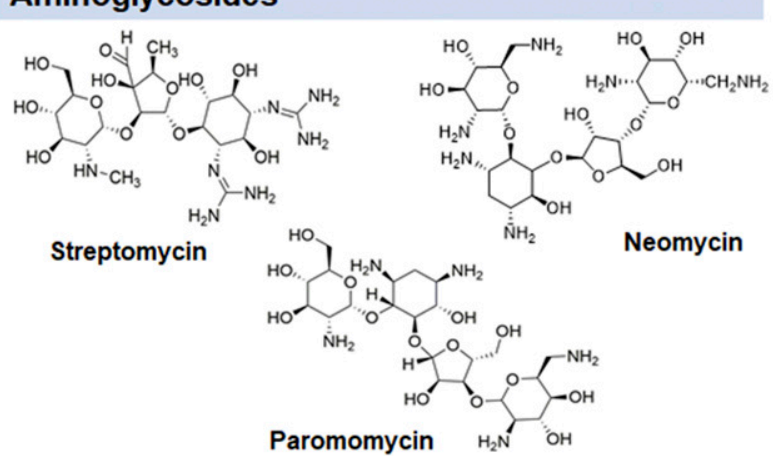

Tetracyclines (including glycylcyclines)
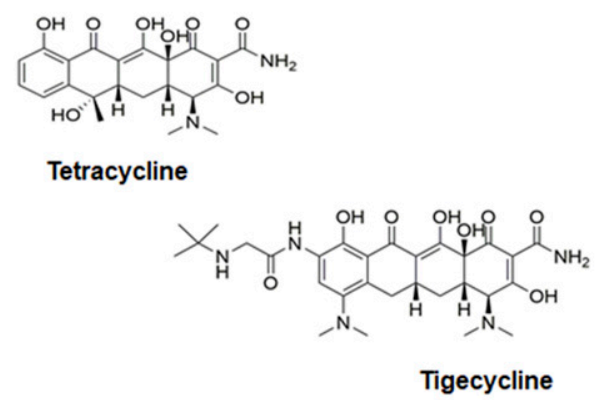

\section{Macrolides (including ketolides)}

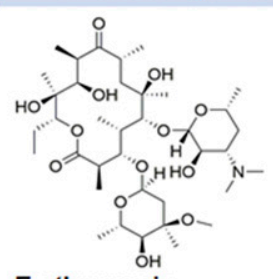

Erythromycin

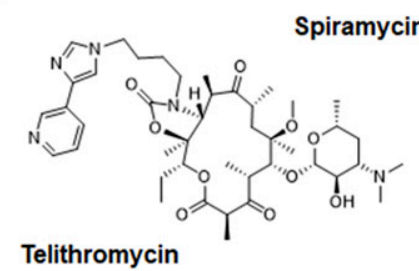

Oxazolidinones

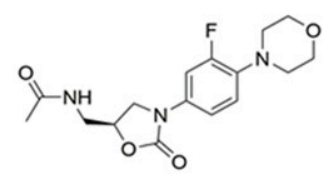

Linezolid

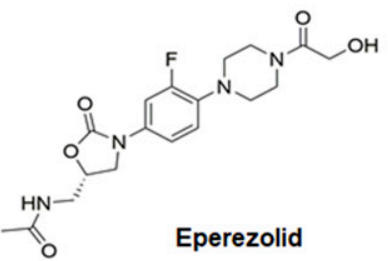

Fig. 4. Chemical structures of some small-molecule antibiotics that are known to target bacterial ribosomal RNAs to inhibit protein synthesis for the treatment of infections. Among them, aminoglycosides (e.g., streptomycin, neomycin, and paromomycin) and tetracyclines (e.g., tetracycline and tigecycline) directly act on $16 \mathrm{~S}$ rRNAs, whereas natural and semisynthetic macrolides (e.g., erythromycin, spiramycin, and telithromycin) as well as synthetic oxazolidinones (e.g., linezolid and eperezolid) bind to $23 \mathrm{~S}$ rRNAs to exert antimicrobial activities.

interactions, RNAs are folded into secondary (e.g., helices or stems, loops, and bulges), tertiary (e.g., junctions, pseudoknot, and motifs), and quaternary (e.g., complexes) structures (Butcher and Pyle, 2011; Jones and Ferré-D'Amaré, 2015; Schlick, 2018); thus, small-molecule compounds have the potential to directly interact with unique higher-order structures rather than the primary sequences. Specific RNA structural elements or motifs, such as bulges, loops, junctions, pseudoknots, and complexes, may be recognized and bound by particular small molecules beyond the attenuation by sRNAs with complementary sequences. Indeed, highly structured RNAs tend to contain pockets permitting specific and high-affinity binding by small molecules with particular functional groups and electrostatic surfaces, similar to those of protein targets. The interactions between small-molecule and disease-related RNA or RNA motif, therefore, could lead to the inhibition or activation of RNA functions or change of gene expression and cellular processes toward the control of disease.

Different from proteins as drug targets, which comprise a total of 22 proteinogenic amino acids, RNAs consist of only four primary nucleotide monomeric units (A, U, G, and C) as building blocks. In comparison with 22 proteinogenic amino acids, showing a combination of physicochemical properties (e.g., basic and acidic, positively and negatively charged, hydrophilic and hydrophobic amino acids, etc.), the four monomeric nucleotides seem less variable. However, with each containing a nucleobase, ribose, and phosphate group, nucleotide monomers are much more complex than individual amino acids. As each phosphate unit carries one negatively charged residue, RNAs are highly charged macromolecules. Under low-salt conditions, many functional RNA molecules may not fold. The addition of cationic ions (e.g., magnesium ion) can induce RNA folding, whereas salt concentrations that are too high will reduce the electrostatic interactions (Lipfert et al., 2014). In addition, RNAs are generally more hydrophilic than a typical protein (McCown et al., 2017; Mustoe et al., 2018). Surrounded by an ion atmosphere under physiologic conditions, the folding and structure of electrostatic RNA, especially the sites for ligand binding, are relatively less understood, and they are very different from those found in proteins (Hermann, 2016; Morgan et al., 2017, 2018).

To identify and develop RNA-targeting small molecules, it is also necessary to understand the structural and physicochemical properties of known small-molecule ligands and recognize the principles of RNA-ligand interactions in addition to the characteristics of diseaserelated RNAs or RNA motifs. Indeed, most RNA-targeted 


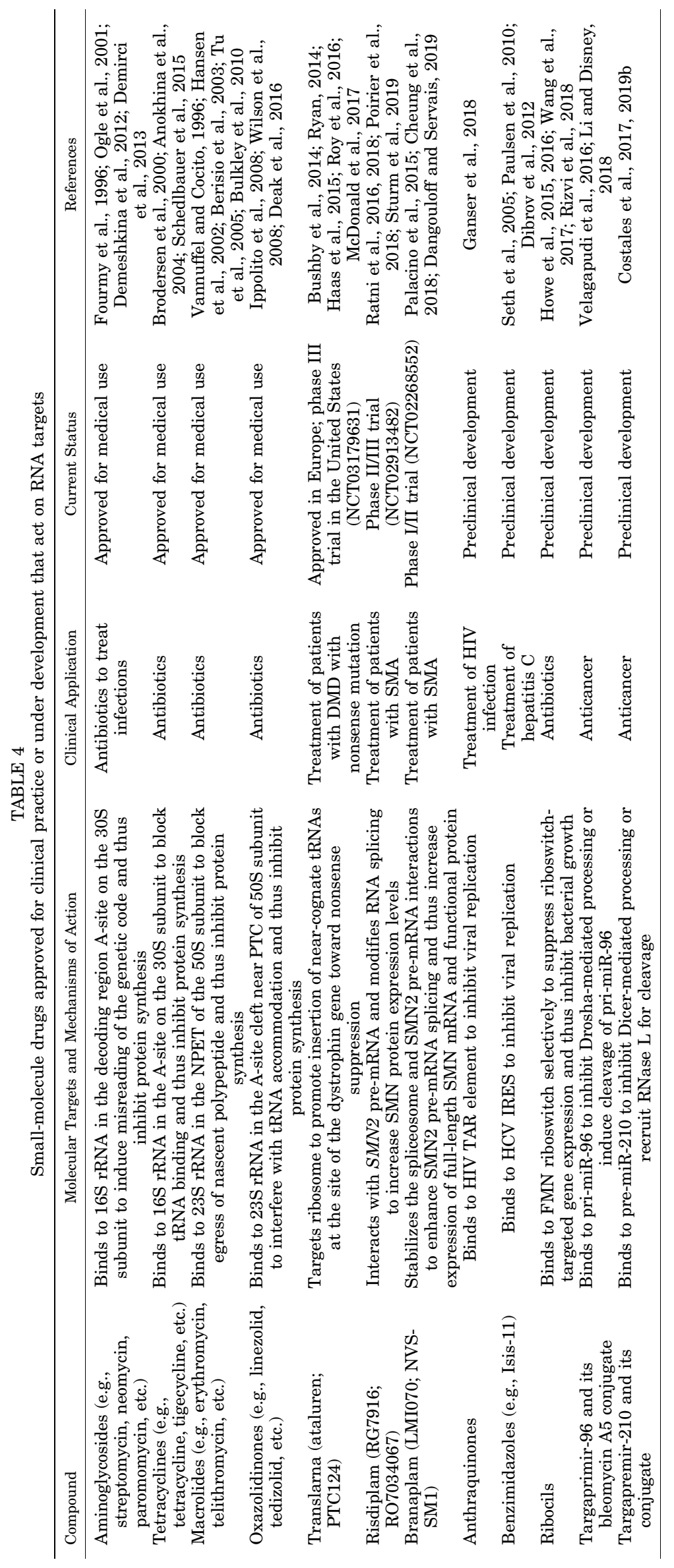


antibiotics (Fig. 4) derived from natural products and given to patients via intravenous administration are more complex molecules, with each containing a large number of hydrogen bond donors and acceptors, having a molecular mass over $500 \mathrm{Da}$, and being hydrophilic. This is in contrast to the majority of protein-targeted, orally bioavailable, small-molecule drugs that usually follow empirical Lipinski's rule of five (Lipinski, 2004; Ritchie and Macdonald, 2014). Therefore, caution should be exercised when adopting the rules of protein-ligand interactions for the design of RNA-targeted small molecules, although there are common principles. Moreover, some small-molecule ligands identified as highly basic and polar molecules tend to bind to RNAs with high affinity but low selectivity (Guan and Disney, 2012; Connelly et al., 2016). Thus far, a number of strategies have been developed and used to design and/or identify small molecules that can bind to RNA targets, such as binding- or phenotype-based screening (Mei et al., 1997; Sztuba-Solinska et al., 2014; Howe et al., 2015; Prado et al., 2016; Rizvi et al., 2018; Velagapudi et al., 2018; Green et al., 2019) and computational modeling and structure- or chemoinformatics-based design or virtual screening (Stelzer et al., 2011; Parkesh et al., 2012; Nguyen et al., 2015; Disney et al., 2016; Luu et al., 2016). These efforts have led to the discovery and development of chemically diverse small molecules targeting RNAs, with many exhibiting more drug-like structural and physicochemical properties (Fig. 6). In this section, representative small molecules that target various RNAs, including rRNAs, viral RNA motifs, riboswitches, premRNAs, and pri or pre-miRNAs, are introduced, followed by the discussion of challenges in the identification of therapeutic RNA targets and verification of ligand binding specificity.

\section{B. Classes of RNA Targets}

1. Ribosomal RNAs. Discovery of the mechanistic actions of natural antibiotics on bacterial ribosome is a major driver for the discovery and development of RNA-targeted drugs. Bacterial ribosome (70S) catalyzing protein synthesis comprises two subunits (50S and $30 \mathrm{~S})$ that are assembled from three rRNA chains (16S, 23S, and 5S rRNAs) and around 55 ribosomal proteins (e.g., L16) (Steitz, 2008; Wilson, 2014; Lin et al., 2018). After the binding of $70 \mathrm{~S}$ ribosome with the initiator tRNA and start codon of the mRNA positioned at the peptidyl-tRNA site (P-site), protein synthesis is initiated. Going through the cycle of accommodating aminoacyl-tRNA at the A-site, forming peptide bond between the A- and P-site tRNAs, translocating the peptidyl-tRNA from the A- to the $\mathrm{P}$-site, and releasing the deacylated tRNAs from the exit site (E-site) that are stringently controlled by corresponding factors, a nascent polypeptide is synthesized. The termination of translation involves the hydrolysis of mature polypeptide from tRNA at the $\mathrm{P}$-site, and the $70 \mathrm{~S}$ ribosome is recycled after the release of deacylated tRNA. The rRNA-assembled ribosome is highly structured for its interactions with individual components required for protein synthesis, in which specific clefts and pockets can be directly blocked by small molecules, leading to the inhibition of translation (Table 4).

X-ray crystallography and NMR spectroscopy studies have revealed that many aminoglycoside antibiotics, such as paromomycin and streptomycin, directly bind to 16S rRNA in the decoding region A-site on the bacterial $30 \mathrm{~S}$ subunit to induce misreading of the genetic code and inhibit protein synthesis (Fourmy et al., 1996; Lynch et al., 2003; Demirci et al., 2013). The drugtarget interactions include the involvement of crucial nucleotides, such as A1408 in 16S rRNA (Fig. 5), which when mutated (e.g., A1408G) or methylated at the N1 position (A1408m1A), confers resistance to aminoglycosides (Kondo, 2012; Kanazawa et al., 2017). The G1408 also distinguishes between prokaryotic and eukaryotic ribosomes, leading to a 25 - to 50-fold lower binding affinity for paromomycin to the eukaryotic decoding site and thus providing structural explanation for the selectivity of aminoglycosides for prokaryotic ribosomes (Lynch and Puglisi, 2001). A recent study using a cryogenic electron microscopy technique has shown that the unfavorable base pairing between C1409 and A1491 in human rRNA versus perfect U1409-A1491 pairing in Leishmania donovai may contribute to the selective inhibition of pathogenic organisms by paromomycin instead of human ribosome (Zhang et al., 2016). Similarly, antibiotic tetracyclines (e.g., tetracycline and tigecycline) have been revealed to inhibit protein synthesis by sterically hindering tRNA binding to the A-site on the $30 \mathrm{~S}$ subunit through direct interactions with the $16 \mathrm{~S}$ rRNA (Brodersen et al., 2000; Anokhina et al., 2004; Schedlbauer et al., 2015). On the other hand, many natural macrolides (e.g., erythromycin, azithromycin, etc.) bind to the $23 \mathrm{~S}$ rRNA in the nascent peptide exit tunnel (NPET) of the 50S subunit to block passage of newly synthesized polypeptides and thus interrupt translation elongation (Vannuffel and Cocito, 1996; Hansen et al., 2002; Tu et al., 2005; Bulkley et al., 2010; Dunkle et al., 2010). In addition, a lot of synthetic antibiotics designed as translation inhibitors are found to target specific sites on ribosomes (Deak et al., 2016; Lin et al., 2018). For instance, oxazolidinones such as linezolid and tedizolid directly interact with the bacterial 23S rRNA (Fig. 5) and bind in the A-site pocket near peptidyl transferase center (PTC) of the 50S subunit to exclude tRNA accommodation and thus inhibit protein synthesis (Ippolito et al., 2008; Wilson et al., 2008; Deak et al., 2016).

With the understanding of species differences in drug-ribosome interactions mentioned above, and given the importance of dysregulated protein synthesis in highly proliferative human carcinoma cells, efforts have 


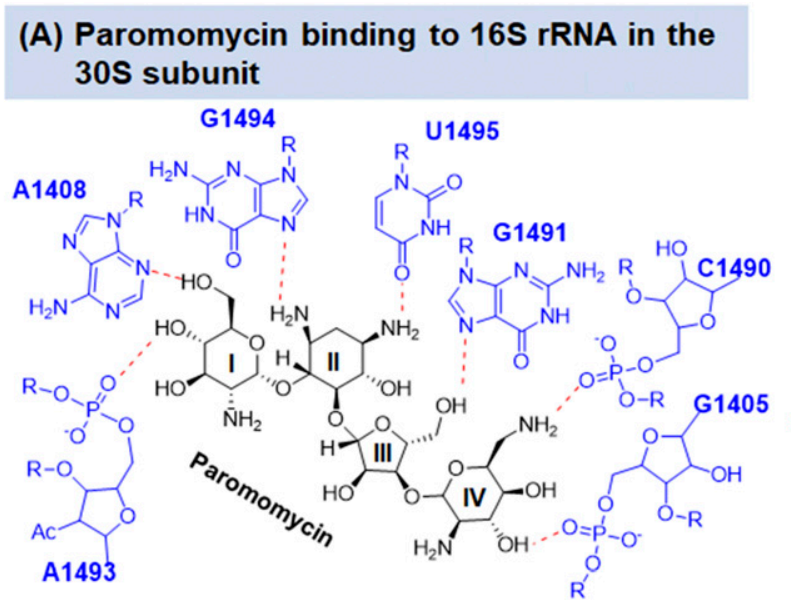

(C) Telithromycin binding to 23s rRNA in the 50 S subunit

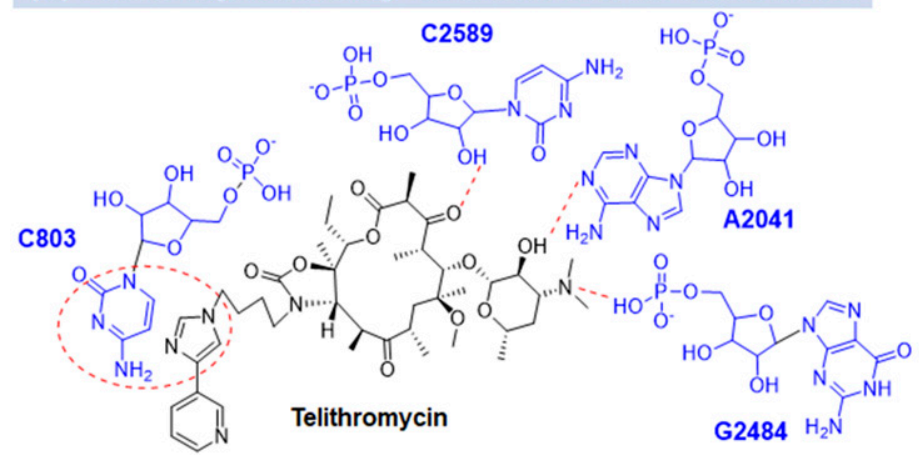

(B) Linezolid binding to 23s rRNA in the 50 S subunit

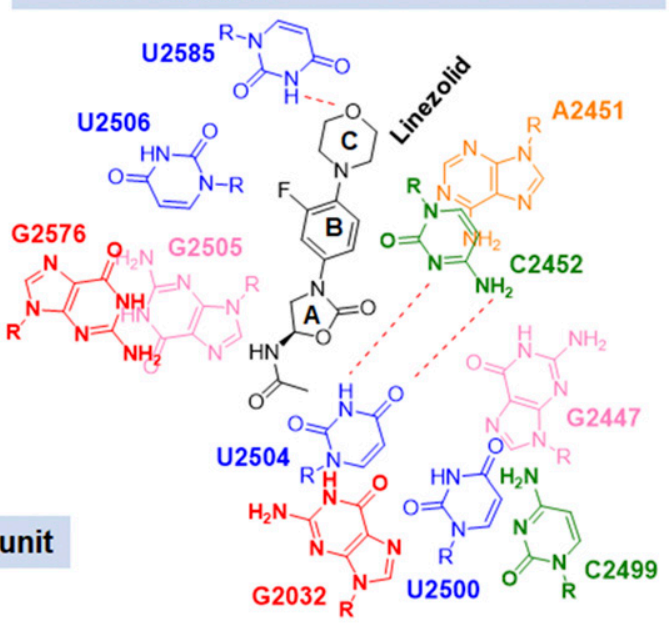

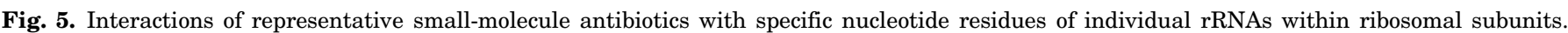

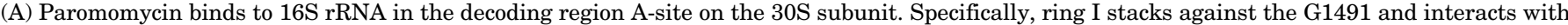

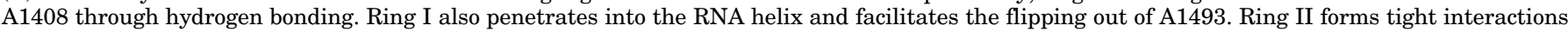

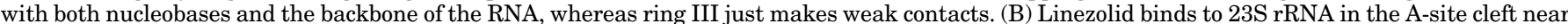

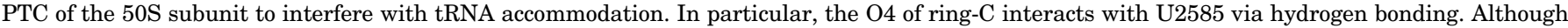

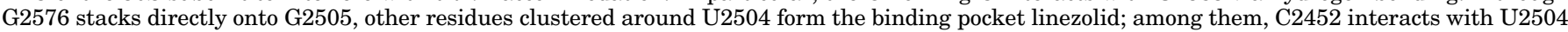

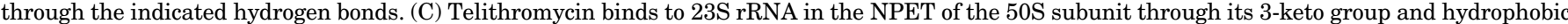
interactions.

been made to elucidate the structural characteristics of human $80 \mathrm{~S}$ ribosome and its detailed interactions with eukaryote-selective protein synthesis inhibitors (e.g., cycloheximide) (Myasnikov et al., 2016). These studies are expected to offer clues to the discovery and development of rRNA- or ribosome-targeted anticancer drugs. In addition, ribosome-targeted small molecules may be identified to interfere with the synthesis of specific protein for the treatment of genetic disorders. For example, mutations of the dystrophin gene leading to the disruption of its reading frame is a major cause of neuromuscular disorder DMD (Cirak et al., 2011), and the approval of ASO/PMO drugs eteplirsen and golodirsen (Table 2) supports the restoration of functional dystrophin protein production as a therapeutic strategy for the treatment of DMD. A small molecule, Translarna (ataluren; PTC124) (Fig. 6), has been developed to target ribosome to promote the insertion of near-cognate tRNAs at the site of the dystrophin gene and thus achieve nonsense suppression and functional protein production (Bushby et al., 2014; Ryan, 2014; Roy et al., 2016; McDonald et al., 2017). Ataluren has been approved in
Europe for the treatment of patients with DMD with a nonsense mutation in the dystrophin gene (Haas et al., 2015), and it is currently under phase III clinical trials (NCT03179631) in the United States (Table 4).

2. Viral RNA Motifs. Viral genomes consist of some highly conserved RNA elements that play pivotal roles in gene regulation and viral replication. Being highly structured, viral RNA motifs have emerged as potential targets for the development of small-molecule antiviral drugs (Hermann, 2016; Di Giorgio and Duca, 2019). The HIV transactivation response (TAR) element located within the first $59 \mathrm{nt}$ of the viral genome is one of the most studied RNA elements (Stevens et al., 2006). The TAR RNA element, folded into a hairpin structure (Kulinski et al., 2003), binds to the Tat protein to form a Tat/TAR complex that stimulates transcription and HIV-1 replication (Le Grice, 2015; Connelly et al., 2016). Efforts have been made to interfere with Tat/TAR interactions to control HIV-1 infections, including the identification and development of TAR-targeted small molecules (Hermann, 2016; Di Giorgio and Duca, 2019). 
(A) Ribosomal RNAs

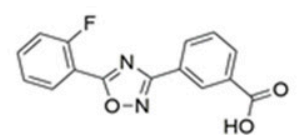

Ataluren
(B) Viral RNAs
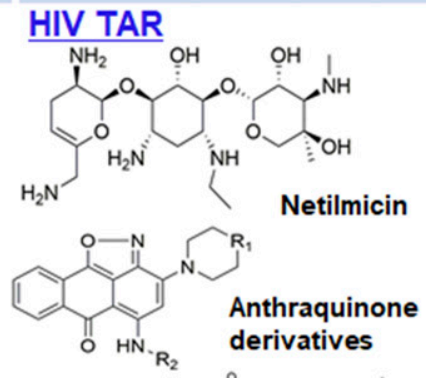

CCG-133994 $R_{1}=c$ 美人 $R_{2}=c \sim N$,

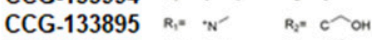

CCG-133868 $R_{1}={ }^{\prime} N^{\prime} \quad R_{2}=C^{\prime}$

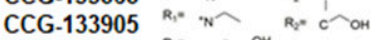

CCG-133879 R, "N ${ }^{\mathrm{N}} \mathrm{OH}_{\mathrm{R}, \mathrm{R}^{*}} \mathrm{C}^{\prime}$

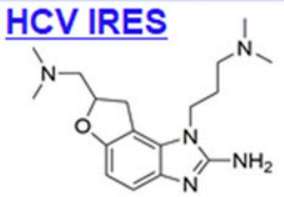

Benzimidazole analog (Isis-11)

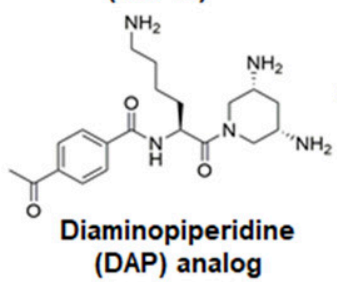

SARS-CoV pseudoknot

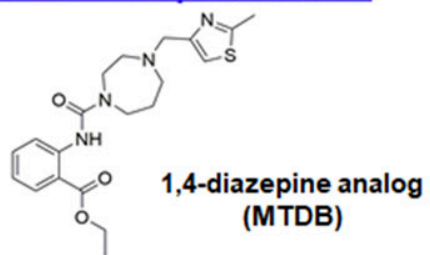

Influenza A promoter RNA<smiles>COc1cc2nc(N3CCNCC3)nc(N)c2cc1OC</smiles>

(C) Riboswitches

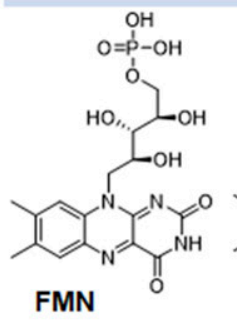<smiles>CNc1ncc(CN2CCCC(c3nc(-c4cccs4)cc(=O)[nH]3)C2)cn1</smiles>

Ribocil-A

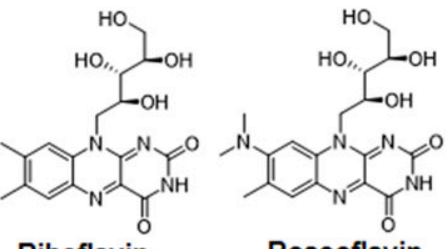

Riboflavin

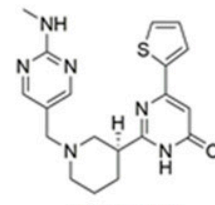

Ribocil-B
(D) Precursor mRNAs

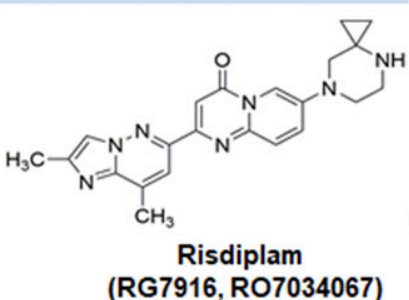

(RG7916, RO7034067)

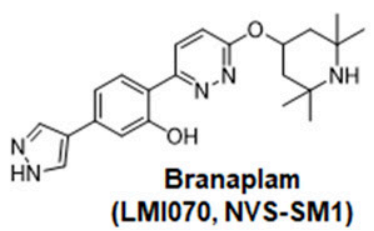

(E) Pri- \& pre-cursor miRNAs

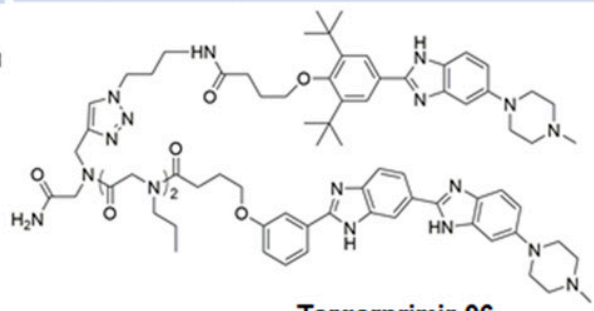

Targarprimir-96

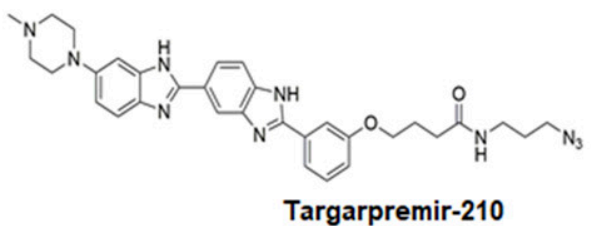

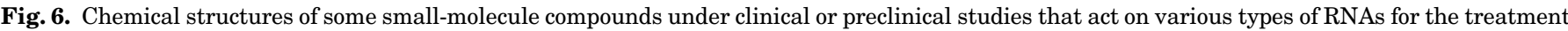

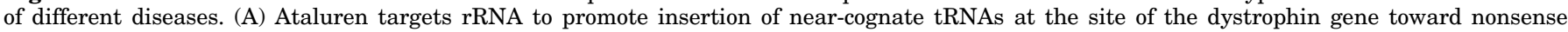

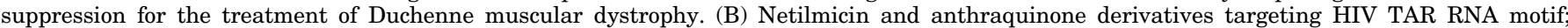

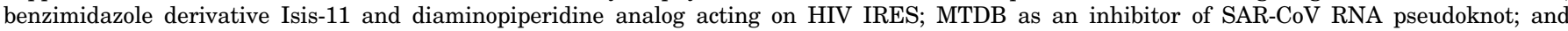

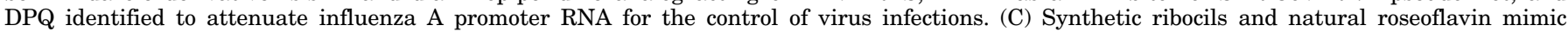

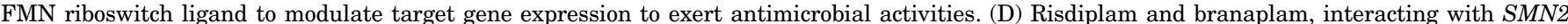

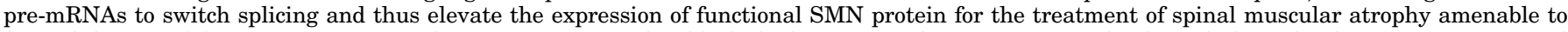

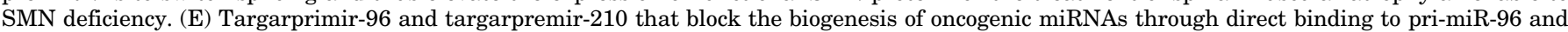
pre-miR-210, respectively, to elicit antitumoral activities.

For example, through viral screening of TAR dynamic structures against $>50,000$ compounds and fluorescencebased experimental assays, one study identified and validated six small molecules that were able to bind to TAR ( $\mathrm{Kd}=55 \mathrm{nM}$ to $22 \mu \mathrm{M})$ and inhibit its interaction with Tat (Ki = $710 \mathrm{nM}$ to $169 \mu \mathrm{M}$ ) (Stelzer et al., 2011). Among them, netilmicin (Fig. 6), a semisynthetic aminoglycoside antibiotic drug, exhibited high selectivity for TAR in the presence of tRNA. The antiviral activity of netilmicin $(100 \mu \mathrm{M})$ was further demonstrated in mammalian cell lines infected with an HIV-1 clone (Stelzer et al., 2011). Using a Tat peptide displacement assaybased high-throughput screening, the same group of investigators identified more TAR binders, including five anthraquinone derivatives (Fig. 6; Table 4) that showed selectivity relevant to tRNA (Ganser et al., 2018). Nevertheless, the efficacy and safety of TAR-targeted small molecules in animal disease models remain obscure.
Another well studied viral RNA target is the internal ribosome entry site (IRES) element located in the $5^{\prime}$ UTR of the hepatitis C virus (HCV) viral genome (Dibrov et al., 2014; Hermann, 2016; Di Giorgio and Duca, 2019). Being a highly structured RNA motif, HCV IRES functions as an RNA-based initiation factor to directly recruit host cell ribosomes with only a subset of host cell initiation factors and thus mediates cap-independent translation initiation (Lukavsky, 2009). Through MS-based high-throughput screening against a 29-nt HCV IRES subdomain IIa, imidazoles were identified as lead binders (Seth et al., 2005). Further structure-activity relationship studies afforded a number of new analogs, e.g., Isis-11 (Fig. 6; Table 4), showing comparable binding affinity $(\mathrm{Kd}=1.7 \mu \mathrm{M})$ and antireplication activity $\left(\mathrm{EC}_{50}=1.5 \mu \mathrm{M}\right)$ (Seth et al., 2005). Separate X-ray crystallography and NMR spectroscopy studies characterized the binding complex between HCV 
IRES subdomain IIa and Isis-11 (Paulsen et al., 2010; Dibrov et al., 2012). As another example, a synthetic diaminopiperidine derivative (Fig. 6) was identified to bind with HCV IRES subdomain IIa using a fluorescence-based ligand binding assay (Carnevali et al., 2010), which likely competes with the magnesium ions, locks the IIa RNA switch in the bent conformation, and prevents ribosome release to inhibit IRES function (Dibrov et al., 2014). Although the HCV IRES arises as a promising target for the treatment of HCV infections, no smallmolecule inhibitors have entered clinical trials yet.

Efforts were also made to explore other viral RNA motifs as targets for small molecules. The SARS-CoV genome consists of an atypical three-stemmed RNA pseudoknot that stimulates -1 programmed ribosomal frameshifting to initiate translation of viral proteins essential for replication (Plant et al., 2005; Su et al., 2005). Through virtual screening of about 80,000 compounds against a computationally constructed, three-dimensional SARS-CoV pseudoknot structure and experimental studies on a number of high-ranked compounds, a 1,4-diazepine analog, 2-[[4-(2-methylthiazol4-ylmethyl)-(1,4)diazepane-1-carbonyl]amino]benzoic acid ethyl ester (MTDB) (Fig. 6), was identified to inhibit the -1 ribosomal frameshifting of SARS-CoV with an $\mathrm{IC}_{50}$ of $0.45 \mu \mathrm{M}$ (Park et al., 2011). Indeed, MTDB directly interacts with SARS-CoV pseudoknot to block the formation of alternate conformers, as revealed by singlemolecule force spectroscopy studies (Ritchie et al., 2014). These findings support the concept of developing smallmolecule inhibitors against SARS-CoV RNA pseudoknot for the treatment of pandemic severe acute respiratory syndrome, including the ongoing SARS-CoV-2, in which the pseudoknot is well conserved.

Among most human influenza A virus variants, there is a highly conserved promoter RNA element comprising $13 \mathrm{nt}$ at the $5^{\prime}$ end and $12 \mathrm{nt}$ at the $3^{\prime}$ end of each viral RNA segment, which are folded together to form a partial duplex called a panhandle-like structure (Bae et al., 2001) that is recognized specifically by the RNAdependent RNA polymerase (Pflug et al., 2014) to control transcription initiation and viral replication (Ferhadian et al., 2018). Through an NMR spectroscopy-based screening, a drug-like quinazoline compound, 6,7dimethoxy-2-(1-piperazinyl)-4-quinazolinamine (DPQ) (Fig. 6), was found to directly bind to the influenza A virus RNA promoter (Kd around $50 \mu \mathrm{M}$ ) and exhibit antiviral activity against influenza viruses $\left(\mathrm{IC}_{50}=\right.$ 70-300 $\mu \mathrm{M}$ ) (Lee et al., 2014). Further screening and structure-activity relationship studies with cell-based anti-influenza activity assays identified a number of quinazoline derivatives that show around 10-fold higher activity against influenza $\mathrm{A}$ virus than the lead compound, DPQ (Bottini et al., 2015). Similar to other viral RNA-targeted small molecules described above, the discovery of quinazolines against influenza A panhandle-like promoter RNA is promising but still in its early stage.
3. Riboswitches. Riboswitches are a diverse group of natural RNA "receptors" commonly found in bacteria that directly control gene expression critical for survival (Tucker and Breaker, 2005; Hallberg et al., 2017; McCown et al., 2017). Riboswitches are usually located in the 5'UTR of particular mRNAs, and each consists of a ligand-sensing domain (or aptamer domain) and a regulatory domain (or expression platform). The specific binding of small-molecule ligand to an "aptamer" domain triggers conformational changes and stimulates the regulatory domain to govern target gene expression. Most bacterial riboswitches modulate gene expression through transcriptional or translational regulation, although some, including eukaryotic riboswitches, may provoke alternative splicing, and others can induce self-cleavage to cause mRNA degradation. In particular, various endogenous metabolite ligands, such as amino acids, vitamins, and FMN, present within cells above threshold concentrations can directly and specifically bind to the aptamer domains of riboswitches (Winkler et al., 2002b; Lee et al., 2009; Ren et al., 2015; Chauvier et al., 2017). Entrapment of a ligand can stabilize the incorporation of the switching sequence into the aptamer domain, and thus the expression platform is induced to fold into a specific structure to modulate the expression of genes controlling the biosynthesis and transport of metabolites (Serganov and Nudler, 2013; Hallberg et al., 2017).

Riboswitches have emerged as potential therapeutic targets because they are highly structured to form unique ligand binding pockets and function as gene regulatory factors, similar to the structural and functional selectivity of proteins. Many riboswitches are unique in bacteria, which upon binding to smallmolecule ligands, turn off or on the transcriptional or translational expression of genes essential for pathogen survival or virulence (Zhang et al., 2004b). Therefore, small molecules may be discovered and developed to mimic or block the actions of natural ligands to interact with riboswitches with reasonable affinity and specificity for the control of infections.

Indeed, some small molecules have been identified to directly bind to targeted riboswitches, although most of them exhibit lower affinities toward the same riboswitch than natural ligand. For instance, L-lysine binds to lysine riboswitch with a Kd value around 0.36 $\mu \mathrm{M}$, in contrast to currently identified lysine mimics, showing Kd values at 1-30 $\mu \mathrm{M}$ (Sudarsan et al., 2003; Blount et al., 2007). Likewise, thiamine pyrophosphate (TPP) binds to TPP riboswitch with high affinity $(\mathrm{Kd}=$ $50 \mathrm{nM}$ ), whereas other small-molecule binders interact with the TPP riboswitch at high concentrations (Kd $\geq$ $50 \mu \mathrm{M}$ ), except the TPP analog pyrithiamine pyrophosphate $(\mathrm{Kd}=160 \mathrm{nM})$ (Sudarsan et al., 2005; Warner et al., 2014).

Although challenges remain in the discovery of highaffinity small molecules to target bacterial riboswitches, 
recent efforts have led to the discovery of a few inhibitors with improved drug-like properties. Roseoflavin (Fig. 6), a natural analog of riboflavin and FMN, was revealed to directly bind to the aptamer domain of bacterial FMN riboswitch with a Kd value of $\sim 100 \mathrm{nM}$ to exhibit antimicrobial activity, in comparison with that of FMN $(5 \mathrm{nM})$ and riboflavin $(3 \mu \mathrm{M})$ (Lee et al., 2009; Serganov et al., 2009). Through phenotypic screening, a structurally distinct compound, ribocil (Table 4), was discovered to mimic FMN actions to suppress FMN riboswitchmediated gene expression and inhibit bacterial growth via direct binding to the aptamer domain $(\mathrm{Kd}=16 \mathrm{nM})$ (Howe et al., 2015). Further derivatization and structure-activity relationship studies identified ribocil-C (Fig. 6) as the most potent and highly selectively inhibitor of FMN riboswitch, showing antimicrobial activities against different bacterial strains, including medically significant Gram positive bacteria such as methicillin-resistant Staphylococcus aureus and Enterococcus faecalis (Howe et al., 2016; Wang et al., 2017). Very recently, an MS-based automated ligand detection system was established and employed for selective detection of small-molecule-ncRNA interactions, which not only verified the direct binding between ribocils and FMN riboswitch but also identified a few new binders that show greater antimicrobial activities (Rizvi et al., 2018). Although these compounds are still under preclinical investigation, these findings shall enlighten the development of a novel class of riboswitch-targeted antibiotics.

4. Precursor Messenger RNAs. Orally bioavailable small molecules (Fig. 6) have also been identified to directly interact with pre-mRNAs to modulate splicing. This strategy seems more feasible for the treatment of genetic disorders, especially those diseases with verified RNA targets. For instance, the neuromuscular disorder SMA is amenable to SMN2 genetic variations that alter pre-mRNA splicing and thus deficiency of functional SMN protein (Aartsma-Rus, 2017; Ottesen, 2017), and targeting SMN2 pre-mRNA splicing as an effective therapeutic strategy is proven by the approval of the ASO drug nusinersen (Table 2). Indeed, a pyrimidin-4-one analog, SMN-C3, was first identified as an effective SMN2 splicing modifier through chemical screening and optimization (Naryshkin et al., 2014). Being orally bioavailable, SMN-C3 was able to increase SMN protein levels in severe SMA disease $\Delta 7$ mouse models, improve motor function, and protect the neuromuscular circuit. An SMN-C3 derivative, RG7800, was further discovered and shown to be effective in two different mouse models of SMA (Ratni et al., 2016). Although RG7800 entered clinical trials, it was terminated as a precautionary measure after the observation of retinal toxicity for chronic treatment (39 weeks) in cynomolgus monkeys (Ratni et al., 2018). Additional chemical modifications and preclinical efficacy and safety studies (Ratni et al., 2018) led to clinical development of RG7916 (risdiplam) (Fig. 6; Table 4).
As risdiplam was well tolerated among healthy volunteers and exhibited effectiveness in shifting SMN2 splicing (Sturm et al., 2019), phase II/III studies (NCT02913482) are underway to evaluate the safety and efficacy of risdiplam in patients with SMA.

Branaplam (LMI070 and NVS-SM1) (Fig. 6) represents another class of small-molecule pyridazine analogs identified to modulate SMN2 pre-mRNA splicing for the treatment of SMA caused by deficiency of SMN protein (Palacino et al., 2015; Cheung et al., 2018). Branaplam was found to bind to the pre-mRNA of SMN2 and stabilize the transient dsRNA structure formed by the SMN2 pre-mRNA and U1 small nuclear RNA protein complex, a key component of the spliceosome, which enhances SMN2 pre-mRNA splicing and increases the expression of full-length SMN mRNA and functional SMN protein (Table 4) (Palacino et al., 2015). With a favorable PK profile, branaplam was effective at improving survival of SMA $\Delta 7$ mice in a dose-dependent manner (Palacino et al., 2015; Cheung et al., 2018). Branaplam has entered a first-in-human study on the safety, tolerability, PK, pharmacological actions, and efficacy of oral branaplam in infants with type 1 SMA (NCT02268552).

5. Primary and Precursor MicroRNAs. Efforts were also made to explore small-molecule inhibitors against the biogenesis of oncogenic miRNAs in comparison with antagonism with complementary oligonucleotides as well as oncolytic miRNA replacement therapy, which was discussed before. This may be achieved through the interference with Drosha-mediated processing of pri-miRNA within nucleus or Dicer-controlled cleavage of pre-miRNA in cytoplasm because both precursors are folded into hairpin structures available for ligand binding (Fig. 7). Indeed, a computational approach has been taken to design and identify lead small molecules based on the predicted human miRNA hairpin precursor structures (Velagapudi et al., 2014). Among 27 lead compounds, a benzimidazole analog was shown to selectively inhibit the processing of pri-miR-96 into oncogenic miR-96 and thus alter miR-96 target gene expression and induce apoptosis in cancer cells. The focus on the Drosha processing site of oncogenic primiR-96 and optimization of benzimidazole led to the discovery of a dimeric benzimidazole and bisbenzimide compound, targaprimir-96 (Fig. 7; Table 4), which showed a favorable PK profile and was effective at releasing tumor burden in a triple-negative breast cancer xenograft mouse model (Velagapudi et al., 2016). In addition, the conjugate of targaprimir-96 with bleomycin A5 resulted in over 100-fold higher selectivity toward pri-miR-96 than DNA (Li and Disney, 2018). Very recently, another dimeric benzimidazole and bisbenzimide analog, targaprimir (TGP)-515, was identified to target pri-miR-515, leading to an induction of human epidermal growth factor receptor 2 expression levels in breast cancer cells and enhancement of the 


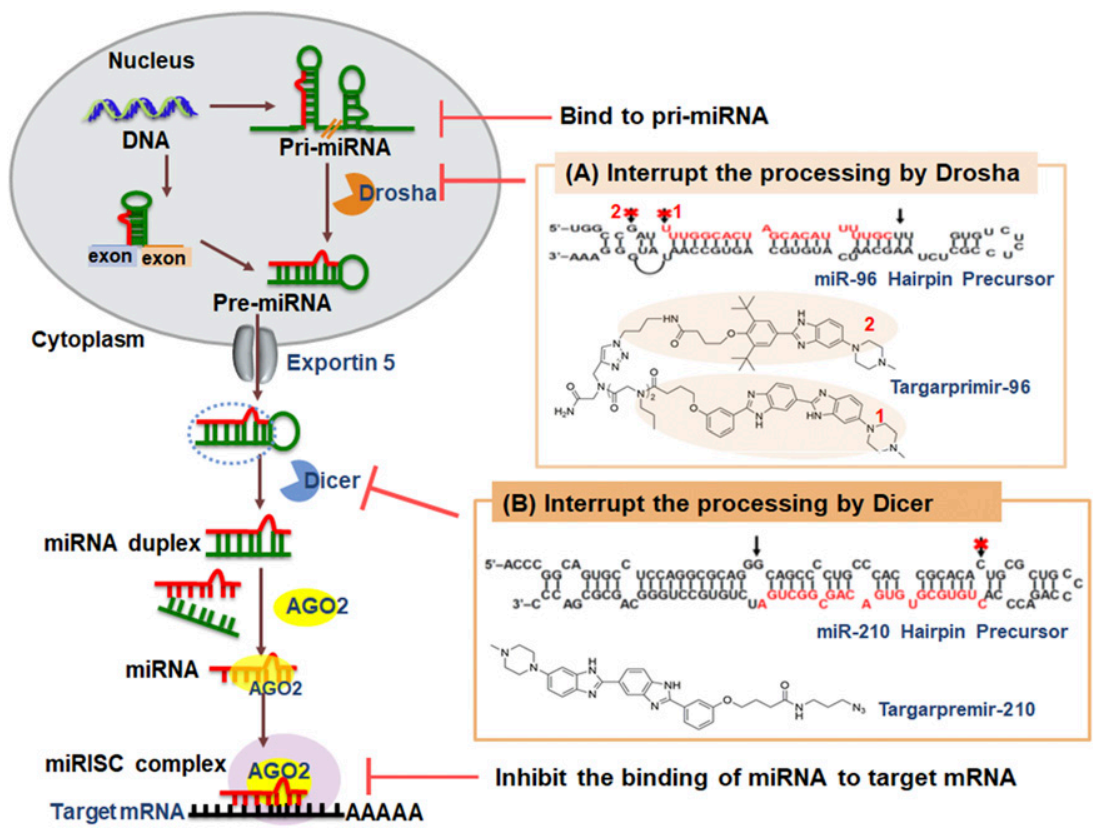

Fig. 7. Pri- and pre-miRNAs as therapeutic targets for small-molecule compounds. (A) Small molecules (e.g., the dimeric benzimidazole and bisbenzimide compound targarprimir-96) may directly bind to pri-miRNA (pri-miR-96) to inhibit Drosha-mediated processing to pre-miRNA. (B) Small molecules (e.g., the bisbenzimide analog targarpremir-210) can be identified to interfere with pre-miRNA (pre-miR-210) processing by Dicer. In addition, the binding of miRNA to target transcripts would be disrupted by small molecules, which remains to be explored.

efficacy of human epidermal growth factor receptor 2 antibody therapeutics (Costales et al., 2019a).

Likewise, a bisbenzimide (Hoechst 33342) analog called targarpremir-210, or TGP-210 (Fig. 7; Table 4), was identified to bind to pre-miR-210, leading to the inhibition of Dicer-mediated processing to mature miR210 in human carcinoma cells and the outgrowth of xenograft tumors in mice (Costales et al., 2017). Direct binding of targarpremir-210 with pre-miR-210 was also validated by a chemical pull-down assay, and the blue fluorescent dye compound remains with a high affinity to DNA. The attachment of a nuclease (RNase L) recruitment module onto targarpremir-210 offered a conjugate, TGP-210-RL, which indeed was able to recruit RNase L onto pre-miR-210 to induce the degradation of pre-miR-210 (Costales et al., 2019b). Interestingly, this TGP-210-RL conjugate exhibited high binding selectivity to the pre-miR-210 while lacking interactions with DNA as compared with TGP-210.

A small-molecule microarray-based approach was also developed for the identification of binders of RNA motifs (Velagapudi et al., 2018). After screening against a library of 727 pharmacologically active compounds being used in the clinic or human trials, a number of DNA-intercalating agents (and topoisomerases inhibitors), such as doxorubicin, ellipticine, and mitoxantrone, as well as other entities, were revealed to bind to RNAs. Further computational and experimental studies demonstrated that mitoxantrone was able to directly bind to pre-miR-21 and subsequently inhibit Dicermediated biogenesis of oncogenic miR-21. Although these pharmacological agents commonly exhibit multiple levels of mechanisms of action and druggability of these pri- and pre-miRNA inhibitors (Fig. 7; Table 4) awaits further investigations, these findings support the development of small molecules to target oncogenic ncRNAs as anticancer drugs.

6. Other RNA Targets. Some small molecules were also found to act on other types of disease-related RNAs or pathogenic RNA motifs. Many of them are for RNA repeats, such as the expanded GGGGCC repeat [r(GGGGCC) ${ }^{\exp }$, or r(G4C2) $)^{\exp }$, or G-quadruplex RNA], which causes frontotemporal dementia and amyotrophic lateral sclerosis (Su et al., 2014; Simone et al., 2018); the CGG repeat ( $\mathrm{rCGG}^{\mathrm{exp}}$ ), which causes fragile $\mathrm{X}$-associated tremor/ataxia syndrome (Disney et al., 2012; Qurashi et al., 2012; Yang et al., 2015; Green et al., 2019); and the CUG repeat $\mathrm{r}(\mathrm{CUG}){ }^{\exp }$ (Parkesh et al., 2012; Luu et al., 2016; Rzuczek et al., 2017; Li et al., 2018a; Angelbello et al., 2019), which is associated with myotonic dystrophy type 1 . Interestingly, there are several G-quadruplex motifs located on the 5'UTR of oncogenic KRAS transcript that could be targeted by 4,11-bis(2-aminoethylamino)anthra[2,3-b]furan-5,10-dione and 4,11-bis(2-aminoethylamino)anthra[2,3-b]thiophene5,10-dione for the control of cancer cell proliferation and colony formation (Miglietta et al., 2017). Another polyaromatic molecule, namely RGB-1, was found to stabilize RNA G-quadruplex, leading to the inhibition of RNA translation and suppression of proto-oncogene neuroblastoma RAS viral oncogene homolog expression in breast cancer cells (Katsuda et al., 2016). In addition, a benzopyrrole analog named synucleozid was identified very recently as a binder to the structured iron-responsive element 
located on the $5^{\prime} \mathrm{UTR}$ of $\alpha$-synuclein mRNA, thus reducing $\alpha$-synuclein protein levels in human cells (Zhang et al., 2020a), which may provide insight into developing smallmolecule remedies for $\alpha$-synuclein-caused Parkinson disease and other $\alpha$-synucleinopathies.

\section{Challenges in the Discovery and Development of RNA-Targeted Small-Molecule Drugs}

With growing interests in developing small molecules to target RNAs for the management of human diseases (Costales et al., 2020), it should be noted that RNAs are unique macromolecules that are distinguished from proteins and are closely related to DNAs. Currently, there are a limited number of verified druggable RNA targets, and validation of a new therapeutic target requires tedious and extensive investigations. A proven therapeutic target is valid until administrative approval of respective medication. Meanwhile, studies should be conducted to critically define the specificity of a small molecule in interacting with the target RNA. Most importantly, caution should be exercised to simply adopt conventional "rules" that are applicable to protein-ligand interactions for the discovery and development of RNA-targeted small-molecule drugs. This notion is also supported by the fact that the majority of RNA-targeted antibiotics (Fig. 4; Table 4) do not follow Lipinski's rule of five, and many "RNA binders" initially designed and/or identified are known to later act on other targets (e.g., direct binding to DNAs). Therefore, structural optimization is necessary to improve the PK properties and selectivity toward a projected RNA target when developing novel efficacious and safe RNAtargeted drugs (Fig. 6).

1. Identification of Druggable RNA Targets. Two critical questions should be addressed for the identification of a druggable RNA target to control chosen disease. The first question is whether the RNA target can be accessed by small-molecule compounds. Beyond the intrinsic properties of small molecules, the accessibility of target RNA is dictated by RNA properties such as the abundance of target RNA in diseased cells, the availability of highly structured and functional sites for smallmolecule binding, and so on. Indeed, rRNAs accounting for the majority of cellular RNAs (e.g., $>80 \%$ ) are folded to form functional binding pockets and clefts that are accessible by small molecules to intervene specifically (Fig. 5), leading to the disruption of protein synthesis and thus bacterial growth. As oncogenic miRNAs are commonly overexpressed in tumor tissues and carcinoma cells, the unique hairpin structures of miRNA precursors amenable to Drosha or Dicer processing (Fig. 7) make them promising targets for the development of smallmolecule inhibitors. Rather, it is necessary to verify selective binding of small molecules with the projected RNA target among complex cellular substances, such as other forms of RNAs, as well as DNAs and large quantities of proteins.
The second question is whether interactions between small molecules and RNA targets in cells and body can lead to an effective control of disease. Prior knowledge of RNA functions related to the pathogenesis and progression of a chosen disease shall be helpful, which could have already involved extensive epidemiologic, genetic, and biochemical studies. Starting from phenotype, specific RNA targets might be pinpointed. On the other hand, the appearance or apparent management of disease with the gain or loss of RNA coding gene or function will strongly support the role of target RNA. As such, pharmacological perturbation of RNA target with small molecules becomes possible, which awaits critical and comprehensive studies using phenotypic assays and animal disease models before entering clinical investigations.

2. Specificity in Targeting RNAs. Similar to the selective actions of a drug on corresponding protein target, new RNA-targeted small-molecule drugs should bind to RNAs with reasonable specificity to elicit ontarget therapeutic efficacy and avoid off-target adverse effects. This is actually a common principle for drug development, but it poses a big challenge for the discovery and development of novel RNA-targeted small-molecule modalities. As different RNA targets possess their intrinsic characteristics, the requirements for and strategies to achieve "selective" targeting may vary (Donlic and Hargrove, 2018). Although structural studies have clearly elucidated the binding of small-molecule antibiotics with rRNAs (Fig. 5; Table 2), it is inevitable that their interactions are based on the participation of essential proteins to assemble ribosomes (Wilson, 2014; Lin et al., 2018). As another example, the small-molecule splicing modifier named AMN-C not only binds to an exonic splicing enhancer ESE2 of exon 7 but also interacts with an RNA helix formed by the 5'ss intron 7 and the $5^{\prime}$ terminus of the U1 small nuclear RNA bound with the U1 small nuclear RNA protein to selectively alter SMN2 pre-mRNA splicing over other transcripts (Sivaramakrishnan et al., 2017).

The concern about specificity of RNA-targeted small molecules is worsened by the fact that RNAs and DNAs are both negatively charged nucleic acids and have common structural features, as well as the observation that the majority of small-molecule binders identified thus far for RNAs are either fluorescent dye derivatives (e.g., bisbenzimide or Hoechst 33342, commonly used to stain DNA), polyaromatic molecules, or highly basic or polar molecules. Many compounds themselves (e.g., doxorubicin and mitoxantrone) are well known as multifunctional DNA-intercalating agents (Wakelin, 1986). Some approaches have developed and successfully improved the selectivity toward target RNA motifs over DNA (Li and Disney, 2018; Costales et al., 2019b); however, the resulting conjugate becomes a much bigger molecule, with a molecular mass over $1500 \mathrm{Da}$, whose druggability warrants further and more extensive 
investigations. In any cases, further structural modification and optimization of lead RNA binders are necessary to improve the selectivity toward RNA target for safe and effective control or eradication of particular diseases (Costales et al., 2020).

\section{Conclusions and Perspectives}

Unparalleled opportunities have emerged to develop the next generation of RNA-based therapeutics, including a broad range of RNA molecules as medications and disease-related RNAs as therapeutic targets for small molecules. RNA-based therapies hold the promise to greatly expand the range of therapeutic targets for safe and effective control or eradication of potentially all types of diseases. Indeed, a number of RNA drugs with novel pharmacological actions, including RNA aptamers, ASOs, and siRNAs, have been approved for medical use, and many others, such as mRNA vaccines and gRNAmediated gene editing therapies, are undergoing active clinical trials. In addition, there is accumulating evidence supporting the mechanistic actions of existing and newly designed antibiotics on rRNAs for the control of infections, which motivates the identification of new viable RNA targets and development of novel RNA-targeted smallmolecule drugs. With growing interest in and enormous efforts devoted to the development of RNA-based therapies and emerging technologies, more and more RNAbased modalities are expected to enter into clinical trials and be approved for clinical practice in the coming decades.

Different from many small-molecule and protein drugs, natural RNA molecules are negatively charged and highly susceptible to ubiquitous RNases that impede them from access to intracellular targets. Application of particular chemical modifications or derivatizations, conjugation with targeting ligands, and utilization of lipid-based carriers have been proved as effective means to improve the stability of RNAs and deliver sufficient RNA molecules into cells to exert the desired pharmacological effects, which are evident in the FDA-approved RNA drugs. However, although chemical synthesis and purification can be automated, chemoengineered RNA drugs are among the most expensive medications on the market (Simoens and Huys, 2017; Burgart et al., 2018), and the access to large quantities of synthetic RNAs required for animal studies, clinical investigations, and medical use among a large population remains a challenge. There were also concerns about inevitable effects of artificial modifications on RNA folding, activity, and safety as compared with natural RNAs produced and folded in living cells (Ho and $\mathrm{Yu}, 2016$; Yu et al., 2019, 2020). Advances in RNA therapeutics will likely rely on the improvements of design and utilization of proper RNA molecules as well as delivery systems and targeting technologies to ensure efficacy and avoid or minimize off-target effects and immunogenicity.

There is also growing interest in developing orally bioavailable small-molecule inhibitors against therapeutic RNA targets beyond the use of RNA entities such as ASOs, siRNAs, and miRNAs. Because highly structured RNAs differ from proteins in many ways, including physicochemical properties and accessibility, the principles of RNA-small-molecule interactions may not necessarily follow the same rules derived from protein-targeted small-molecule drugs. By contrast, biological RNA macromolecules share common features with DNAs, although their cellular localizations can be very different. Therefore, it is necessary to verify the selectivity of small-molecule binder toward RNA target over DNAs, in addition to other types of RNAs and relevant proteins. An improved understanding of RNA structures and functions (especially those ncRNAs), identification of new pathogenic RNAs or RNA motifs as viable targets, and validation of their accessibilities for small molecules will greatly benefit future discovery and development of RNA-targeted small-molecule drugs.

\section{Authorship Contributions}

Participated in research design: Yu, Choi, Tu.

Performed data analysis: Yu, Choi, Tu.

Wrote or contributed to the writing of the manuscript: $\mathrm{Yu}, \mathrm{Choi}, \mathrm{Tu}$.

\section{References}

Aaldering LJ, Tayeb H, Krishnan S, Fletcher S, Wilton SD, and Veedu RN (2015) Smart functional nucleic acid chimeras: enabling tissue specific RNA targeting therapy. RNA Biol 12:412-425.

Aartsma-Rus A (2017) FDA approval of nusinersen for spinal muscular atrophy makes 2016 the year of splice modulating oligonucleotides. Nucleic Acid Ther 27: $67-69$.

Aartsma-Rus A and Krieg AM (2017) FDA approves eteplirsen for Duchenne muscular dystrophy: the next chapter in the eteplirsen saga. Nucleic Acid Ther 27:1-3. Adams BD, Parsons C, Walker L, Zhang WC, and Slack FJ (2017) Targeting noncoding RNAs in disease. $J$ Clin Invest 127:761-771.

Adams D, Gonzalez-Duarte A, O'Riordan WD, Yang CC, Ueda M, Kristen AV, Tournev I, Schmidt HH, Coelho T, Berk JL, et al. (2018) Patisiran, an RNAi therapeutic, for hereditary transthyretin amyloidosis. N Engl J Med 379:11-21.

Akinc A, Zumbuehl A, Goldberg M, Leshchiner ES, Busini V, Hossain N, Bacallado SA, Nguyen DN, Fuller J, Alvarez R, et al. (2008) A combinatorial library of lipidlike materials for delivery of RNAi therapeutics. Nat Biotechnol 26:561-569.

Alexopoulou L, Holt AC, Medzhitov R, and Flavell RA (2001) Recognition of doublestranded RNA and activation of NF-kappaB by Toll-like receptor 3. Nature 413: $732-738$.

Allard SD, De Keersmaecker B, de Goede AL, Verschuren EJ, Koetsveld J, Reedijk ML, Wylock C, De Bel AV, Vandeloo J, Pistoor F, et al. (2012) A phase I/IIa immunotherapy trial of HIV-1-infected patients with Tat, Rev and Nef expressing dendritic cells followed by treatment interruption. Clin Immunol 142:252-268.

Ambros V (2004) The functions of animal microRNAs. Nature 431:350-355.

An D, Frassetto A, Jacquinet E, Eybye M, Milano J, DeAntonis C, Nguyen V, Laureano R, Milton J, Sabnis S, et al. (2019) Long-term efficacy and safety of mRNA therapy in two murine models of methylmalonic acidemia. EBioMedicine 45: 519-528.

An D, Schneller JL, Frassetto A, Liang S, Zhu X, Park JS, Theisen M, Hong SJ, Zhou J, Rajendran R, et al. (2017) Systemic messenger RNA therapy as a treatment for methylmalonic acidemia. Cell Rep 21:3548-3558.

Anderson BR, Muramatsu H, Nallagatla SR, Bevilacqua PC, Sansing LH, Weissman $\mathrm{D}$, and Karikó K (2010) Incorporation of pseudouridine into mRNA enhances translation by diminishing PKR activation. Nucleic Acids Res 38:5884-5892.

Angelbello AJ, Rzuczek SG, Mckee KK, Chen JL, Olafson H, Cameron MD, Moss WN, Wang ET, and Disney MD (2019) Precise small-molecule cleavage of an r(CUG) repeat expansion in a myotonic dystrophy mouse model. Proc Natl Acad Sci USA 116:7799-7804.

Anokhina MM, Barta A, Nierhaus KH, Spiridonova VA, and Kopylov AM (2004) Mapping of the second tetracycline binding site on the ribosomal small subunit of E.coli. Nucleic Acids Res 32:2594-2597.

Anzalone AV, Randolph PB, Davis JR, Sousa AA, Koblan LW, Levy JM, Chen PJ, Wilson C, Newby GA, Raguram A, et al. (2019) Search-and-replace genome editing without double-strand breaks or donor DNA. Nature 576:149-157. 
Bader AG (2012) miR-34 - a microRNA replacement therapy is headed to the clinic. Front Genet 3:120.

Bader AG, Brown D, and Winkler M (2010) The promise of microRNA replacement therapy. Cancer Res 70:7027-7030.

Bae SH, Cheong HK, Lee JH, Cheong C, Kainosho M, and Choi BS (2001) Structural features of an influenza virus promoter and their implications for viral RNA synthesis. Proc Natl Acad Sci USA 98:10602-10607.

Bagga S, Bracht J, Hunter S, Massirer K, Holtz J, Eachus R, and Pasquinelli AE (2005) Regulation by let-7 and lin-4 miRNAs results in target mRNA degradation. Cell 122:553-563.

Bahl K, Senn JJ, Yuzhakov O, Bulychev A, Brito LA, Hassett KJ, Laska ME, Smith M, Almarsson Ö, Thompson J, et al. (2017) Preclinical and clinical demonstration of immunogenicity by mRNA vaccines against H10N8 and H7N9 influenza viruses. Mol Ther 25:1316-1327.

Ban N, Nissen P, Hansen J, Moore PB, and Steitz TA (2000) The complete atomic structure of the large ribosomal subunit at 2.4 A resolution. Science 289:905-920.

Barrangou R, Fremaux C, Deveau H, Richards M, Boyaval P, Moineau S, Romero DA and Horvath P (2007) CRISPR provides acquired resistance against viruses in prokaryotes. Science 315:1709-1712.

Beckert B and Masquida B (2011) Synthesis of RNA by in vitro transcription. Methods Mol Biol 703:29-41.

Beg MS, Brenner AJ, Sachdev J, Borad M, Kang YK, Stoudemire J, Smith S, Bader AG, Kim S, and Hong DS (2017) Phase I study of MRX34, a liposomal miR-34a mimic, administered twice weekly in patients with advanced solid tumors. Invest New Drugs 35:180-188.

Bennett CF (2019) Therapeutic antisense oligonucleotides are coming of age. Annu Rev Med 70:307-321.

Benson MD, Waddington-Cruz M, Berk JL, Polydefkis M, Dyck PJ, Wang AK, PlantéBordeneuve V, Barroso FA, Merlini G, Obici L, et al. (2018) Inotersen treatment for patients with hereditary transthyretin amyloidosis. N Engl J Med 379:22-31.

Berisio R, Harms J, Schluenzen F, Zarivach R, Hansen HA, Fucini P, and Yonath A (2003) Structural insight into the antibiotic action of telithromycin against resistant mutants. J Bacteriol 185:4276-4279.

Bernstein E, Caudy AA, Hammond SM, and Hannon GJ (2001) Role for a bidentate ribonuclease in the initiation step of RNA interference. Nature 409:363-366.

Birmingham A, Anderson EM, Reynolds A, Ilsley-Tyree D, Leake D, Fedorov Y, Baskerville S, Maksimova E, Robinson K, Karpilow J, et al. (2006) 3' UTR seed matches, but not overall identity, are associated with RNAi off-targets. Nat Methods 3:199-204.

Blount KF, Wang JX, Lim J, Sudarsan N, and Breaker RR (2007) Antibacterial lysine analogs that target lysine riboswitches. Nat Chem Biol 3:44-49.

Bohnsack MT, Czaplinski K, and Gorlich D (2004) Exportin 5 is a RanGTPdependent dsRNA-binding protein that mediates nuclear export of pre-miRNAs. RNA 10:185-191.

Bottini A, De SK, Wu B, Tang C, Varani G, and Pellecchia M (2015) Targeting influenza A virus RNA promoter. Chem Biol Drug Des 86:663-673.

Bouchard PR, Hutabarat RM, and Thompson KM (2010) Discovery and development of therapeutic aptamers. Annu Rev Pharmacol Toxicol 50:237-257.

Bouvier-Müller A and Ducongé F (2018) Application of aptamers for in vivo molecular imaging and theranostics. Adv Drug Deliv Rev 134:94-106.

Boyce M, Warrington S, Cortezi B, Zöllner S, Vauléon S, Swinkels DW, Summo L, Schwoebel F, and Riecke K (2016) Safety, pharmacokinetics and pharmacodynamics of the anti-hepcidin Spiegelmer lexaptepid pegol in healthy subjects. $\mathrm{Br}$ $J$ Pharmacol 173:1580-1588.

Bramsen JB and Kjems J (2012) Development of therapeutic-grade small interfering RNAs by chemical engineering. Front Genet 3:154.

Brodersen DE, Clemons WM Jr., Carter AP, Morgan-Warren RJ, Wimberly BT, and Ramakrishnan V (2000) The structural basis for the action of the antibiotics tetracycline, pactamycin, and hygromycin $\mathrm{B}$ on the $30 \mathrm{~S}$ ribosomal subunit. Cell 103:1143-1154.

Brummelkamp TR, Bernards R, and Agami R (2002) A system for stable expression of short interfering RNAs in mammalian cells. Science 296:550-553.

Brzustowicz LM, Lehner T, Castilla LH, Penchaszadeh GK, Wilhelmsen KC, Daniels R, Davies KE, Leppert M, Ziter F, Wood D, et al. (1990) Genetic mapping of chronic childhood-onset spinal muscular atrophy to chromosome $5 q 11.2-13.3$. Nature $\mathbf{3 4 4}$ : 540-541.

Bulkley D, Innis CA, Blaha G, and Steitz TA (2010) Revisiting the structures of several antibiotics bound to the bacterial ribosome. Proc Natl Acad Sci USA 107: 17158-17163.

Bunka DH and Stockley PG (2006) Aptamers come of age - at last. Nat Rev Microbiol 4:588-596.

Burgart AM, Magnus D, Tabor HK, Paquette ED, Frader J, Glover JJ, Jackson BM, Harrison CH, Urion DK, Graham RJ, et al. (2018) Ethical challenges confronted when providing nusinersen treatment for spinal muscular atrophy. JAMA Pediatr 172:188-192.

Burnett JC and Rossi JJ (2012) RNA-based therapeutics: current progress and future prospects. Chem Biol 19:60-71.

Bushby K, Finkel R, Wong B, Barohn R, Campbell C, Comi GP, Connolly AM, Day JW, Flanigan KM, Goemans N, et al.; PTC124-GD-007-DMD Study Group (2014) Ataluren treatment of patients with nonsense mutation dystrophinopathy. Muscle Nerve 50:477-487.

Butcher SE and Pyle AM (2011) The molecular interactions that stabilize RNA tertiary structure: RNA motifs, patterns, and networks. Acc Chem Res 44: 1302-1311.

Campbell JM, Bacon TA, and Wickstrom E (1990) Oligodeoxynucleoside phosphorothioate stability in subcellular extracts, culture media, sera and cerebrospinal fluid. J Biochem Biophys Methods 20:259-267.

Cantara WA, Crain PF, Rozenski J, McCloskey JA, Harris KA, Zhang X, Vendeix FA, Fabris D, and Agris PF (2011) The RNA modification database, RNAMDB: 2011 update. Nucleic Acids Res 39:D195-D201.
Carnevali M, Parsons J, Wyles DL, and Hermann T (2010) A modular approach to synthetic RNA binders of the hepatitis $\mathrm{C}$ virus internal ribosome entry site. ChemBioChem 11:1364-1367.

Caron NS, Southwell AL, Brouwers CC, Cengio LD, Xie Y, Black HF, Anderson LM, Ko S, Zhu X, van Deventer SJ, et al. (2020) Potent and sustained huntingtin lowering via AAV5 encoding miRNA preserves striatal volume and cognitive function in a humanized mouse model of Huntington disease. Nucleic Acids Res 48: $36-54$

Castanotto D and Rossi JJ (2009) The promises and pitfalls of RNA-interferencebased therapeutics. Nature 457:426-433.

Chauvier A, Picard-Jean F, Berger-Dancause JC, Bastet L, Naghdi MR, Dubé A Turcotte P, Perreault J, and Lafontaine DA (2017) Transcriptional pausing at the translation start site operates as a critical checkpoint for riboswitch regulation. Nat Commun 8:13892.

Cheloufi S, Dos Santos CO, Chong MM, and Hannon GJ (2010) A dicer-independent miRNA biogenesis pathway that requires Ago catalysis. Nature 465:584-589.

Chen C, Ridzon DA, Broomer AJ, Zhou Z, Lee DH, Nguyen JT, Barbisin M, Xu NL, Mahuvakar VR, Andersen MR, et al. (2005) Real-time quantification of microRNAs by stem-loop RT-PCR. Nucleic Acids Res 33:e179.

Chen F, Alphonse M, and Liu Q (2020) Strategies for nonviral nanoparticle-based delivery of CRISPR/Cas9 therapeutics. Wiley Interdiscip Rev Nanomed Nanobiotechnol 12:e1609.

Chen QX, Wang WP, Zeng S, Urayama S, and Yu AM (2015) A general approach to high-yield biosynthesis of chimeric RNAs bearing various types of functional small RNAs for broad applications. Nucleic Acids Res 43:3857-3869.

Cheung AK, Hurley B, Kerrigan R, Shu L, Chin DN, Shen Y, O'Brien G, Sung MJ, Hou Y, Axford J, et al. (2018) Discovery of small molecule splicing modulators of survival motor neuron-2 (SMN2) for the treatment of spinal muscular atrophy (SMA). J Med Chem 61:11021-11036.

Chi JT, Chang HY, Wang NN, Chang DS, Dunphy N, and Brown PO (2003) Genomewide view of gene silencing by small interfering RNAs. Proc Natl Acad Sci USA 100:6343-6346.

Cifuentes D, Xue H, Taylor DW, Patnode H, Mishima Y, Cheloufi S, Ma E, Mane S, Hannon GJ, Lawson ND, et al. (2010) A novel miRNA processing pathway independent of Dicer requires Argonaute 2 catalytic activity. Science 328:1694-1698.

Cirak S, Arechavala-Gomeza V, Guglieri M, Feng L, Torelli S, Anthony K, Abbs S, Garralda ME, Bourke J, Wells DJ, et al. (2011) Exon skipping and dystrophin restoration in patients with Duchenne muscular dystrophy after systemic phosphorodiamidate morpholino oligomer treatment: an open-label, phase 2, doseescalation study. Lancet 378:595-605.

Coelho T, Yarlas A, Waddington-Cruz M, White MK, Sikora Kessler A, Lovley A, Pollock M, Guthrie S, Ackermann EJ, Hughes SG, et al. (2020) Inotersen preserves or improves quality of life in hereditary transthyretin amyloidosis. $J$ Neurol 267: 1070-1079.

Condon TP and Bennett CF (1996) Altered mRNA splicing and inhibition of human E-selectin expression by an antisense oligonucleotide in human umbilical vein endothelial cells. J Biol Chem 271:30398-30403.

Cong L, Ran FA, Cox D, Lin S, Barretto R, Habib N, Hsu PD, Wu X, Jiang W, Marraffini LA, et al. (2013) Multiplex genome engineering using CRISPR/Cas systems. Science 339:819-823.

Connelly CM, Moon MH, and Schneekloth JS Jr. (2016) The emerging role of RNA as a therapeutic target for small molecules. Cell Chem Biol 23:1077-1090.

Conway A, Mendel M, Kim K, McGovern K, Boyko A, Zhang L, Miller JC, DeKelver RC, Paschon DE, Mui BL, et al. (2019) Non-viral delivery of zinc finger nuclease mRNA enables highly efficient in vivo genome editing of multiple therapeutic gene targets. Mol Ther 27:866-877.

Corey L, Mascola JR, Fauci AS, and Collins FS (2020) A strategic approach to COVID-19 vaccine R\&D. Science 368:948-950.

Costales MG, Childs-Disney JL, Haniff HS, and Disney MD (2020) How we think about targeting RNA with small molecules. J Med Chem DOI: 10.1021/acs.jmedchem.9b01927 [published ahead of print].

Costales MG, Haga CL, Velagapudi SP, Childs-Disney JL, Phinney DG, and Disney MD (2017) Small molecule inhibition of microRNA-210 reprograms an oncogenic hypoxic circuit. J Am Chem Soc 139:3446-3455.

Costales MG, Hoch DG, Abegg D, Childs-Disney JL, Velagapudi SP, Adibekian A and Disney MD (2019a) A designed small molecule inhibitor of a non-coding RNA sensitizes HER2 negative cancers to herceptin. J Am Chem Soc 141:2960-2974.

Costales MG, Suresh B, Vishnu K, and Disney MD (2019b) Targeted degradation of a hypoxia-associated non-coding RNA enhances the selectivity of a small molecule interacting with RNA. Cell Chem Biol 26:1180-1186.e5.

Craig VJ, Tzankov A, Flori M, Schmid CA, Bader AG, and Müller A (2012) Systemic microRNA-34a delivery induces apoptosis and abrogates growth of diffuse large B-cell lymphoma in vivo. Leukemia 26:2421-2424.

Cromer MK, Vaidyanathan S, Ryan DE, Curry B, Lucas AB, Camarena J, Kaushik M, Hay SR, Martin RM, Steinfeld I, et al. (2018) Global transcriptional response to CRISPR/Cas9-AAV6-based genome editing in $\mathrm{CD}^{+} 4^{+}$hematopoietic stem and progenitor cells. Mol Ther 26:2431-2442.

Crooke ST and Geary RS (2013) Clinical pharmacological properties of mipomersen (Kynamro), a second generation antisense inhibitor of apolipoprotein B. Br J Clin Pharmacol 76:269-276.

Crooke ST, Witztum JL, Bennett CF, and Baker BF (2018) RNA-targeted therapeutics. Cell Metab 27:714-739.

Cruz JA and Westhof E (2009) The dynamic landscapes of RNA architecture. Cell 136:604-609.

Dahlman JE, Barnes C, Khan O, Thiriot A, Jhunjunwala S, Shaw TE, Xing Y, Sager HB, Sahay G, Speciner L, et al. (2014) In vivo endothelial siRNA delivery using polymeric nanoparticles with low molecular weight. Nat Nanotechnol 9:648-655.

Dalpke A and Helm M (2012) RNA mediated Toll-like receptor stimulation in health and disease. RNA Biol 9:828-842. 
Dangouloff T and Servais L (2019) Clinical evidence supporting early treatment of patients with spinal muscular atrophy: current perspectives. Ther Clin Risk Manag 15:1153-1161.

Dassie JP and Giangrande PH (2013) Current progress on aptamer-targeted oligonucleotide therapeutics. Ther Deliv 4:1527-1546.

Davis ME, Zuckerman JE, Choi CH, Seligson D, Tolcher A, Alabi CA, Yen Y, Heidel JD, and Ribas A (2010) Evidence of RNAi in humans from systemically administered siRNA via targeted nanoparticles. Nature 464:1067-1070.

Deak D, Outterson K, Powers JH, and Kesselheim AS (2016) Progress in the fight against multidrug-resistant bacteria? A review of U.S. Food and Drug Administration-approved antibiotics, 2010-2015. Ann Intern Med 165:363-372.

de Jong W, Aerts J, Allard S, Brander C, Buyze J, Florence E, van Gorp E, Vanham G, Leal L, Mothe B, et al. (2019) iHIVARNA phase IIa, a randomized, placebocontrolled, double-blinded trial to evaluate the safety and immunogenicity of iHIVARNA-01 in chronically HIV-infected patients under stable combined antiretroviral therapy. Trials 20:361.

Demeshkina N, Jenner L, Westhof E, Yusupov M, and Yusupova G (2012) A new understanding of the decoding principle on the ribosome. Nature 484:256-259.

Demirci H, Murphy F IV, Murphy E, Gregory ST, Dahlberg AE, and Jogl G (2013) A structural basis for streptomycin-induced misreading of the genetic code. Nat Commun 4:1355.

Deng L, Stafford JH, Liu SC, Chernikova SB, Merchant M, Recht L, and Martin Brown J (2017) SDF-1 blockade enhances anti-VEGF therapy of glioblastoma and can be monitored by MRI. Neoplasia 19:1-7.

Denli AM, Tops BB, Plasterk RH, Ketting RF, and Hannon GJ (2004) Processing of primary microRNAs by the Microprocessor complex. Nature 432:231-235.

de Paula Brandao PR, Titze-de-Almeida SS, and Titze-de-Almeida R (2020) Leading RNA interference therapeutics part 2: silencing delta-aminolevulinic acid synthase 1, with a focus on givosiran. Mol Diagn Ther 24:61-68.

Dever DP, Bak RO, Reinisch A, Camarena J, Washington G, Nicolas CE, Pavel-Dinu M, Saxena N, Wilkens AB, Mantri S, et al. (2016) CRISPR/Cas9 $\beta$-globin gene targeting in human haematopoietic stem cells. Nature 539:384-389.

DeVincenzo J, Lambkin-Williams R, Wilkinson T, Cehelsky J, Nochur S, Walsh E, Meyers R, Gollob J, and Vaishnaw A (2010) A randomized, double-blind, placebocontrolled study of an RNAi-based therapy directed against respiratory syncytial virus. Proc Natl Acad Sci USA 107:8800-8805.

Dibrov SM, Ding K, Brunn ND, Parker MA, Bergdahl BM, Wyles DL, and Hermann T (2012) Structure of a hepatitis C virus RNA domain in complex with a translation inhibitor reveals a binding mode reminiscent of riboswitches. Proc Natl Acad Sci USA 109:5223-5228.

Dibrov SM, Parsons J, Carnevali M, Zhou S, Rynearson KD, Ding K, Garcia Sega E, Brunn ND, Boerneke MA, Castaldi MP, et al. (2014) Hepatitis C virus translation inhibitors targeting the internal ribosomal entry site. J Med Chem 57:1694-1707.

Di Giorgio A and Duca M (2019) Synthetic small-molecule RNA ligands: future prospects as therapeutic agents. MedChemComm 10:1242-1255.

Disney MD, Liu B, Yang WY, Sellier C, Tran T, Charlet-Berguerand N, and Childs-Disney JL (2012) A small molecule that targets r(CGG)(exp) and improves defects in fragile $\mathrm{X}$-associated tremor ataxia syndrome. ACS Chem Biol 7:1711-1718.

Disney MD, Winkelsas AM, Velagapudi SP, Southern M, Fallahi M, and ChildsDisney JL (2016) Inforna 2.0: a platform for the sequence-based design of small molecules targeting structured RNAs. ACS Chem Biol 11:1720-1728.

Djebali S, Davis CA, Merkel A, Dobin A, Lassmann T, Mortazavi A, Tanzer A, Lagarde J, Lin W, Schlesinger F, et al. (2012) Landscape of transcription in human cells. Nature 489:101-108

Donlic A and Hargrove AE (2018) Targeting RNA in mammalian systems with small molecules. Wiley Interdiscip Rev RNA 9:e1477.

Dowdy SF (2017) Overcoming cellular barriers for RNA therapeutics. Nat Biotechnol 35:222-229.

Dulla K, Aguila M, Lane A, Jovanovic K, Parfitt DA, Schulkens I, Chan HL, Schmidt I, Beumer W, Vorthoren L, et al. (2018) Splice-modulating oligonucleotide QR-110 restores CEP290 mRNA and function in human c.2991+1655A $>$ G LCA10 models. Mol Ther Nucleic Acids 12:730-740.

Dunkle JA, Xiong L, Mankin AS, and Cate JH (2010) Structures of the Escherichia coli ribosome with antibiotics bound near the peptidyl transferase center explain spectra of drug action. Proc Natl Acad Sci USA 107:17152-17157.

Ecker JR and Davis RW (1986) Inhibition of gene expression in plant cells by expression of antisense RNA. Proc Natl Acad Sci USA 83:5372-5376.

Eckstein F (1985) Nucleoside phosphorothioates. Annu Rev Biochem 54:367-402.

Elbashir SM, Harborth J, Lendeckel W, Yalcin A, Weber K, and Tuschl T (2001) Duplexes of 21-nucleotide RNAs mediate RNA interference in cultured mammalian cells. Nature 411:494-498.

Ellington AD and Szostak JW (1990) In vitro selection of RNA molecules that bind specific ligands. Nature 346:818-822.

Ellis MJ, Trussler RS, Charles O, and Haniford DB (2017) A transposon-derived small RNA regulates gene expression in Salmonella Typhimurium. Nucleic Acids Res 45:5470-5486

Ender C, Krek A, Friedländer MR, Beitzinger M, Weinmann L, Chen W, Pfeffer S, Rajewsky N, and Meister G (2008) A human snoRNA with microRNA-like func tions. Mol Cell 32:519-528.

Esteller M (2011) Non-coding RNAs in human disease. Nat Rev Genet 12:861-874.

Evers MM, Miniarikova J, Juhas S, Vallès A, Bohuslavova B, Juhasova J, Skalnikova HK, Vodicka P, Valekova I, Brouwers C, et al. (2018) AAV5-miHTT gene therapy demonstrates broad distribution and strong human mutant huntingtin lowering in a Huntington's disease minipig model. Mol Ther 26:2163-2177.

Ewe A, Panchal O, Pinnapireddy SR, Bakowsky U, Przybylski S, Temme A, and Aigner A (2017) Liposome-polyethylenimine complexes (DPPC-PEI lipopolyplexes) for therapeutic siRNA delivery in vivo. Nanomedicine (Lond) 13: 209-218.
Ewe A, Schaper A, Barnert S, Schubert R, Temme A, Bakowsky U, and Aigner A (2014) Storage stability of optimal liposome-polyethylenimine complexes (lipopolyplexes) for DNA or siRNA delivery. Acta Biomater 10:2663-2673.

Ewles M, Goodwin L, Schneider A, and Rothhammer-Hampl T (2014) Quantification of oligonucleotides by LC-MS/MS: the challenges of quantifying a phosphorothioate oligonucleotide and multiple metabolites. Bioanalysis 6:447-464.

Eyquem J, Mansilla-Soto J, Giavridis T, van der Stegen SJ, Hamieh M, Cunanan KM, Odak A, Gönen M, and Sadelain M (2017) Targeting a CAR to the TRAC locus with CRISPR/Cas9 enhances tumour rejection. Nature 543:113-117.

Fakhr E, Zare F, and Teimoori-Toolabi L (2016) Precise and efficient siRNA design a key point in competent gene silencing. Cancer Gene Ther 23:73-82.

Feng S and Holland EC (1988) HIV-1 tat trans-activation requires the loop sequence within tar. Nature 334:165-167.

Ferhadian D, Contrant M, Printz-Schweigert A, Smyth RP, Paillart JC, and Marquet $R$ (2018) Structural and functional motifs in influenza virus RNAs. Front Microbio 9:559.

Filippova J, Matveeva A, Zhuravlev E, and Stepanov G (2019) Guide RNA modification as a way to improve CRISPR/Cas9-based genome-editing systems. Biochimie 167:49-60.

Finkel RS, Mercuri E, Darras BT, Connolly AM, Kuntz NL, Kirschner J, Chiriboga CA, Saito K, Servais L, Tizzano E, et al.; ENDEAR Study Group (2017) Nusinersen versus sham control in infantile-onset spinal muscular atrophy. $N$ Engl J Med 377: $1723-1732$

Fire A, Xu S, Montgomery MK, Kostas SA, Driver SE, and Mello CC (1998) Potent and specific genetic interference by double-stranded RNA in Caenorhabditis elegans. Nature 391:806-811.

Fitzgerald K, Frank-Kamenetsky M, Shulga-Morskaya S, Liebow A, Bettencourt BR, Sutherland JE, Hutabarat RM, Clausen VA, Karsten V, Cehelsky J, et al. (2014) Effect of an RNA interference drug on the synthesis of proprotein convertase subtilisin/kexin type 9 (PCSK9) and the concentration of serum LDL cholesterol in healthy volunteers: a randomised, single-blind, placebo-controlled, phase 1 trial. Lancet 383:60-68.

Fitzgerald K, White S, Borodovsky A, Bettencourt BR, Strahs A, Clausen V, Wijngaard P, Horton JD, Taubel J, Brooks A, et al. (2017) A highly durable RNAi therapeutic inhibitor of PCSK9. N Engl J Med 376:41-51.

Fotin-Mleczek M, Duchardt KM, Lorenz C, Pfeiffer R, Ojkić-Zrna S, Probst J, and Kallen KJ (2011) Messenger RNA-based vaccines with dual activity induce balanced TLR-7 dependent adaptive immune responses and provide antitumor activity. $J$ Immunother 34:1-15.

Fourmy D, Recht MI, Blanchard SC, and Puglisi JD (1996) Structure of the A site of Escherichia coli 16S ribosomal RNA complexed with an aminoglycoside antibiotic. Science 274:1367-1371.

Frank DE, Schnell FJ, Akana C, El-Husayni SH, Desjardins CA, Morgan J, Charleston JS, Sardone V, Domingos J, Dickson G, et al.; SKIP-NMD Study Group (2020) Increased dystrophin production with golodirsen in patients with Duchenne muscular dystrophy. Neurology 94:e2270-e2282.

Frock RL, Hu J, Meyers RM, Ho YJ, Kii E, and Alt FW (2015) Genome-wide detection of DNA double-stranded breaks induced by engineered nucleases. Nat Biotechnol 33:179-186.

Gandhi RT, Kwon DS, Macklin EA, Shopis JR, McLean AP, McBrine N, Flynn T, Peter L, Sbrolla A, Kaufmann DE, et al. (2016) Immunization of HIV-1-infected persons with autologous dendritic cells transfected with mRNA encoding HIV-1 Gag and Nef: results of a randomized, placebo-controlled clinical trial. J Acquir Immune Defic Syndr 71:246-253.

Ganser LR, Lee J, Rangadurai A, Merriman DK, Kelly ML, Kansal AD, Sathyamoorthy B, and Al-Hashimi HM (2018) High-performance virtual screening by targeting a high-resolution RNA dynamic ensemble. Nat Struct Mol Biol 25 425-434.

García MA, Gil J, Ventoso I, Guerra S, Domingo E, Rivas C, and Esteban M (2006) Impact of protein kinase PKR in cell biology: from antiviral to antiproliferative action. Microbiol Mol Biol Rev 70:1032-1060.

Gehrig S, Eberle ME, Botschen F, Rimbach K, Eberle F, Eigenbrod T, Kaiser S, Holmes WM, Erdmann VA, Sprinzl M, et al. (2012) Identification of modifications in microbial, native tRNA that suppress immunostimulatory activity. $J$ Exp Med 209:225-233.

Georgiadis C, Preece R, Nickolay L, Etuk A, Petrova A, Ladon D, Danyi A, Humphryes-Kirilov N, Ajetunmobi A, Kim D, et al (2018) Long terminal repeat CRISPR-CAR-coupled "universal" T cells mediate potent anti-leukemic effects. $M o$ Ther 26:1215-1227.

Geurts AM, Cost GJ, Freyvert Y, Zeitler B, Miller JC, Choi VM, Jenkins SS, Wood A Cui X, Meng X, et al. (2009) Knockout rats via embryo microinjection of zinc-finger nucleases. Science 325:433.

Golan T, Khvalevsky EZ, Hubert A, Gabai RM, Hen N, Segal A, Domb A, Harari G, David EB, Raskin S, et al. (2015) RNAi therapy targeting KRAS in combination with chemotherapy for locally advanced pancreatic cancer patients. Oncotarget 6 $24560-24570$.

Gonzales CR; VEGF Inhibition Study in Ocular Neovascularization (V.I.S.I.O.N.) Clinical Trial Group (2005) Enhanced efficacy associated with early treatment of neovascular age-related macular degeneration with pegaptanib sodium: an exploratory analysis. Retina 25:815-827.

Goodchild A, Nopper N, King A, Doan T, Tanudji M, Arndt GM, Poidinger M, Rivory LP, and Passioura T (2009) Sequence determinants of innate immune activation by short interfering RNAs. BMC Immunol 10:40.

Gragoudas ES, Adamis AP, Cunningham ET Jr., Feinsod M, and Guyer DR VEGF Inhibition Study in Ocular Neovascularization Clinical Trial Group (2004) Pegaptanib for neovascular age-related macular degeneration. $N$ Engl J Med 351:2805-2816.

Green KM, Sheth UJ, Flores BN, Wright SE, Sutter AB, Kearse MG, Barmada SJ, Ivanova MI, and Todd PK (2019) High-throughput screening yields several smallmolecule inhibitors of repeat-associated non-AUG translation. J Biol Chem 294: 18624-18638. 
Gregory RI, Yan KP, Amuthan G, Chendrimada T, Doratotaj B, Cooch N, and Shiekhattar R (2004) The Microprocessor complex mediates the genesis of microRNAs. Nature 432:235-240.

Gryziewicz L (2005) Regulatory aspects of drug approval for macular degeneration. Adv Drug Deliv Rev 57:2092-2098.

Guan L and Disney MD (2012) Recent advances in developing small molecules targeting RNA. ACS Chem Biol 7:73-86.

Gurumurthy CB, Sato M, Nakamura A, Inui M, Kawano N, Islam MA, Ogiwara S, Takabayashi S, Matsuyama M, Nakagawa S, et al. (2019) Creation of CRISPRbased germline-genome-engineered mice without ex vivo handling of zygotes by i-GONAD. Nat Protoc 14:2452-2482.

Haas M, Vlcek V, Balabanov P, Salmonson T, Bakchine S, Markey G, Weise M, Schlosser-Weber G, Brohmann H, Yerro CP, et al. (2015) European Medicines Agency review of ataluren for the treatment of ambulant patients aged 5 years and older with Duchenne muscular dystrophy resulting from a nonsense mutation in the dystrophin gene. Neuromuscul Disord 25:5-13.

Haase AD, Jaskiewicz L, Zhang H, Lainé S, Sack R, Gatignol A, and Filipowicz W (2005) TRBP, a regulator of cellular PKR and HIV-1 virus expression, interacts with Dicer and functions in RNA silencing. EMBO Rep 6:961-967.

Hallberg ZF, Su Y, Kitto RZ, and Hammond MC (2017) Engineering and in vivo applications of riboswitches. Annu Rev Biochem 86:515-539.

Hammond SM, Bernstein E, Beach D, and Hannon GJ (2000) An RNA-directed nuclease mediates post-transcriptional gene silencing in Drosophila cells. Nature 404: 293-296.

Hammond SM, Boettcher S, Caudy AA, Kobayashi R, and Hannon GJ (2001) Argonaute2, a link between genetic and biochemical analyses of RNAi. Science 293: $1146-1150$

Han J, Lee Y, Yeom KH, Kim YK, Jin H, and Kim VN (2004) The Drosha-DGCR8 complex in primary microRNA processing. Genes Dev 18:3016-3027.

Hansen JL, Ippolito JA, Ban N, Nissen P, Moore PB, and Steitz TA (2002) The structures of four macrolide antibiotics bound to the large ribosomal subunit. $\mathrm{Mol}$ Cell 10:117-128.

Hashiro S, Mitsuhashi M, Chikami Y, Kawaguchi H, Niimi T, and Yasueda H (2019a) Construction of Corynebacterium glutamicum cells as containers encapsulating dsRNA overexpressed for agricultural pest control. Appl Microbiol Biotechnol 103: 8485-8496.

Hashiro S, Mitsuhashi M, and Yasueda H (2019b) Overexpression system for recombinant RNA in Corynebacterium glutamicum using a strong promoter derived from corynephage BFK20. J Biosci Bioeng 128:255-263.

Hayes J, Peruzzi PP, and Lawler S (2014) MicroRNAs in cancer: biomarkers, functions and therapy. Trends Mol Med 20:460-469.

Heasman J, Kofron M, and Wylie C (2000) Beta-catenin signaling activity dissected in the early Xenopus embryo: a novel antisense approach. Dev Biol 222 124-134.

Heiser A, Coleman D, Dannull J, Yancey D, Maurice MA, Lallas CD, Dahm P, Niedzwiecki D, Gilboa E, and Vieweg J (2002) Autologous dendritic cells transfected with prostate-specific antigen RNA stimulate CTL responses against metastatic prostate tumors. $J$ Clin Invest 109:409-417.

Hendel A, Bak RO Clark JT, Kennedy AB, Ryan DE, Roy S, Steinfeld I, Lunstad BD, Kaiser RJ, Wilkens AB, et al. (2015) Chemically modified guide RNAs enhance CRISPR-Cas genome editing in human primary cells. Nat Biotechnol 33:985-989.

Hentze MW, Castello A, Schwarzl T, and Preiss T (2018) A brave new world of RNAbinding proteins. Nat Rev Mol Cell Biol 19:327-341.

Heo YA (2020) Golodirsen: first approval. Drugs 80:329-333.

Hermann T (2016) Small molecules targeting viral RNA. Wiley Interdiscip Rev RNA 7:726-743.

Ho PY, Duan Z, Batra N, Jilek JL, Tu MJ, Qiu JX, Hu Z, Wun T, Lara PN, DeVere White RW, et al. (2018) Bioengineered noncoding RNAs selectively change cellular miRNome profiles for cancer therapy. J Pharmacol Exp Ther 365:494-506.

Ho PY and Yu AM (2016) Bioengineering of noncoding RNAs for research agents and therapeutics. Wiley Interdiscip Rev RNA 7:186-197.

Hoerr I, Obst R, Rammensee HG, and Jung G (2000) In vivo application of RNA leads to induction of specific cytotoxic T lymphocytes and antibodies. Eur J Immunol 30: $1-7$.

Hoffmann M, Kleine-Weber H, Schroeder S, Krüger N, Herrler T, Erichsen S, Schiergens TS, Herrler G, Wu NH, Nitsche A, et al. (2020) SARS-CoV-2 cell entry depends on ACE2 and TMPRSS2 and is blocked by a clinically proven protease inhibitor. Cell 181:271-280.e8.

Holdt LM, Kohlmaier A, and Teupser D (2018) Circular RNAs as therapeutic agents and targets. Front Physiol 9:1262.

Hong DS, Kang YK, Borad M, Sachdev J, Ejadi S, Lim HY, Brenner AJ, Park K, Lee JL, Kim TY, et al. (2020) Phase 1 study of MRX34, a liposomal miR-34a mimic, in patients with advanced solid tumours. Br J Cancer 122:1630-1637.

Hornung V, Ellegast J, Kim S, Brzózka K, Jung A, Kato H, Poeck H, Akira S, Conzelmann KK, Schlee M, et al. (2006) 5'-Triphosphate RNA is the ligand for RIG-I. Science 314:994-997.

Houseley J and Tollervey D (2009) The many pathways of RNA degradation. Cell 136:763-776.

Howe JA, Wang H, Fischmann TO, Balibar CJ, Xiao L, Galgoci AM, Malinverni JC, Mayhood T, Villafania A, Nahvi A, et al. (2015) Selective small-molecule inhibition of an RNA structural element. Nature 526:672-677.

Howe JA, Xiao L, Fischmann TO, Wang H, Tang H, Villafania A, Zhang R, Barbieri CM, and Roemer T (2016) Atomic resolution mechanistic studies of ribocil: a highly selective unnatural ligand mimic of the E. coli FMN riboswitch. RNA Biol 13: 946-954

Huang XJ, Zhang HX, Wang H, Xiong K, Qin L, and Liu H (2014) Disruption of the myostatin gene in porcine primary fibroblasts and embryos using zinc-finger nucleases. Mol Cells 37:302-306.

Hubschman JP, Reddy S, and Schwartz SD (2009) Age-related macular degeneration: experimental and emerging treatments. Clin Ophthalmol 3:167-174.
Humphreys SC, Thayer MB, Lade JM, Wu B, Sham K, Basiri B, Hao Y, Huang X, Smith R, and Rock BM (2019) Plasma and liver protein binding of $N$-acetylgalactosamineconjugated small interfering RNA. Drug Metab Dispos 47:1174-1182.

Husser C, Brink A, Zell M, Müller MB, Koller E, and Schadt S (2017) Identification of GalNAc-conjugated antisense oligonucleotide metabolites using an untargeted and generic approach based on high resolution mass spectrometry. Anal Chem 89: $6821-6826$

Hutvágner G, McLachlan J, Pasquinelli AE, Bálint E, Tuschl T, and Zamore PD (2001) A cellular function for the RNA-interference enzyme Dicer in the maturation of the let-7 small temporal RNA. Science 293:834-838.

Hutvágner G and Zamore PD (2002) A microRNA in a multiple-turnover RNAi enzyme complex. Science 297:2056-2060.

Ippolito JA, Kanyo ZF, Wang D, Franceschi FJ, Moore PB, Steitz TA, and Duffy EM (2008) Crystal structure of the oxazolidinone antibiotic linezolid bound to the 50S ribosomal subunit. $J$ Med Chem 51:3353-3356.

Ivics Z, Hiripi L, Hoffmann OI, Mátés L, Yau TY, Bashir S, Zidek V, Landa V, Geurts A, Pravenec M, et al. (2014a) Germline transgenesis in rabbits by pronuclear microinjection of Sleeping Beauty transposons. Nat Protoc 9:794-809.

Ivics Z, Mátés L, Yau TY, Landa V, Zidek V, Bashir S, Hoffmann OI, Hiripi L, Garrels W, Kues WA, et al. (2014b) Germline transgenesis in rodents by pronuclear microinjection of Sleeping Beauty transposons. Nat Protoc 9:773-793.

Izant JG and Weintraub H (1984) Inhibition of thymidine kinase gene expression by anti-sense RNA: a molecular approach to genetic analysis. Cell 36:1007-1015.

Jackson AL, Bartz SR, Schelter J, Kobayashi SV, Burchard J, Mao M, Li B, Cavet G, and Linsley PS (2003) Expression profiling reveals off-target gene regulation by RNAi. Nat Biotechnol 21:635-637.

Jackson AL, Burchard J, Schelter J, Chau BN, Cleary M, Lim L, and Linsley PS (2006) Widespread siRNA "off-target" transcript silencing mediated by seed region sequence complementarity. RNA 12:1179-1187.

Jackson AL and Linsley PS (2010) Recognizing and avoiding siRNA off-target effects for target identification and therapeutic application. Nat Rev Drug Discov 9: $57-67$.

Janas MM, Schlegel MK, Harbison CE, Yilmaz VO, Jiang Y, Parmar R, Zlatev I, Castoreno A, Xu H, Shulga-Morskaya S, et al. (2018) Selection of GalNAcconjugated siRNAs with limited off-target-driven rat hepatotoxicity. Nat Commun 9:723.

Jansen R, Embden JD, Gaastra W, and Schouls LM (2002) Identification of genes that are associated with DNA repeats in prokaryotes. Mol Microbiol 43:1565-1575. Jian C, Tu MJ, Ho PY, Duan Z, Zhang Q, Qiu JX, DeVere White RW, Wun T, Lara PN, Lam KS, et al. (2017) Co-targeting of DNA, RNA, and protein molecules provides optimal outcomes for treating osteosarcoma and pulmonary metastasis in spontaneous and experimental metastasis mouse models. Oncotarget 8: 30742-30755

Jilek JL, Tian Y, and Yu AM (2017) Effects of microRNA-34a on the pharmacokinetics of cytochrome P450 probe drugs in mice. Drug Metab Dispos 45:512-522.

Jilek JL, Zhang QY, Tu MJ, Ho PY, Duan Z, Qiu JX, and Yu AM (2019) Bioengineered Let-7c inhibits orthotopic hepatocellular carcinoma and improves overall survival with minimal immunogenicity. Mol Ther Nucleic Acids 14: 498-508

Jinek M, Chylinski K, Fonfara I, Hauer M, Doudna JA, and Charpentier E (2012) A programmable dual-RNA-guided DNA endonuclease in adaptive bacterial immunity. Science 337:816-821.

Jones CP and Ferré-D'Amaré AR (2015) RNA quaternary structure and global symmetry. Trends Biochem Sci 40:211-220.

Kaczmarek JC, Kowalski PS, and Anderson DG (2017) Advances in the delivery of RNA therapeutics: from concept to clinical reality. Genome Med 9:60.

Kanasty R, Dorkin JR, Vegas A, and Anderson D (2013) Delivery materials for siRNA therapeutics. Nat Mater 12:967-977.

Kanazawa H, Baba F, Koganei M, and Kondo J (2017) A structural basis for the antibiotic resistance conferred by an N1-methylation of A1408 in 16S rRNA Nucleic Acids Res 45:12529-12535.

Karikó K, Buckstein M, Ni H, and Weissman D (2005) Suppression of RNA recognition by Toll-like receptors: the impact of nucleoside modification and the evolutionary origin of RNA. Immunity 23:165-175.

Karikó K, Muramatsu H, Welsh FA, Ludwig J, Kato H, Akira S, and Weissman D (2008) Incorporation of pseudouridine into mRNA yields superior nonimmunogenic vector with increased translational capacity and biological stability. Mol Ther 16: 1833-1840.

Karikó K and Weissman D (2007) Naturally occurring nucleoside modifications suppress the immunostimulatory activity of RNA: implication for therapeutic RNA development. Curr Opin Drug Discov Devel 10:523-532.

Kasinski AL and Slack FJ (2012) miRNA-34 prevents cancer initiation and progression in a therapeutically resistant K-ras and p53-induced mouse model of lung adenocarcinoma. Cancer Res 72:5576-5587.

Katsuda Y, Sato S, Asano L, Morimura Y, Furuta T, Sugiyama H, Hagihara M, and Uesugi M (2016) A small molecule that represses translation of G-quadruplexcontaining mRNA. J Am Chem Soc 138:9037-9040.

Kauffman KJ, Mir FF, Jhunjhunwala S, Kaczmarek JC, Hurtado JE, Yang JH, Webber MJ, Kowalski PS, Heartlein MW, DeRosa F, et al. (2016) Efficacy and immunogenicity of unmodified and pseudouridine-modified mRNA delivered systemically with lipid nanoparticles in vivo. Biomaterials 109:78-87.

Kaur H, Bruno JG, Kumar A, and Sharma TK (2018) Aptamers in the therapeutics and diagnostics pipelines. Theranostics 8:4016-4032.

Kaza M, Karaźniewicz-Łada M, Kosicka K, Siemiątkowska A, and Rudzki PJ (2019) Bioanalytical method validation: new FDA guidance vs. EMA guideline. Better or worse? J Pharm Biomed Anal 165:381-385.

Keam SJ (2018) Inotersen: first global approval. Drugs 78:1371-1376.

Kelnar K, Peltier HJ, Leatherbury N, Stoudemire J, and Bader AG (2014) Quantification of therapeutic miRNA mimics in whole blood from nonhuman primates. Anal Chem 86:1534-1542. 
Keskin S, Brouwers CC, Sogorb-Gonzalez M, Martier R, Depla JA, Vallès A, van Deventer SJ, Konstantinova P, and Evers MM (2019) AAV5-miHTT lowers Huntingtin mRNA and protein without off-target effects in patient-derived neuronal cultures and astrocytes. Mol Ther Methods Clin Dev 15:275-284.

Khan N, Eliopoulos H, Han L, Kinane TB, Lowes LP, Mendell JR, Gordish-Dressman $\mathrm{H}$, Henricson EK, and McDonald CM; Eteplirsen Investigators and the CINRG DNHS Investigators (2019) Eteplirsen treatment attenuates respiratory decline in ambulatory and non-ambulatory patients with Duchenne muscular dystrophy. $J$ Neuromuscul Dis 6:213-225.

Khvorova A, Reynolds A, and Jayasena SD (2003) Functional siRNAs and miRNAs exhibit strand bias. Cell 115:209-216.

Khvorova A and Watts JK (2017) The chemical evolution of oligonucleotide therapies of clinical utility. Nat Biotechnol 35:238-248.

Kim DH, Behlke MA, Rose SD, Chang MS, Choi S, and Rossi JJ (2005) Synthetic dsRNA Dicer substrates enhance RNAi potency and efficacy. Nat Biotechnol 23 $222-226$.

Kim H, Kim ST, Ryu J, Kang BC, Kim JS, and Kim SG (2017) CRISPR/Cpf1-mediated DNA-free plant genome editing. Nat Commun 8:14406.

Kleinman ME, Yamada K, Takeda A, Chandrasekaran V, Nozaki M, Baffi JZ, Albuquerque RJ, Yamasaki S, Itaya M, Pan Y, et al. (2008) Sequence- and targetindependent angiogenesis suppression by siRNA via TLR3. Nature 452:591-597.

Kobayashi H, Eckhardt SG, Lockridge JA, Rothenberg ML, Sandler AB, O'Bryant CL, Cooper W, Holden SN, Aitchison RD, Usman N, et al. (2005) Safety and pharmacokinetic study of RPI.4610 (ANGIOZYME), an anti-VEGFR-1 ribozyme, in combination with carboplatin and paclitaxel in patients with advanced solid tumors. Cancer Chemother Pharmacol 56:329-336.

Kole R and Altman S (1979) Reconstitution of RNase P activity from inactive RNA and protein. Proc Natl Acad Sci USA 76:3795-3799.

Kole R, Krainer AR, and Altman S (2012) RNA therapeutics: beyond RNA interference and antisense oligonucleotides. Nat Rev Drug Discov 11:125-140.

Kondo $J$ (2012) A structural basis for the antibiotic resistance conferred by an A1408G mutation in 16S rRNA and for the antiprotozoal activity of aminoglycosides. Angew Chem Int Ed Engl 51:465-468.

Kowalski PS, Rudra A, Miao L, and Anderson DG (2019) Delivering the messenger: advances in technologies for therapeutic mRNA delivery. Mol Ther 27:710-728.

Kozomara A, Birgaoanu M, and Griffiths-Jones S (2019) miRBase: from microRNA sequences to function. Nucleic Acids Res 47:D155-D162.

Kozomara A and Griffiths-Jones S (2014) miRBase: annotating high confidence microRNAs using deep sequencing data. Nucleic Acids Res 42:D68-D73.

Kreth S, Hübner M, and Hinske LC (2018) MicroRNAs as clinical biomarkers and therapeutic tools in perioperative medicine. Anesth Analg 126:670-681.

Kruger K, Grabowski PJ, Zaug AJ, Sands J, Gottschling DE, and Cech TR (1982) Self-splicing RNA: autoexcision and autocyclization of the ribosomal RNA intervening sequence of Tetrahymena. Cell 31:147-157.

Kulinski T, Olejniczak M, Huthoff H, Bielecki L, Pachulska-Wieczorek K, Das AT, Berkhout B, and Adamiak RW (2003) The apical loop of the HIV-1 TAR RNA hairpin is stabilized by a cross-loop base pair. J Biol Chem 278:38892-38901.

Kuscu C, Kumar P, Kiran M, Su Z, Malik A, and Dutta A (2018) tRNA fragments (tRFs) guide Ago to regulate gene expression post-transcriptionally in a Dicerindependent manner. RNA 24:1093-1105.

Landen CN Jr., Chavez-Reyes A, Bucana C, Schmandt R, Deavers MT, LopezBerestein G, and Sood AK (2005) Therapeutic EphA2 gene targeting in vivo using neutral liposomal small interfering RNA delivery. Cancer Res 65:6910-6918.

Leal L, Guardo AC, Morón-López S, Salgado M, Mothe B, Heirman C, Pannus P, Vanham G, van den Ham HJ, Gruters R, et al.; iHIVARNA consortium (2018) Phase I clinical trial of an intranodally administered mRNA-based therapeutic vaccine against HIV-1 infection. AIDS 32:2533-2545.

Lee ER, Blount KF, and Breaker RR (2009) Roseoflavin is a natural antibacterial compound that binds to FMN riboswitches and regulates gene expression. RNA Biol 6:187-194

Lee MK, Bottini A, Kim M, Bardaro MF Jr., Zhang Z, Pellecchia M, Choi BS, and Varani G (2014) A novel small-molecule binds to the influenza A virus RNA promoter and inhibits viral replication. Chem Commun (Camb) 50:368-370.

Lee RC, Feinbaum RL, and Ambros V (1993) The C. elegans heterochronic gene lin-4 encodes small RNAs with antisense complementarity to lin-14. Cell 75:843-854.

Lee Y, Ahn C, Han J, Choi H, Kim J, Yim J, Lee J, Provost P, Rådmark O, Kim S, et al. (2003) The nuclear RNase III Drosha initiates microRNA processing. Nature 425:415-419.

Lee Y, Jeon K, Lee JT, Kim S, and Kim VN (2002) MicroRNA maturation: stepwise processing and subcellular localization. EMBO J 21:4663-4670.

Lee Y, Kim M, Han J, Yeom KH, Lee S, Baek SH, and Kim VN (2004) MicroRNA genes are transcribed by RNA polymerase II. EMBO J 23:4051-4060.

Lefebvre S, Bürglen L, Reboullet S, Clermont O, Burlet P, Viollet L, Benichou B, Cruaud C, Millasseau P, Zeviani M, et al. (1995) Identification and characterization of a spinal muscular atrophy-determining gene. Cell 80:155-165.

Le Grice SF (2015) Targeting the HIV RNA genome: high-hanging fruit only needs a longer ladder. Curr Top Microbiol Immunol 389:147-169.

Lennox KA and Behlke MA (2016) Cellular localization of long non-coding RNAs affects silencing by RNAi more than by antisense oligonucleotides. Nucleic Acids Res 44:863-877.

Letko M, Marzi A, and Munster V (2020) Functional assessment of cell entry and receptor usage for SARS-CoV-2 and other lineage B betacoronaviruses. Nat Microbiol 5:562-569.

Levin AA (2019) Treating disease at the RNA level with oligonucleotides. $N E n g l$ J Med 380:57-70.

Li J, Nakamori M, Matsumoto J, Murata A, Dohno C, Kiliszek A, Taylor K, Sobczak $\mathrm{K}$, and Nakatani K (2018a) A dimeric 2,9-diamino-1,10-phenanthroline derivative improves alternative splicing in myotonic dystrophy type 1 cell and mouse models. Chemistry 24:18115-18122.
Li MM, Addepalli B, Tu MJ, Chen QX, Wang WP, Limbach PA, LaSalle JM, Zeng S, Huang M, and Yu AM (2015) Chimeric microRNA-1291 biosynthesized efficiently in Escherichia coli is effective to reduce target gene expression in human carcinoma cells and improve chemosensitivity. Drug Metab Dispos 43:1129-1136.

Li MM, Wang WP, Wu WJ, Huang M, and Yu AM (2014) Rapid production of novel pre-microRNA agent hsa-mir-27b in Escherichia coli using recombinant RNA technology for functional studies in mammalian cells. Drug Metab Dispos 42: 1791-1795

Li PC, Tu MJ, Ho PY, Jilek JL, Duan Z, Zhang QY, Yu AX, and Yu AM (2018b) Bioengineered NRF2-siRNA is effective to interfere with NRF2 pathways and improve chemosensitivity of human cancer cells. Drug Metab Dispos 46:2-10.

Li X, Tian Y, Tu MJ, Ho PY, Batra N, and Yu AM (2019) Bioengineered miR-27b-3p and miR-328-3p modulate drug metabolism and disposition via the regulation of target ADME gene expression. Acta Pharm Sin B 9:639-647.

Li Y and Disney MD (2018) Precise small molecule degradation of a noncoding RNA identifies cellular binding sites and modulates an oncogenic phenotype. ACS Chem Biol 13:3065-3071.

Liang P, Xu Y, Zhang X, Ding C, Huang R, Zhang Z, Lv J, Xie X, Chen Y, Li Y, et al. (2015) CRISPR/Cas9-mediated gene editing in human tripronuclear zygotes. Protein Cell 6:363-372.

Lieberman J (2018) Tapping the RNA world for therapeutics. Nat Struct Mol Biol 25: $357-364$

Liebow A, Li X, Racie T, Hettinger J, Bettencourt BR, Najafian N, Haslett P, Fitzgerald K, Holmes RP, Erbe D, et al. (2017) An investigational RNAi therapeutic targeting glycolate oxidase reduces oxalate production in models of primary hyperoxaluria. J Am Soc Nephrol 28:494-503.

Light J and Molin S (1983) Post-transcriptional control of expression of the repA gene of plasmid R1 mediated by a small RNA molecule. EMBO J 2:93-98.

Limbach PA, Crain PF, and McCloskey JA (1994) Summary: the modified nucleosides of RNA. Nucleic Acids Res 22:2183-2196.

Lin J, Zhou D, Steitz TA, Polikanov YS, and Gagnon MG (2018) Ribosome-targeting antibiotics: modes of action, mechanisms of resistance, and implications for drug design. Annu Rev Biochem 87:451-478.

Lipfert J, Doniach S, Das R, and Herschlag D (2014) Understanding nucleic acid-ion interactions. Annu Rev Biochem 83:813-841.

Lipinski CA (2004) Lead- and drug-like compounds: the rule-of-five revolution. Drug Discov Today Technol 1:337-341.

Liu C, Kelnar K, Liu B, Chen X, Calhoun-Davis T, Li H, Patrawala L, Yan H, Jeter C, Honorio S, et al. (2011) The microRNA miR-34a inhibits prostate cancer stem cells and metastasis by directly repressing CD44. Nat Med 17:211-215.

Liu J, Carmell MA, Rivas FV, Marsden CG, Thomson JM, Song JJ, Hammond SM, Joshua-Tor L, and Hannon GJ (2004) Argonaute2 is the catalytic engine of mammalian RNAi. Science 305:1437-1441.

Liu J, Li J, Tran C, Aluri K, Zhang X, Clausen V, Zlatev I, Guan L, Chong S, Charisse $\mathrm{K}$, et al. (2019) Oligonucleotide quantification and metabolite profiling by highresolution and accurate mass spectrometry. Bioanalysis 11:1967-1980.

Long C, Amoasii L, Mireault AA, McAnally JR, Li H, Sanchez-Ortiz E, Bhattacharyya S, Shelton JM, Bassel-Duby R, and Olson EN (2016) Postnatal genome editing partially restores dystrophin expression in a mouse model of muscular dystrophy. Science 351:400-403.

Love KT, Mahon KP, Levins CG, Whitehead KA, Querbes W, Dorkin JR, Qin J, Cantley W, Qin LL, Racie T, et al. (2010) Lipid-like materials for low-dose, in vivo gene silencing. Proc Natl Acad Sci USA 107:1864-1869.

Ludwig H, Weisel K, Petrucci MT, Leleu X, Cafro AM, Garderet L, Leitgeb C, Foa R, Greil R, Yakoub-Agha I, et al. (2017) Olaptesed pegol, an anti-CXCL12/SDF-1 Spiegelmer, alone and with bortezomib-dexamethasone in relapsed/refractory multiple myeloma: a Phase IIa Study. Leukemia 31:997-1000.

Lukavsky PJ (2009) Structure and function of HCV IRES domains. Virus Res 139: $166-171$.

Lund E, Güttinger S, Calado A, Dahlberg JE, and Kutay U (2004) Nuclear export of microRNA precursors. Science 303:95-98

Luu LM, Nguyen L, Peng S, Lee J, Lee HY, Wong CH, Hergenrother PJ, Chan HY, and Zimmerman SC (2016) A potent inhibitor of protein sequestration by expanded triplet (CUG) repeats that shows phenotypic improvements in a Drosophila model of myotonic dystrophy. ChemMedChem 11:1428-1435

Lv H, Zhang S, Wang B, Cui S, and Yan J (2006) Toxicity of cationic lipids and cationic polymers in gene delivery. $J$ Control Release 114:100-109.

Lynch SR, Gonzalez RL, and Puglisi JD (2003) Comparison of X-ray crystal structure of the $30 \mathrm{~S}$ subunit-antibiotic complex with NMR structure of decoding site oligonucleotide-paromomycin complex. Structure 11:43-53.

Lynch SR and Puglisi JD (2001) Structural origins of aminoglycoside specificity for prokaryotic ribosomes. J Mol Biol 306:1037-1058.

Machin N and Ragni MV (2018) An investigational RNAi therapeutic targeting antithrombin for the treatment of hemophilia A and B. J Blood Med 9:135-140.

Makarova KS, Grishin NV, Shabalina SA, Wolf YI, and Koonin EV (2006) A putative RNA-interference-based immune system in prokaryotes: computational analysis of the predicted enzymatic machinery, functional analogies with eukaryotic RNAi, and hypothetical mechanisms of action. Biol Direct 1:7.

Mali P, Yang L, Esvelt KM, Aach J, Guell M, DiCarlo JE, Norville JE, and Church GM (2013) RNA-guided human genome engineering via Cas9. Science 339: 823-826.

Marciniak RA, Garcia-Blanco MA, and Sharp PA (1990) Identification and characterization of a HeLa nuclear protein that specifically binds to the trans-activationresponse (TAR) element of human immunodeficiency virus. Proc Natl Acad Sci USA 87:3624-3628.

Martinez J, Patkaniowska A, Urlaub H, Lührmann R, and Tuschl T (2002) Singlestranded antisense siRNAs guide target RNA cleavage in RNAi. Cell 110:563-574.

Martini PGV and Guey LT (2019) A new era for rare genetic diseases: messenger RNA therapy. Hum Gene Ther 30:1180-1189. 
Mashiko D, Fujihara Y, Satouh Y, Miyata H, Isotani A, and Ikawa M (2013) Generation of mutant mice by pronuclear injection of circular plasmid expressing Cas9 and single guided RNA. Sci Rep 3:3355.

Matranga C, Tomari Y, Shin C, Bartel DP, and Zamore PD (2005) Passenger-strand cleavage facilitates assembly of siRNA into Ago2-containing RNAi enzyme complexes. Cell 123:607-620.

Mattick JS (2004) RNA regulation: a new genetics? Nat Rev Genet 5:316-323.

Maus MV, Haas AR, Beatty GL, Albelda SM, Levine BL, Liu X, Zhao Y, Kalos M, and June CH (2013) T cells expressing chimeric antigen receptors can cause anaphylaxis in humans. Cancer Immunol Res 1:26-31.

Maute RL, Schneider C, Sumazin P, Holmes A, Califano A, Basso K, and DallaFavera R (2013) tRNA-derived microRNA modulates proliferation and the DNA damage response and is down-regulated in B cell lymphoma. Proc Natl Acad Sci USA 110:1404-1409.

McClorey G, Moulton HM, Iversen PL, Fletcher S, and Wilton SD (2006) Antisense oligonucleotide-induced exon skipping restores dystrophin expression in vitro in a canine model of DMD. Gene Ther 13:1373-1381.

McCown PJ, Corbino KA, Stav S, Sherlock ME, and Breaker RR (2017) Riboswitch diversity and distribution. RNA 23:995-1011.

McDonald CM, Campbell C, Torricelli RE, Finkel RS, Flanigan KM, Goemans N, Heydemann P, Kaminska A, Kirschner J, Muntoni F, et al.; Clinical Evaluator Training Group; ACT DMD Study Group (2017) Ataluren in patients with nonsense mutation Duchenne muscular dystrophy (ACT DMD): a multicentre, randomised, double-blind, placebo-controlled, phase 3 trial. Lancet 390: $1489-1498$.

McGinnis AC, Chen B, and Bartlett MG (2012) Chromatographic methods for the determination of therapeutic oligonucleotides. J Chromatogr B Analyt Technol Biomed Life Sci 883-884:76-94.

McGinnis AC, Cummings BS, and Bartlett MG (2013) Ion exchange liquid chromatography method for the direct determination of small ribonucleic acids. Anal Chim Acta 799:57-67.

McMahon MA, Prakash TP, Cleveland DW, Bennett CF, and Rahdar M (2018) Chemically modified Cpf1-CRISPR RNAs mediate efficient genome editing in mammalian cells. Mol Ther 26:1228-1240.

Mei HY, Mack DP, Galan AA, Halim NS, Heldsinger A, Loo JA, Moreland DW, Sannes-Lowery KA, Sharmeen L, Truong HN, et al. (1997) Discovery of selective, small-molecule inhibitors of RNA complexes--I. The Tat protein/TAR RNA complexes required for HIV-1 transcription. Bioorg Med Chem 5:1173-1184.

Meister G, Landthaler M, Patkaniowska A, Dorsett Y, Teng G, and Tuschl T (2004) Human Argonaute 2 mediates RNA cleavage targeted by miRNAs and siRNAs. $M o l$ Cell 15:185-197.

Mendell JR, Goemans N, Lowes LP, Alfano LN, Berry K, Shao J, Kaye EM, and Mercuri E; Eteplirsen Study Group and Telethon Foundation DMD Italian Network (2016) Longitudinal effect of eteplirsen versus historical control on ambulation in Duchenne muscular dystrophy. Ann Neurol 79·257-271.

Mendell JR, Rodino-Klapac LR, Sahenk Z, Roush K, Bird L, Lowes LP, Alfano L, Gomez AM, Lewis S, Kota J, et al.; Eteplirsen Study Group (2013) Eteplirsen for the treatment of Duchenne muscular dystrophy. Ann Neurol 74:637-647.

Mercuri E, Darras BT, Chiriboga CA, Day JW, Campbell C, Connolly AM, Iannaccone ST, Kirschner J, Kuntz NL, Saito K, et al.; CHERISH Study Group (2018) Nusinersen versus sham control in later-onset spinal muscular atrophy. $N$ Engl J Med 378:625-635.

Miglietta G, Cogoi S, Marinello J, Capranico G, Tikhomirov AS, Shchekotikhin A, and Xodo LE (2017) RNA G-quadruplexes in Kirsten Ras (KRAS) oncogene as targets for small molecules inhibiting translation. J Med Chem 60:9448-9461.

Miller JW (2019) Developing therapies for age-related macular degeneration: the art and science of problem-solving: the 2018 Charles L. Schepens, MD, Lecture. Ophthalmol Retina 3:900-909.

Milligan JF, Groebe DR, Witherell GW, and Uhlenbeck OC (1987) Oligoribonucleotide synthesis using T7 RNA polymerase and synthetic DNA templates. Nucleic Acids Res 15:8783-8798.

Miniarikova J, Zanella I, Huseinovic A, van der Zon T, Hanemaaijer E, Martier R, Koornneef A, Southwell AL, Hayden MR, van Deventer SJ, et al. (2016) Design, characterization, and lead selection of therapeutic miRNAs targeting Huntingtin for development of gene therapy for Huntington's disease. Mol Ther Nucleic Acids 5:e297.

Miniarikova J, Zimmer V, Martier R, Brouwers CC, Pythoud C, Richetin K, Rey M, Lubelski J, Evers MM, van Deventer SJ, et al. (2017) AAV5-miHTT gene therapy demonstrates suppression of mutant huntingtin aggregation and neuronal dysfunction in a rat model of Huntington's disease. Gene Ther 24:630-639.

Mironov AS, Gusarov I, Rafikov R, Lopez LE, Shatalin K, Kreneva RA, Perumov DA, and Nudler E (2002) Sensing small molecules by nascent RNA: a mechanism to control transcription in bacteria. Cell 111:747-756.

Morgan BS, Forte JE, Culver RN, Zhang Y, and Hargrove AE (2017) Discovery of key physicochemical, structural, and spatial properties of RNA-targeted bioactive ligands. Angew Chem Int Ed Engl 56:13498-13502.

Morgan BS, Forte JE, and Hargrove AE (2018) Insights into the development of chemical probes for RNA. Nucleic Acids Res 46:8025-8037.

Morrow PK, Murthy RK, Ensor JD, Gordon GS, Margolin KA, Elias AD, Urba WJ, Weng DE, Rugo HS, and Hortobagyi GN (2012) An open-label, phase 2 trial of RPI.4610 (Angiozyme) in the treatment of metastatic breast cancer. Cancer 118 4098-4104.

Morrow T (2013) For patients who inherit homozygous familial hypercholesterolemia, 2 new treatments available. Manag Care 22:47-48.

Mustoe AM, Busan S, Rice GM, Hajdin CE, Peterson BK, Ruda VM, Kubica N, Nutiu R, Baryza JL, and Weeks KM (2018) Pervasive regulatory functions of mRNA structure revealed by high-resolution SHAPE probing. Cell 173:181-195.e18.

Myasnikov AG, Kundhavai Natchiar S, Nebout M, Hazemann I, Imbert V, Khatter H, Peyron JF, and Klaholz BP (2016) Structure-function insights reveal the human ribosome as a cancer target for antibiotics. Nat Commun 7:12856.
Nahvi A, Sudarsan N, Ebert MS, Zou X, Brown KL, and Breaker RR (2002) Genetic control by a metabolite binding mRNA. Chem Biol 9:1043.

Nair JK, Attarwala H, Sehgal A, Wang Q, Aluri K, Zhang X, Gao M, Liu J, Indrakanti R, Schofield S, et al. (2017) Impact of enhanced metabolic stability on pharmacokinetics and pharmacodynamics of GalNAc-siRNA conjugates. Nucleic Acids Res 45:10969-10977.

Nair JK, Willoughby JL, Chan A, Charisse K, Alam MR, Wang Q, Hoekstra M, Kandasamy P, Kel'in AV, Milstein S, et al. (2014) Multivalent N-acetylgalactosamine-conjugated siRNA localizes in hepatocytes and elicits robust RNAi-mediated gene silencing. J Am Chem Soc 136:16958-16961.

Naito Y and Ui-Tei K (2012) siRNA design software for a target gene-specific RNA interference. Front Genet 3:102.

Nallagatla SR, Toroney R, and Bevilacqua PC (2008) A brilliant disguise for self RNA: 5 '-end and internal modifications of primary transcripts suppress elements of innate immunity. RNA Biol 5:140-144.

Nanjidsuren T, Park CW, Sim BW, Kim SU, Chang KT, Kang MH, and Min KS (2016) GRK5-knockout mice generated by TALEN-mediated gene targeting. Anim Biotechnol 27:223-230.

Naryshkin NA, Weetall M, Dakka A, Narasimhan J, Zhao X, Feng Z, Ling KK, Karp GM, Qi H, Woll MG, et al. (2014) Motor neuron disease. SMN2 splicing modifiers improve motor function and longevity in mice with spinal muscular atrophy. Science 345:688-693.

Neff CP, Zhou J, Remling L, Kuruvilla J, Zhang J, Li H, Smith DD, Swiderski P, Rossi JJ, and Akkina R (2011) An aptamer-siRNA chimera suppresses HIV-1 viral loads and protects from helper CD4(+) T cell decline in humanized mice. Sci Transl Med 3:66ra6.

Nelson CE, Hakim CH, Ousterout DG, Thakore PI, Moreb EA, Castellanos Rivera RM, Madhavan S, Pan X, Ran FA, Yan WX, et al. (2016) In vivo genome editing improves muscle function in a mouse model of Duchenne muscular dystrophy. Science 351:403-407.

Nguyen L, Luu LM, Peng S, Serrano JF, Chan HY, and Zimmerman SC (2015) Rationally designed small molecules that target both the DNA and RNA causing myotonic dystrophy type 1. J Am Chem Soc 137:14180-14189.

Nishizawa M, Ikeya Y, Okumura T, and Kimura T (2015) Post-transcriptional in ducible gene regulation by natural antisense RNA. Front Biosci 20:1-36.

Ogle JM, Brodersen DE, Clemons WM Jr., Tarry MJ, Carter AP, and Ramakrishnan V (2001) Recognition of cognate transfer RNA by the 30 S ribosomal subunit. Science 292:897-902.

Okamura K, Hagen JW, Duan H, Tyler DM, and Lai EC (2007) The mirtron pathway generates microRNA-class regulatory RNAs in Drosophila. Cell 130:89-100.

Okamura K, Ishizuka A, Siomi H, and Siomi MC (2004) Distinct roles for Argonaute proteins in small RNA-directed RNA cleavage pathways. Genes Dev 18:1655-1666. Ottesen EW (2017) ISS-N1 makes the first FDA-approved drug for spinal muscular atrophy. Transl Neurosci 8:1-6.

Paddison PJ, Caudy AA, Bernstein E, Hannon GJ, and Conklin DS (2002) Short hairpin RNAs (shRNAs) induce sequence-specific silencing in mammalian cells. Genes Dev 16:948-958.

Palacino J, Swalley SE, Song C, Cheung AK, Shu L, Zhang X, Van Hoosear M, Shin Y, Chin DN, Keller CG, et al. (2015) SMN2 splice modulators enhance U1-premRNA association and rescue SMA mice. Nat Chem Biol 11:511-517.

Pan YZ, Zhou A, Hu Z, and Yu AM (2013) Small nucleolar RNA-derived microRNA hsa-miR-1291 modulates cellular drug disposition through direct targeting of ABC transporter ABCC1. Drug Metab Dispos 41:1744-1751.

Papachristofilou A, Hipp MM, Klinkhardt U, Früh M, Sebastian M, Weiss C, Pless M, Cathomas R, Hilbe W, Pall G, et al. (2019) Phase Ib evaluation of a self-adjuvanted protamine formulated mRNA-based active cancer immunotherapy, BI1361849 CV9202), combined with local radiation treatment in patients with stage IV nonsmall cell lung cancer. $J$ Immunother Cancer 7:38.

Pardi N, Hogan MJ, Porter FW, and Weissman D (2018) mRNA vaccines - a new era in vaccinology. Nat Rev Drug Discov 17:261-279.

Park SJ, Kim YG, and Park HJ (2011) Identification of RNA pseudoknot-binding ligand that inhibits the -1 ribosomal frameshifting of SARS-coronavirus by structure-based virtual screening. J Am Chem Soc 133:10094-10100.

Parkesh R, Childs-Disney JL, Nakamori M, Kumar A, Wang E, Wang T, Hoskins J, Tran T, Housman D, Thornton CA, et al. (2012) Design of a bioactive small molecule that targets the myotonic dystrophy type 1 RNA via an RNA motif-ligand database and chemical similarity searching. J Am Chem Soc 134:4731-4742.

Pasi KJ, Rangarajan S, Georgiev P, Mant T, Creagh MD, Lissitchkov T, Bevan D, Austin S, Hay CR, Hegemann I, et al. (2017) Targeting of antithrombin in hemophilia A or B with RNAi therapy. $N$ Engl J Med 377:819-828.

Pastor F, Kolonias D, Giangrande PH, and Gilboa E (2010) Induction of tumour immunity by targeted inhibition of nonsense-mediated mRNA decay. Nature 465 : $227-230$.

Paulsen RB, Seth PP, Swayze EE, Griffey RH, Skalicky JJ, Cheatham TE III, and Davis DR (2010) Inhibitor-induced structural change in the HCV IRES domain IIa RNA. Proc Natl Acad Sci USA 107:7263-7268.

Pavco PA, Bouhana KS, Gallegos AM, Agrawal A, Blanchard KS, Grimm SL, Jensen KL, Andrews LE, Wincott FE, Pitot PA, et al. (2000) Antitumor and antimetastatic activity of ribozymes targeting the messenger RNA of vascular endothelial growth factor receptors. Clin Cancer Res 6:2094-2103.

Pelechano V and Steinmetz LM (2013) Gene regulation by antisense transcription. Nat Rev Genet 14:880-893.

Petersen CP, Bordeleau ME, Pelletier J, and Sharp PA (2006) Short RNAs repress translation after initiation in mammalian cells. Mol Cell 21:533-542.

Petrek H, Batra N, Ho PY, Tu MJ, and Yu AM (2019) Bioengineering of a single long noncoding RNA molecule that carries multiple small RNAs. Appl Microbiol Biotechnol 103:6107-6117.

Petrek H and Yu AM (2019) MicroRNAs in non-small cell lung cancer: gene regulation, impact on cancer cellular processes, and therapeutic potential. Pharmacol Res Perspect 7:e00528. 
Pflug A, Guilligay D, Reich S, and Cusack S (2014) Structure of influenza A polymerase bound to the viral RNA promoter. Nature 516:355-360.

Pillai RS, Bhattacharyya SN, Artus CG, Zoller T, Cougot N, Basyuk E, Bertrand E, and Filipowicz W (2005) Inhibition of translational initiation by Let-7 MicroRNA in human cells. Science 309:1573-1576.

Plant EP, Pérez-Alvarado GC, Jacobs JL, Mukhopadhyay B, Hennig M, and Dinman JD (2005) A three-stemmed mRNA pseudoknot in the SARS coronavirus frameshift signal. PLoS Biol 3:e172.

Pogribny IP (2018) MicroRNAs as biomarkers for clinical studies. Exp Biol Med (Maywood) 243:283-290.

Poirier A, Weetall M, Heinig K, Bucheli F, Schoenlein K, Alsenz J, Bassett S, Ullah M, Senn C, Ratni H, et al. (2018) Risdiplam distributes and increases SMN protein in both the central nervous system and peripheral organs. Pharmacol Res Perspect 6:e00447.

Poirot L, Philip B, Schiffer-Mannioui C, Le Clerre D, Chion-Sotinel I, Derniame S, Potrel P, Bas C, Lemaire L, Galetto R, et al. (2015) Multiplex genome-edited T-cell manufacturing platform for "off-the-shelf" adoptive T-cell immunotherapies. Cancer Res 75:3853-3864.

Ponchon L, Beauvais G, Nonin-Lecomte S, and Dardel F (2009) A generic protocol for the expression and purification of recombinant RNA in Escherichia coli using a tRNA scaffold. Nat Protoc 4:947-959.

Ponchon L and Dardel F (2007) Recombinant RNA technology: the tRNA scaffold. Nat Methods 4:571-576.

Popplewell LJ, Adkin C, Arechavala-Gomeza V, Aartsma-Rus A, de Winter CL, Wilton SD, Morgan JE, Muntoni F, Graham IR, and Dickson G (2010) Comparative analysis of antisense oligonucleotide sequences targeting exon 53 of the human DMD gene: implications for future clinical trials. Neuromuscul Disord 20:102-110.

Post N, Yu R, Greenlee S, Gaus H, Hurh E, Matson J, and Wang Y (2019) Metabolism and disposition of volanesorsen, a 2'-O-(2 methoxyethyl) antisense oligonucleotide, across species. Drug Metab Dispos 47:1164-1173.

Prado S, Beltrán M, Coiras M, Bedoya LM, Alcamí J, and Gallego J (2016) Bioavailable inhibitors of HIV-1 RNA biogenesis identified through a Rev-based screen. Biochem Pharmacol 107:14-28.

Pramanik D, Campbell NR, Karikari C, Chivukula R, Kent OA, Mendell JT, and Maitra A (2011) Restitution of tumor suppressor microRNAs using a systemic nanovector inhibits pancreatic cancer growth in mice. Mol Cancer Ther 10: $1470-1480$.

Qurashi A, Liu H, Ray L, Nelson DL, Duan R, and Jin P (2012) Chemical screen reveals small molecules suppressing fragile $\mathrm{X}$ premutation $\mathrm{rCGG}$ repeat-mediated neurodegeneration in Drosophila. Hum Mol Genet 21:2068-2075.

Rahdar M, McMahon MA, Prakash TP, Swayze EE, Bennett CF, and Cleveland DW (2015) Synthetic CRISPR RNA-Cas9-guided genome editing in human cells. Proc Natl Acad Sci USA 112:E7110-E7117.

Ramot Y, Rotkopf S, Gabai RM, Zorde Khvalevsky E, Muravnik S, Marzoli GA, Domb AJ, Shemi A, and Nyska A (2016) Preclinical safety evaluation in rats of a polymeric matrix containing an siRNA drug used as a local and prolonged delivery system for pancreatic cancer therapy. Toxicol Pathol 44:856-865.

Rand TA, Ginalski K, Grishin NV, and Wang X (2004) Biochemical identification of Argonaute 2 as the sole protein required for RNA-induced silencing complex activity. Proc Natl Acad Sci USA 101:14385-14389.

Rand TA, Petersen S, Du F, and Wang X (2005) Argonaute2 cleaves the anti-guide strand of siRNA during RISC activation. Cell 123:621-629.

Rao DD, Jay C, Wang Z, Luo X, Kumar P, Eysenbach H, Ghisoli M, Senzer N, and Nemunaitis J (2016) Preclinical Justification of pbi-shRNA EWS/FLI1 Lipoplex (LPX) Treatment for Ewing's Sarcoma. Mol Ther 24:1412-1422.

Ratni H, Ebeling M, Baird J, Bendels S, Bylund J, Chen KS, Denk N, Feng Z, Green L, Guerard M, et al. (2018) Discovery of risdiplam, a selective survival of motor neuron-2 ( SMN2) gene splicing modifier for the treatment of spinal muscular atrophy (SMA). J Med Chem 61:6501-6517.

Ratni H, Karp GM, Weetall M, Naryshkin NA, Paushkin SV, Chen KS, McCarthy KD, Qi H, Turpoff A, Woll MG, et al. (2016) Specific correction of alternative survival motor neuron 2 splicing by small molecules: discovery of a potential novel medicine to treat spinal muscular atrophy. J Med Chem 59:6086-6100.

Ray KK, Landmesser U, Leiter LA, Kallend D, Dufour R, Karakas M, Hall T, Troquay RP, Turner T, Visseren FL, et al. (2017) Inclisiran in patients at high cardiovascular risk with elevated LDL cholesterol. N Engl J Med 376:1430-1440.

Ray KK, Stoekenbroek RM, Kallend D, Nishikido T, Leiter LA, Landmesser U, Wright RS, Wijngaard PLJ, and Kastelein JJP (2019) Effect of 1 or 2 doses of inclisiran on low-density lipoprotein cholesterol levels: one-year follow-up of the ORION-1 randomized clinical trial. JAMA Cardiol 4:1067-1075.

Ray PS, Jia J, Yao P, Majumder M, Hatzoglou M, and Fox PL (2009) A stressresponsive RNA switch regulates VEGFA expression. Nature 457:915-919.

Ren A, Wang XC, Kellenberger CA, Rajashankar KR, Jones RA, Hammond MC, and Patel DJ (2015) Structural basis for molecular discrimination by a $3^{\prime}, 3^{\prime}$ cGAMP sensing riboswitch. Cell Rep 11:1-12.

Ren J, Liu X, Fang C, Jiang S, June CH, and Zhao Y (2017) Multiplex genome editing to generate universal CAR T cells resistant to PD1 inhibition. Clin Cancer Res 23 $2255-2266$.

Rezaee M, Oskuee RK, Nassirli H, and Malaekeh-Nikouei B (2016) Progress in the development of lipopolyplexes as efficient non-viral gene delivery systems. $J$ Control Release 236:1-14.

Rigo F, Chun SJ, Norris DA, Hung G, Lee S, Matson J, Fey RA, Gaus H, Hua Y, Grundy JS, et al. (2014) Pharmacology of a central nervous system delivered 2'-Omethoxyethyl-modified survival of motor neuron splicing oligonucleotide in mice and nonhuman primates. J Pharmacol Exp Ther 350:46-55.

Ritchie DB, Soong J, Sikkema WK, and Woodside MT (2014) Anti-frameshifting ligand reduces the conformational plasticity of the SARS virus pseudoknot. J Am Chem Soc 136:2196-2199.

Ritchie TJ and Macdonald SJ (2014) How drug-like are 'ugly' drugs: do drug-likeness metrics predict ADME behaviour in humans? Drug Discov Today 19:489-495.
Rittig SM, Haentschel M, Weimer KJ, Heine A, Muller MR, Brugger W, Horger MS, Maksimovic O, Stenzl A, Hoerr I, et al (2011) Intradermal vaccinations with RNA coding for TAA generate CD8+ and CD4+ immune responses and induce clinical benefit in vaccinated patients. Mol Ther 19:990-999.

Rizvi NF, Howe JA, Nahvi A, Klein DJ, Fischmann TO, Kim HY, McCoy MA, Walker SS, Hruza A, Richards MP, et al. (2018) Discovery of selective RNA-binding small molecules by affinity-selection mass spectrometry. ACS Chem Biol 13:820-831.

Robbins M, Judge A, Liang L, McClintock K, Yaworski E, and MacLachlan I (2007) 2'-O-methyl-modified RNAs act as TLR7 antagonists. Mol Ther 15:1663-1669.

Robertson DL and Joyce GF (1990) Selection in vitro of an RNA enzyme that specifically cleaves single-stranded DNA. Nature 344:467-468.

Robinson JG (2013) Management of familial hypercholesterolemia: a review of the recommendations from the National Lipid Association Expert Panel on Familial Hypercholesterolemia. J Manag Care Pharm 19:139-149.

Roccaro AM, Sacco A, Purschke WG, Moschetta M, Buchner K, Maasch C, Zboralski D, Zöllner S, Vonhoff S, Mishima Y, et al. (2014) SDF-1 inhibition targets the bone marrow niche for cancer therapy. Cell Rep 9:118-128.

Rock BM and Foti RS (2019) Pharmacokinetic and drug metabolism properties of novel therapeutic modalities. Drug Metab Dispos 47:1097-1099.

Roehr B (1998) Fomivirsen approved for CMV retinitis. J Int Assoc Physicians AIDS Care 4:14-16.

Roy B, Friesen WJ, Tomizawa Y, Leszyk JD, Zhuo J, Johnson B, Dakka J, Trotta CR, Xue X, Mutyam V, et al. (2016) Ataluren stimulates ribosomal selection of near-cognate tRNAs to promote nonsense suppression. Proc Natl Acad Sci USA 113:12508-12513.

Ruby JG, Jan CH, and Bartel DP (2007) Intronic microRNA precursors that bypass Drosha processing. Nature 448:83-86.

Rupaimoole R and Slack FJ (2017) MicroRNA therapeutics: towards a new era for the management of cancer and other diseases. Nat Rev Drug Discov 16:203-222.

Ryan NJ (2014) Ataluren: first global approval. Drugs 74:1709-1714.

Rzuczek SG, Colgan LA, Nakai Y, Cameron MD, Furling D, Yasuda R, and Disney MD (2017) Precise small-molecule recognition of a toxic CUG RNA repeat expansion. Nat Chem Biol 13:188-193.

Sahel DK, Mittal A, and Chitkara D (2019) CRISPR/Cas system for genome editing: progress and prospects as a therapeutic tool. J Pharmacol Exp Ther 370:725-735. Sahin U, Karikó K, and Türeci Ö (2014) mRNA-based therapeutics--developing a new class of drugs. Nat Rev Drug Discov 13:759-780.

Salehi-Ashtiani K, Lupták A, Litovchick A, and Szostak JW (2006) A genomewide search for ribozymes reveals an HDV-like sequence in the human CPEB3 gene. Science 313:1788-1792.

Santer L, Bär C, and Thum T (2019) Circular RNAs: a novel class of functional RNA molecules with a therapeutic perspective. Mol Ther 27:1350-1363.

Santos R, Ursu O, Gaulton A, Bento AP, Donadi RS, Bologa CG, Karlsson A, AlLazikani B, Hersey A, Oprea TI, et al. (2017) A comprehensive map of molecular drug targets. Nat Rev Drug Discov 16:19-34.

Sardh E, Harper P, Balwani M, Stein P, Rees D, Bissell DM, Desnick R, Parker C, Phillips J, Bonkovsky HL, et al. (2019) Phase 1 trial of an RNA interference therapy for acute intermittent porphyria. N Engl J Med 380:549-558.

Schäfer J, Höbel S, Bakowsky U, and Aigner A (2010) Liposome-polyethylenimine complexes for enhanced DNA and siRNA delivery. Biomaterials 31:6892-6900.

Schedlbauer A, Kaminishi T, Ochoa-Lizarralde B, Dhimole N, Zhou S, López-Alonso JP, Connell SR, and Fucini P (2015) Structural characterization of an alternative mode of tigecycline binding to the bacterial ribosome. Antimicrob Agents Chemother 59:2849-2854.

Scherer LJ and Rossi JJ (2003) Approaches for the sequence-specific knockdown of mRNA. Nat Biotechnol 21:1457-1465.

Schlake T, Thran M, Fiedler K, Heidenreich R, Petsch B, and Fotin-Mleczek M (2019) mRNA: a novel avenue to antibody therapy? Mol Ther 27:773-784.

Schlick T (2018) Adventures with RNA graphs. Methods 143:16-33.

Schwarz DS, Hutvágner G, Du T, Xu Z, Aronin N, and Zamore PD (2003) Asymmetry in the assembly of the RNAi enzyme complex. Cell 115:199-208.

Schwoebel F, van Eijk LT, Zboralski D, Sell S, Buchner K, Maasch C, Purschke WG, Humphrey M, Zöllner S, Eulberg D, et al. (2013) The effects of the anti-hepcidin Spiegelmer NOX-H94 on inflammation-induced anemia in cynomolgus monkeys. Blood 121:2311-2315.

Scott LJ (2020) Givosiran: first approval. Drugs 80:335-339.

Semizarov D, Frost L, Sarthy A, Kroeger P, Halbert DN, and Fesik SW (2003) Specificity of short interfering RNA determined through gene expression signatures. Proc Natl Acad Sci USA 100:6347-6352.

Serganov A, Huang L, and Patel DJ (2009) Coenzyme recognition and gene regulation by a flavin mononucleotide riboswitch. Nature 458:233-237.

Serganov A and Nudler E (2013) A decade of riboswitches. Cell 152:17-24.

Seth PP, Miyaji A, Jefferson EA, Sannes-Lowery KA, Osgood SA, Propp SS, Ranken R, Massire C, Sampath R, Ecker DJ, et al. (2005) SAR by MS: discovery of a new class of RNA-binding small molecules for the hepatitis $\mathrm{C}$ virus: internal ribosome entry site IIA subdomain. $J$ Med Chem 48:7099-7102.

Setten RL, Rossi JJ, and Han SP (2019) The current state and future directions of RNAi-based therapeutics. Nat Rev Drug Discov 18:421-446.

Simoens S and Huys I (2017) Market access of Spinraza (Nusinersen) for spinal muscular atrophy: intellectual property rights, pricing, value and coverage considerations. Gene Ther 24:539-541.

Simone R, Balendra R, Moens TG, Preza E, Wilson KM, Heslegrave A, Woodling NS, Niccoli T, Gilbert-Jaramillo J, Abdelkarim S, et al. (2018) G-quadruplex-binding small molecules ameliorate C9orf72 FTD/ALS pathology in vitro and in vivo. EMBO Mol Med 10:22-31.

Simons RW and Kleckner N (1983) Translational control of IS10 transposition. Cell 34:683-691.

Sivaramakrishnan M, McCarthy KD, Campagne S, Huber S, Meier S, Augustin A Heckel T, Meistermann H, Hug MN, Birrer P, et al. (2017) Binding to SMN2 premRNA-protein complex elicits specificity for small molecule splicing modifiers. Nat Commun 8:1476. 
Spiegelman WG, Reichardt LF, Yaniv M, Heinemann SF, Kaiser AD, and Eisen H (1972) Bidirectional transcription and the regulation of Phage lambda repressor synthesis. Proc Natl Acad Sci USA 69:3156-3160.

Stark BC, Kole R, Bowman EJ, and Altman S (1978) Ribonuclease P: an enzyme with an essential RNA component. Proc Natl Acad Sci USA 75:3717-3721.

Stein CA (2016) Eteplirsen approved for Duchenne muscular dystrophy: the FDA faces a difficult choice. $M o l$ Ther 24:1884-1885.

Stein CA and Castanotto D (2017) FDA-approved oligonucleotide therapies in 2017. Mol Ther 25:1069-1075.

Stein EA, Dufour R, Gagne C, Gaudet D, East C, Donovan JM, Chin W, Tribble DL, and McGowan M (2012) Apolipoprotein B synthesis inhibition with mipomersen in heterozygous familial hypercholesterolemia: results of a randomized, double-blind, placebo-controlled trial to assess efficacy and safety as add-on therapy in patients with coronary artery disease. Circulation 126:2283-2292.

Steitz TA (2008) A structural understanding of the dynamic ribosome machine. Nat Rev Mol Cell Biol 9:242-253.

Stelzer AC, Frank AT, Kratz JD, Swanson MD, Gonzalez-Hernandez MJ, Lee J, Andricioaei I, Markovitz DM, and Al-Hashimi HM (2011) Discovery of selective bioactive small molecules by targeting an RNA dynamic ensemble. Nat Chem Biol 7:553-559.

Stephenson ML and Zamecnik PC (1978) Inhibition of Rous sarcoma viral RNA translation by a specific oligodeoxyribonucleotide. Proc Natl Acad Sci USA $\mathbf{7 5}$ $285-288$

Steurer M, Montillo M, Scarfô L, Mauro FR, Andel J, Wildner S, Trentin L, Janssens A, Burgstaller S, Frömming A, et al. (2019) Olaptesed pegol (NOX-A12) with bendamustine and rituximab: a phase IIa study in patients with relapsed/refractory chronic lymphocytic leukemia. Haematologica 104:2053-2060.

Stevens M, De Clercq E, and Balzarini J (2006) The regulation of HIV-1 transcription: molecular targets for chemotherapeutic intervention. Med Res Rev 26 $595-625$

Strapps WR, Pickering V, Muiru GT, Rice J, Orsborn S, Polisky BA, Sachs A and Bartz SR (2010) The siRNA sequence and guide strand overhangs are determinants of in vivo duration of silencing. Nucleic Acids Res 38:4788-4797.

Sturm S, Günther A, Jaber B, Jordan P, Al Kotbi N, Parkar N, Cleary Y, Frances N, Bergauer T, Heinig K, et al. (2019) A phase 1 healthy male volunteer single escalating dose study of the pharmacokinetics and pharmacodynamics of risdiplam (RG7916, RO7034067), a SMN2 splicing modifier. Br J Clin Pharmacol 85 181-193.

Su MC, Chang CT, Chu CH, Tsai CH, and Chang KY (2005) An atypical RNA pseudoknot stimulator and an upstream attenuation signal for -1 ribosomal frameshifting of SARS coronavirus. Nucleic Acids Res 33:4265-4275.

Su Z, Zhang Y, Gendron TF, Bauer PO, Chew J, Yang WY, Fostvedt E, Jansen-West K, Belzil VV, Desaro P, et al. (2014) Discovery of a biomarker and lead small molecules to target r(GGGGCC)-associated defects in c9FTD/ALS. Neuron $\mathbf{8 3}$ $1043-1050$

Sudarsan N, Cohen-Chalamish S, Nakamura S, Emilsson GM, and Breaker RR (2005) Thiamine pyrophosphate riboswitches are targets for the antimicrobial compound pyrithiamine. Chem Biol 12:1325-1335.

Sudarsan N, Wickiser JK, Nakamura S, Ebert MS, and Breaker RR (2003) An mRNA structure in bacteria that controls gene expression by binding lysine. Genes Dev 17: 2688-2697.

Summerton JE (2017) Invention and early history of morpholinos: from pipe dream to practical products. Methods Mol Biol 1565:1-15.

Svitkin YV, Cheng YM, Chakraborty T, Presnyak V, John M, and Sonenberg N (2017) N1-methyl-pseudouridine in mRNA enhances translation through eIF2 $\alpha$ dependent and independent mechanisms by increasing ribosome density. Nucleic Acids Res 45:6023-6036.

Syed YY (2016) Eteplirsen: first global approval. Drugs 76:1699-1704.

Szebeni J, Simberg D, González-Fernández Á, Barenholz Y, and Dobrovolskaia MA (2018) Roadmap and strategy for overcoming infusion reactions to nanomedicines. Nat Nanotechnol 13:1100-1108.

Sztuba-Solinska J, Shenoy SR, Gareiss P, Krumpe LR, Le Grice SF, O'Keefe BR, and Schneekloth JS Jr. (2014) Identification of biologically active, HIV TAR RNA binding small molecules using small molecule microarrays. J Am Chem Soc 136 $8402-8410$

Tabebordbar M, Zhu K, Cheng JKW, Chew WL, Widrick JJ, Yan WX, Maesner C, Wu $\mathrm{EY}$, Xiao R, Ran FA, et al. (2016) In vivo gene editing in dystrophic mouse muscle and muscle stem cells. Science 351:407-411.

Tan W, Carlson DF, Lancto CA, Garbe JR, Webster DA, Hackett PB, and Fahrenkrug SC (2013) Efficient nonmeiotic allele introgression in livestock using custom endonucleases. Proc Natl Acad Sci USA 110:16526-16531.

Tanji H, Ohto U, Shibata T, Taoka M, Yamauchi Y, Isobe T, Miyake K, and Shimizu T (2015) Toll-like receptor 8 senses degradation products of single-stranded RNA Nat Struct Mol Biol 22:109-115.

Thayer MB, Lade JM, Doherty D, Xie F, Basiri B, Barnaby OS, Bala NS, and Rock BM (2019) Application of locked nucleic acid oligonucleotides for siRNA preclinical bioanalytics. Sci Rep 9:3566.

Thomas GS, Cromwell WC, Ali S, Chin W, Flaim JD, and Davidson M (2013) Mipomersen, an apolipoprotein B synthesis inhibitor, reduces atherogenic lipoproteins in patients with severe hypercholesterolemia at high cardiovascular risk: a randomized, double-blind, placebo-controlled trial. J Am Coll Cardiol 62 $2178-2184$

Tibbitt MW, Dahlman JE, and Langer R (2016) Emerging frontiers in drug delivery. $J$ Am Chem Soc 138:704-717.

Tu D, Blaha G, Moore PB, and Steitz TA (2005) Structures of MLSBK antibiotics bound to mutated large ribosomal subunits provide a structural explanation for resistance. Cell 121:257-270.

Tu MJ, Ho PY, Zhang QY, Jian C, Qiu JX, Kim EJ, Bold RJ, Gonzalez FJ, Bi H, and Yu AM (2019) Bioengineered miRNA-1291 prodrug therapy in pancreatic cancer cells and patient-derived xenograft mouse models. Cancer Lett 442:82-90.
Tucker BJ and Breaker RR (2005) Riboswitches as versatile gene control elements. Curr Opin Struct Biol 15:342-348.

Tuerk C and Gold L (1990) Systematic evolution of ligands by exponential enrichment: RNA ligands to bacteriophage T4 DNA polymerase. Science 249:505-510.

Ui-Tei K, Naito Y, Nishi K, Juni A, and Saigo K (2008) Thermodynamic stability and Watson-Crick base pairing in the seed duplex are major determinants of the efficiency of the siRNA-based off-target effect. Nucleic Acids Res 36:7100-7109.

Usmani SS, Bedi G, Samuel JS, Singh S, Kalra S, Kumar P, Ahuja AA, Sharma M, Gautam A, and Raghava GPS (2017) THPdb: database of FDA-approved peptide and protein therapeutics. PLoS One 12:e0181748.

van Deutekom JC, Janson AA, Ginjaar IB, Frankhuizen WS, Aartsma-Rus A Bremmer-Bout M, den Dunnen JT, Koop K, van der Kooi AJ, Goemans NM, et al. (2007) Local dystrophin restoration with antisense oligonucleotide PRO051. $N$ Engl J Med 357:2677-2686.

Van Gulck E, Vlieghe E, Vekemans M, Van Tendeloo VF, Van De Velde A, Smits E, Anguille S, Cools N, Goossens H, Mertens L, et al. (2012) mRNA-based dendritic cell vaccination induces potent antiviral T-cell responses in HIV-1-infected patients. AIDS 26:F1-F12.

Vanhée-Brossollet C and Vaquero C (1998) Do natural antisense transcripts make sense in eukaryotes? Gene 211:1-9.

Vannuffel P and Cocito C (1996) Mechanism of action of streptogramins and macrolides. Drugs 51 (Suppl 1):20-30.

Vater A and Klussmann S (2015) Turning mirror-image oligonucleotides into drugs: the evolution of Spiegelmer(®) therapeutics. Drug Discov Today 20:147-155.

Velagapudi SP, Cameron MD, Haga CL, Rosenberg LH, Lafitte M, Duckett DR, Phinney DG, and Disney MD (2016) Design of a small molecule against an oncogenic noncoding RNA. Proc Natl Acad Sci USA 113:5898-5903.

Velagapudi SP, Costales MG, Vummidi BR, Nakai Y, Angelbello AJ, Tran T, Haniff HS, Matsumoto Y, Wang ZF, Chatterjee AK, et al. (2018) Approved anti-cancer drugs target oncogenic non-coding RNAs. Cell Chem Biol 25:1086-1094.e7.

Velagapudi SP, Gallo SM, and Disney MD (2014) Sequence-based design of bioactive small molecules that target precursor microRNAs. Nat Chem Biol 10: 291-297.

Vickers TA, Koo S, Bennett CF, Crooke ST, Dean NM, and Baker BF (2003) Efficient reduction of target RNAs by small interfering RNA and RNase H-dependent antisense agents. A comparative analysis. J Biol Chem 278:7108-7118.

Vogel WH (2010) Infusion reactions: diagnosis, assessment, and management. Clin J Oncol Nurs 14:E10-E21.

Wagner MJ, Mitra R, McArthur MJ, Baze W, Barnhart K, Wu SY, Rodriguez-Aguayo C, Zhang X, Coleman RL, Lopez-Berestein G, et al. (2017) Preclinical mammalian safety studies of EPHARNA (DOPC nanoliposomal EphA2-targeted siRNA). Mol Cancer Ther 16:1114-1123.

Wakelin LP (1986) Polyfunctional DNA intercalating agents. Med Res Rev 6:275-340 Wang H, Mann PA, Xiao L, Gill C, Galgoci AM, Howe JA, Villafania A, Barbieri CM, Malinverni JC, Sher X, et al. (2017) Dual-targeting small-molecule inhibitors of the Staphylococcus aureus FMN riboswitch disrupt riboflavin homeostasis in an infectious setting. Cell Chem Biol 24:576-588.e6.

Wang H, Yang H, Shivalila CS, Dawlaty MM, Cheng AW, Zhang F, and Jaenisch R (2013) One-step generation of mice carrying mutations in multiple genes by CRISPR/Cas-mediated genome engineering. Cell 153:910-918.

Wang J, Exline CM, DeClercq JJ, Llewellyn GN, Hayward SB, Li PW, Shivak DA, Surosky RT, Gregory PD, Holmes MC, et al. (2015a) Homology-driven genome editing in hematopoietic stem and progenitor cells using ZFN mRNA and AAV6 donors. Nat Biotechnol 33:1256-1263.

Wang L and Ji C (2016) Advances in quantitative bioanalysis of oligonucleotide biomarkers and therapeutics. Bioanalysis 8:143-155.

Wang M, Zuris JA, Meng F, Rees H, Sun S, Deng P, Han Y, Gao X, Pouli D, Wu Q, et al. (2016) Efficient delivery of genome-editing proteins using bioreducible lipid nanoparticles. Proc Natl Acad Sci USA 113:2868-2873.

Wang WP, Ho PY, Chen QX, Addepalli B, Limbach PA, Li MM, Wu WJ, Jilek JL, Qiu JX, Zhang HJ, et al. (2015b) Bioengineering novel chimeric microRNA-34a for prodrug cancer therapy: high-yield expression and purification, and structural and functional characterization. J Pharmacol Exp Ther 354:131-141.

Wang X, Wang X, Varma RK, Beauchamp L, Magdaleno S, and Sendera TJ (2009) Selection of hyperfunctional siRNAs with improved potency and specificity. Nucleic Acids Res 37:e152.

Warner KD, Hajdin CE, and Weeks KM (2018) Principles for targeting RNA with drug-like small molecules. Nat Rev Drug Discov 17:547-558.

Warner KD, Homan P, Weeks KM, Smith AG, Abell C, and Ferré-D’Amaré AR (2014) Validating fragment-based drug discovery for biological RNAs: lead fragments bind and remodel the TPP riboswitch specifically. Chem Biol 21:591-595.

Watanabe A, Nakajima M, Kasuya T, Onishi R, Kitade N, Mayumi K, Ikehara T, and Kugimiya A (2016) Comparative characterization of hepatic distribution and mRNA reduction of antisense oligonucleotides conjugated with triantennary $\mathrm{N}$-acetyl galactosamine and lipophilic ligands targeting apolipoprotein B. J Pharmacol Exp Ther 357:320-330.

Wefers B, Panda SK, Ortiz O, Brandl C, Hensler S, Hansen J, Wurst W, and Kühn R (2013) Generation of targeted mouse mutants by embryo microinjection of TALEN mRNA. Nat Protoc 8:2355-2379.

Weide B, Pascolo S, Scheel B, Derhovanessian E, Pflugfelder A, Eigentler TK, Pawelec G, Hoerr I, Rammensee HG, and Garbe C (2009) Direct injection of protamine-protected mRNA: results of a phase $1 / 2$ vaccination trial in metastatic melanoma patients. $J$ Immunother 32:498-507.

Weissman D and Karikó K (2015) mRNA: fulfilling the promise of gene therapy. Mol Ther 23:1416-1417.

Weissman D, Ni H, Scales D, Dude A, Capodici J, McGibney K, Abdool A, Isaacs SN, Cannon G, and Karikó K (2000) HIV gag mRNA transfection of dendritic cells (DC) delivers encoded antigen to MHC class I and II molecules, causes DC maturation, and induces a potent human in vitro primary immune response. J Immunol 165: $4710-4717$ 
Wheeler TM, Leger AJ, Pandey SK, MacLeod AR, Nakamori M, Cheng SH, Wentworth BM, Bennett CF, and Thornton CA (2012) Targeting nuclear RNA for in vivo correction of myotonic dystrophy. Nature 488:111-115.

Wiggins JF, Ruffino L, Kelnar K, Omotola M, Patrawala L, Brown D, and Bader AG (2010) Development of a lung cancer therapeutic based on the tumor suppressor microRNA-34. Cancer Res 70:5923-5930.

Wightman B, Ha I, and Ruvkun G (1993) Posttranscriptional regulation of the heterochronic gene lin-14 by lin-4 mediates temporal pattern formation in C. elegans. Cell 75:855-862.

Wilber A, Frandsen JL, Geurts JL, Largaespada DA, Hackett PB, and McIvor RS (2006) RNA as a source of transposase for Sleeping Beauty-mediated gene insertion and expression in somatic cells and tissues. Mol Ther 13:625-630.

Wilgenhof S, Van Nuffel AM, Benteyn D, Corthals J, Aerts C, Heirman C, Van Riet I, Bonehill A, Thielemans K, and Neyns B (2013) A phase IB study on intravenous synthetic mRNA electroporated dendritic cell immunotherapy in pretreated advanced melanoma patients. Ann Oncol 24:2686-2693.

Wilson DN (2009) The A-Z of bacterial translation inhibitors. Crit Rev Biochem Mol Biol 44:393-433.

Wilson DN (2014) Ribosome-targeting antibiotics and mechanisms of bacterial resistance. Nat Rev Microbiol 12:35-48.

Wilson DN, Schluenzen F, Harms JM, Starosta AL, Connell SR, and Fucini P (2008) The oxazolidinone antibiotics perturb the ribosomal peptidyl-transferase center and effect tRNA positioning. Proc Natl Acad Sci USA 105:13339-13344.

Winkler W, Nahvi A, and Breaker RR (2002a) Thiamine derivatives bind messenger RNAs directly to regulate bacterial gene expression. Nature 419: 952-956.

Winkler WC, Cohen-Chalamish S, and Breaker RR (2002b) An mRNA structure that controls gene expression by binding FMN. Proc Natl Acad Sci USA 99 15908-15913.

Wolff JA, Malone RW, Williams P, Chong W, Acsadi G, Jani A, and Felgner PL (1990) Direct gene transfer into mouse muscle in vivo. Science 247:1465-1468.

Wood AJ, Lo TW, Zeitler B, Pickle CS, Ralston EJ, Lee AH, Amora R, Miller JC, Leung E, Meng X, et al. (2011) Targeted genome editing across species using ZFNs and TALENs. Science 333:307.

Wood H (2018) FDA approves patisiran to treat hereditary transthyretin amyloidosis. Nat Rev Neurol 14:570.

Wright RS, Collins MG, Stoekenbroek RM, Robson R, Wijngaard PLJ, Landmesser U, Leiter LA, Kastelein JJP, Ray KK, and Kallend D (2020) Effects of renal impairment on the pharmacokinetics, efficacy, and safety of inclisiran: an analysis of the ORION-7 and ORION-1 studies. Mayo Clin Proc 95:77-89.

Wu Y, Liang D, Wang Y, Bai M, Tang W, Bao S, Yan Z, Li D, and Li J (2013) Correction of a genetic disease in mouse via use of CRISPR-Cas9. Cell Stem Cell 13: $659-662$.

Xu C, Lu Z, Luo Y, Liu Y, Cao Z, Shen S, Li H, Liu J, Chen K, Chen Z, et al. (2018) Targeting of NLRP3 inflammasome with gene editing for the amelioration of inflammatory diseases. Nat Commun 9:4092.

Xu J, Sun J, Ho PY, Luo Z, Ma W, Zhao W, Rathod SB, Fernandez CA, Venkataramanan $\mathrm{R}$, Xie W, et al. (2019a) Creatine based polymer for codelivery of bioengineered MicroRNA and chemodrugs against breast cancer lung metastasis. Biomaterials 210 25-40.

Xu S, Luk K, Yao Q, Shen AH, Zeng J, Wu Y, Luo HY, Brendel C, Pinello L, Chui DHK, et al. (2019b) Editing aberrant splice sites efficiently restores $\beta$-globin expression in $\beta$-thalassemia. Blood 133:2255-2262.

Xue W, Chen S, Yin H, Tammela T, Papagiannakopoulos T, Joshi NS, Cai W, Yang G, Bronson R, Crowley DG, et al. (2014) CRISPR-mediated direct mutation of cancer genes in the mouse liver. Nature 514:380-384.

Yang WY, Wilson HD, Velagapudi SP, and Disney MD (2015) Inhibition of non-ATG translational events in cells via covalent small molecules targeting RNA. J Am Chem Soc 137:5336-5345.
Yi C, Yi Y, and Li J (2020a) mRNA vaccines: possible tools to combat SARS-CoV-2. Virol Sin 35:259-262.

Yi W, Tu MJ, Liu Z, Zhang C, Batra N, Yu AX, and Yu AM (2020b) Bioengineered miR-328-3p modulates GLUT1-mediated glucose uptake and metabolism to exert synergistic antiproliferative effects with chemotherapeutics. Acta Pharm Sin B 10: 159-170.

Yin H, Song CQ, Dorkin JR, Zhu LJ, Li Y, Wu Q, Park A, Yang J, Suresh S, Bizhanova A, et al. (2016) Therapeutic genome editing by combined viral and non-viral delivery of CRISPR system components in vivo. Nat Biotechnol 34:328-333.

Yin W and Rogge M (2019) Targeting RNA: a transformative therapeutic strategy. Clin Transl Sci 12:98-112.

Yu AM, Batra N, Tu MJ, and Sweeney C (2020) Novel approaches for efficient in vivo fermentation production of noncoding RNAs. Appl Microbiol Biotechnol 104: 1927-1937.

Yu AM, Jian C, Yu AH, and Tu MJ (2019) RNA therapy: are we using the right molecules? Pharmacol Ther 196:91-104.

Zamecnik PC and Stephenson ML (1978) Inhibition of Rous sarcoma virus replication and cell transformation by a specific oligodeoxynucleotide. Proc Natl Acad Sci USA 75:280-284.

Zamore PD, Tuschl T, Sharp PA, and Bartel DP (2000) RNAi: double-stranded RNA directs the ATP-dependent cleavage of mRNA at 21 to 23 nucleotide intervals. Cell 101:25-33.

Zhang H, Kolb FA, Jaskiewicz L, Westhof E, and Filipowicz W (2004a) Single processing center models for human Dicer and bacterial RNase III. Cell 118:57-68.

Zhang P, Park HJ, Zhang J, Junn E, Andrews RJ, Velagapudi SP, Abegg D, Vishnu K, Costales MG, Childs-Disney JL, et al. (2020a) Translation of the intrinsically disordered protein $\alpha$-synuclein is inhibited by a small molecule targeting its structured mRNA. Proc Natl Acad Sci USA 117:1457-1467.

Zhang QY, Ho PY, Tu MJ, Jilek JL, Chen QX, Zeng S, and Yu AM (2018) Lipidation of polyethylenimine-based polyplex increases serum stability of bioengineered RNAi agents and offers more consistent tumoral gene knockdown in vivo. Int J Pharm 547:537-544.

Zhang R, Ou HY, and Zhang CT (2004b) DEG: a database of essential genes. Nucleic Acids Res 32:D271-D272.

Zhang X, Goel V, Attarwala H, Sweetser MT, Clausen VA, and Robbie GJ (2020b) Patisiran pharmacokinetics, pharmacodynamics, and exposure-response analyses in the phase 3 APOLLO trial in patients with hereditary transthyretin-mediated (hATTR) amyloidosis. J Clin Pharmacol 60:37-49.

Zhang X, Goel V, and Robbie GJ (2019) Pharmacokinetics of patisiran, the first approved RNA interference therapy in patients with hereditary transthyretinmediated amyloidosis. J Clin Pharmacol 60:573-585.

Zhang X, Lai M, Chang W, Yu I, Ding K, Mrazek J, Ng HL, Yang OO, Maslov DA, and Zhou ZH (2016) Structures and stabilization of kinetoplastid-specific split rRNAs revealed by comparing leishmanial and human ribosomes. Nat Commun 7: 13223 .

Zhang Y, Long C, Li H, McAnally JR, Baskin KK, Shelton JM, Bassel-Duby R, and Olson EN (2017) CRISPR-Cpf1 correction of muscular dystrophy mutations in human cardiomyocytes and mice. Sci Adv 3:e1602814.

Zhao Y, Tu MJ, Wang WP, Qiu JX, Yu AX, and Yu AM (2016) Genetically engineered pre-microRNA-34a prodrug suppresses orthotopic osteosarcoma xenograft tumor growth via the induction of apoptosis and cell cycle arrest. Sci Rep 6:26611.

Zhao Y, Tu MJ, Yu YF, Wang WP, Chen QX, Qiu JX, Yu AX, and Yu AM (2015) Combination therapy with bioengineered miR-34a prodrug and doxorubicin synergistically suppresses osteosarcoma growth. Biochem Pharmacol 98:602-613.

Zorde Khvalevsky E, Gabai R, Rachmut IH, Horwitz E, Brunschwig Z, Orbach A, Shemi A, Golan T, Domb AJ, Yavin E, et al. (2013) Mutant KRAS is a druggable target for pancreatic cancer. Proc Natl Acad Sci USA 110:20723-20728.

Zuckerman JE and Davis ME (2015) Clinical experiences with systemically administered siRNA-based therapeutics in cancer. Nat Rev Drug Discov 14:843-856. 